\title{
Swinging the Pendulum from Recipes to Relationships
}

Citation for published version (APA):

Ramani, S. (2018). Swinging the Pendulum from Recipes to Relationships: Enhancing impact of feedback through transformation of institutional culture. [Doctoral Thesis, Maastricht University]. Datawyse / Universitaire Pers Maastricht. https://doi.org/10.26481/dis.20181031sr

Document status and date:

Published: 01/01/2018

DOI:

10.26481/dis.20181031sr

Document Version:

Publisher's PDF, also known as Version of record

\section{Please check the document version of this publication:}

- A submitted manuscript is the version of the article upon submission and before peer-review. There can be important differences between the submitted version and the official published version of record.

People interested in the research are advised to contact the author for the final version of the publication, or visit the DOI to the publisher's website.

- The final author version and the galley proof are versions of the publication after peer review.

- The final published version features the final layout of the paper including the volume, issue and page numbers.

Link to publication

\footnotetext{
General rights rights.

- You may freely distribute the URL identifying the publication in the public portal. please follow below link for the End User Agreement:

www.umlib.nl/taverne-license

Take down policy

If you believe that this document breaches copyright please contact us at:

repository@maastrichtuniversity.nl

providing details and we will investigate your claim.
}

Copyright and moral rights for the publications made accessible in the public portal are retained by the authors and/or other copyright owners and it is a condition of accessing publications that users recognise and abide by the legal requirements associated with these

- Users may download and print one copy of any publication from the public portal for the purpose of private study or research.

- You may not further distribute the material or use it for any profit-making activity or commercial gain

If the publication is distributed under the terms of Article $25 \mathrm{fa}$ of the Dutch Copyright Act, indicated by the "Taverne" license above, 


\title{
Swinging the Pendulum from Recipes to Relationships:
}

\section{Enhancing impact of feedback through transformation of institutional culture}

\author{
DISSERTATION \\ to obtain the degree of Doctor at Maastricht University, \\ on the authority of the Rector Magnificus, Prof. Dr. Rianne M. Letschert \\ in accordance with the decision of the Board of Deans, \\ to be defended in public \\ on 31 October 2018, at 14.00 hours
}

by

Dr. Subha Ramani, MBBS, MMEd, MPH 


\section{Supervisors}

Prof. Dr. Cees P.M. van der Vleuten (supervisor)

Prof. Dr. Karen V. Mannt (former supervisor), Dalhousie University

Prof. Dr. Shiphra Ginsburg, University of Toronto (supervisor)

Dr. Karen D. Könings (co-supervisor)

\section{Assessment committee:}

Prof. Dr. S. Heeneman (Chair)

Prof. Dr. T.J. ten Cate, UMC, Utrecht

Prof. Dr. I.C. Heyligers

Prof. Dr. J.J. Rethans

Prof. Dr. F. Scheele, VU Medical Centre Amsterdam 


\section{Contents}

$\begin{array}{lll}\text { Chapter } 1 & \text { Introduction }\end{array}$

Chapter 2 A Guide to Reflexivity for Qualitative Researchers in Education 29 Academic Medicine 2018, AM Last Page, April 24. [Epub ahead of print]

Chapter 3 "It's Just Not The Culture": A qualitative study exploring residents' perceptions of the impact of institutional culture on feedback.

Teaching and Learning in Medicine 2017; 29 (2): 153-61.

Chapter 4 About Politeness, Face, And Feedback: Exploring resident and faculty perceptions of how institutional feedback culture influences feedback practices

Acad Med 2018, Mar 6. [Epub ahead of print]

Chapter 5 Uncovering the Unknown: A grounded theory study exploring the impact of self-awareness on the culture of feedback in residency education $\quad 79$ Medical Teacher 2017, 39:10, 1065-73.

Chapter 6 It's all about the relationship - Exploring preceptor-resident feedback conversations

Manuscript submitted to Medical Education journal.

Chapter 7 Twelve Tips To Promote A Feedback Culture With A Growth Mind-Set:

Swinging the feedback pendulum from recipes to relationships

Med Teach. 2018 Feb 7. [Epub ahead of print]

Chapter 8 Discussion and Conclusions

Summary

Samenvatting

Valorisation 

Chapter

Introduction 



\section{Feedback: The history}

The term 'feedback' has its origins in mechanical environments and refers to an autoregulatory mechanism where the effect of an action is fed-back to modify future action. While this term has been used as a verb since the late $19^{\text {th }}$ century to indicate returning to an earlier position in a mechanical process, the Nobel Laureate physicist, Kaul Ferdinand Braun first used it as a noun to refer to undesired coupling between components of an electronic circuit. Based on whether the gap between actual and desired performance is narrowing or widening, the type of feedback is referred to as positive or negative feedback respectively. The term feedback has since been disseminated to various professions such as science, leadership, business and education, for the purposes of performance appraisal and practice improvement of professionals in training and in the workplace. In medical education, regulation of performance through external appraisal as well as encouragement of self-appraisal is crucial for progression towards independent practice. Reviewing older and newer definitions of feedback, models that have been used over the last couple of decades and evolution of feedback practices in medical education, would be very helpful prior to exploring key factors that could influence the impact of feedback conversations. The feedback literature, once dominated by expert opinions and recommendations, has more recently focussed on provider-recipient relationships, acceptance and incorporation of feedback. However, there is little knowledge about actual behaviours and practices during real-life feedback conversations, and this is an area that warrants further exploration.

\section{Feedback: A vital cog in the wheel of competency-based medical education}

Feedback is essential for performance improvement and growth of trainees in any profession. ${ }^{1-4}$ In the era of competency-based training and assessment, now mandated by many medical accreditation organisations, it is essential that learners receive timely information about their clinical performance from multiple sources including teachers, peers and other team members. Competency-based medical education requires that learners receive specific information regarding any gap between observed performance and expected performance for a given stage of training, with the primary goal of improving future performance and enabling professional growth., ${ }^{5,6}$ Competency goals cannot be achieved by completion of end-of-rotation evaluation forms alone. Formative performance-based feedback is critical to inform learners whether their performance is at the expected level, generate resources or action items to achieve their goals and formulate performance improvement plans. ${ }^{7-10}$

Feedback has been described as a bridge between stated curricular goals and achievement of learner outcomes, whilst also demonstrating the committment by teachers and 
institutions to learners' development. ${ }^{11,12}$ Medical students and residents acknowledge that feedback helps calibrate their performance at various stages and develop action plans for improvement. Despite its perceived importance, clinical learners report that faculty feedback is infrequently provided, features mostly non-specific comments and may have little to no impact on their performance. ${ }^{7,13-17}$ Clinical teachers report several barriers to effective feedback including: lack of time, inadequate direct observation of trainees, lack of skills in giving feedback, hesitation to give "negative" feedback and concerns about damaging teacher-learner relationships. ${ }^{9,18-26}$ While some of the barriers such as inadequate observation or skills in providing feedback can potentially be overcome, it may be much more challenging to tackle barriers that relate to factors such as interpersonal relationships or institutional culture.,13,27-29 It may be helpful to review older definitions and models of feedback before moving to recent descriptions of feedback which emphasise sociocultural factors.

\section{Feedback: Traditional definitions and models}

A brief review of older definitions of feedback in the educational context shows emphasis on teachers' skills in providing feedback and a mostly static unidirectional model of feedback conversations. ${ }^{8,30,31}$ The landmark article by Ende defined feedback in medical education as the information describing students' or house officers' performance in a given activity that is intended to guide their future performance in the same activity. ${ }^{8}$ While the article emphasises the role of direct observation of performance in guiding feedback conversations, most educators have recommended best practices for 'giving' feedback where the role of the learner was hardly discussed. Clinical teachers were advised to provide timely, specific, non-judgemental feedback on performance, based on first hand data and include positive and 'negative' feedback. The feedback sandwich model, which recommends starting and ending with positive feedback, interposed by negative feedback, and still used in many faculty development sessions ${ }^{32}$, has not been shown to improve learner performance. ${ }^{33}$ The Pendleton model was one of the earliest frameworks that placed learner self-assessment on par with teacher feedback. ${ }^{34}$ In fact, this model recommended starting with learner reflection on their own strengths followed by teacher comments, learner reflections on weaknesses and teacher agreement, disagreement and / or additions to those comments. Neither of these models emphasised action plans in their steps. Thus, most earlier feedback training approaches placed the teacher in a dominant position in the feedback conversation. It was assumed that improving teachers' skills in providing feedback would lead learners to change their practice and improve their performance. This approach is depicted in Figure 1. 


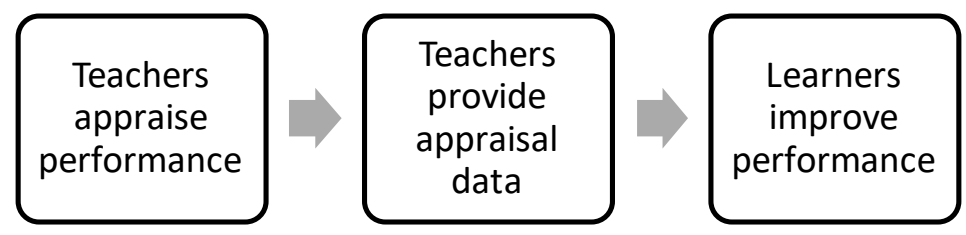

Figure 1: A teacher-centred unidirectional approach to feedback

However, several research reports consistently showed that medical students and residents feel they do not receive enough effective feedback or feedback provided is underrecognised by learners. ${ }^{35-37}$ The process of feedback in postgraduate medical education poses additional challenges as it occurs in the context of real-life patient care, residents are typically the first-line physician providers of patient care and their autonomy in the workplace needs to be preserved. This setting warrants a more learner-focussed model with learners being active seekers of feedback rather than passive recipients and contributing equally to the conversation. ${ }^{11,12,14,28,38-41}$ Thus, it is essential to shift the landscape of feedback from the teacher to the learner and focus on their learning goals, goal orientation, acceptance and assimilation of feedback. To do this effectively, various factors that influence a feedback conversation should be analysed and understood. Below, newer definitions of feedback are discussed through a sociocultural lens.

\section{Feedback redefined: a sociocultural phenomenon}

It is increasingly accepted that the importance of feedback lies not in how it is provided but in its impact on recipients. ${ }^{4,7,10}$ Until learners act on it, the feedback loop remains incomplete. ${ }^{10}$ Moreover, feedback is accepted by learners only if they view it as credible and congruent with their own self-assessment. ${ }^{23,24,42}$ Knowledge of factors that influence credibility would be beneficial for all teachers engaging in feedback conversations with the goal of changing learners' practice.

\section{Credibility and acceptance of feedback}

Several authors have indicated that medical trainees reject feedback if they do not believe that it is accurate or credible. ${ }^{28,43-45}$ Factors that influence learners' perception of credibility include: their relationship with the teacher, the manner of feedback delivery, perception of teacher beneficence (intentions and characteristics of feedback providers), direct observation of performance, congruence of data with their self-assessment, threat to self-efficacy and autonomy etc. ${ }^{28,45-49}$ Postgraduate trainees are even more likely to reject feedback if they have doubts about its accuracy and legitimacy, thus there would be minimal to no impact on their performance. ${ }^{50}$ There are concerns that suboptimal feedback can further reduce recipient performance. ${ }^{51}$ In addition, there is a real potential 
for harm if it is viewed as a threat to self-esteem by learners. ${ }^{3,41}$ It has been reported that learners reject constructive feedback if it conflicts with their own self-assessment, they perceived the process as flawed in some way or that the process and / or sender lacked credibility. ${ }^{14,21,25,26,39,42,43}$ There are also concerns that learners may accept feedback that reinforces their positive performance and ignore constructive comments especially in the context of summative evaluations. ${ }^{52-54}$ Educators themselves have reported that fear of hurting feelings, potential threat to learner self-esteem, or damage to working relationships with learners are major barriers to providing constructive feedback. ${ }^{3,22,25}$ It has been suggested that institutions should build in time and space for feedback, promote trusting teacher-trainee relationships in a safe learning environment, and facilitate more direct observation of performance, formative feedback and meaningful feedback exchanges. ${ }^{3,14,55}$

\section{Feedback: A complex interpersonal encounter}

The feedback encounter is now viewed as a complex exchange of information influenced by many factors such as the stress of the clinical environment, time pressures, emotions during the conversation especially if the information is viewed as criticism, interpersonal tensions and cultural contexts. 22,25,27,28 Although faculty are aware that the goals of a feedback session are to improve trainee performance, many struggle to provide constructive feedback due to perceived psychosocial challenges. ${ }^{3,25}$ Teachers do not want to appear harsh while giving feedback, want to maintain their trainee's self-esteem and preserve their relationship with the trainee.

Many medical educators have strongly recommended a learning culture that supports and embeds feedback, but examining professional or institutional culture would be an essential prerequisite to improving its frequency and quality at a given institution. $3,56,57$ Sociocultural factors, that impact the quality of feedback conversations and influence credibility, can be described through different viewpoints: the recipient, provider and the context. Figure 2 is a depiction of a central role for learners' performance improvement in the feedback loop, influenced by factors related to feedback providers, feedback recipients and the institutional context. 


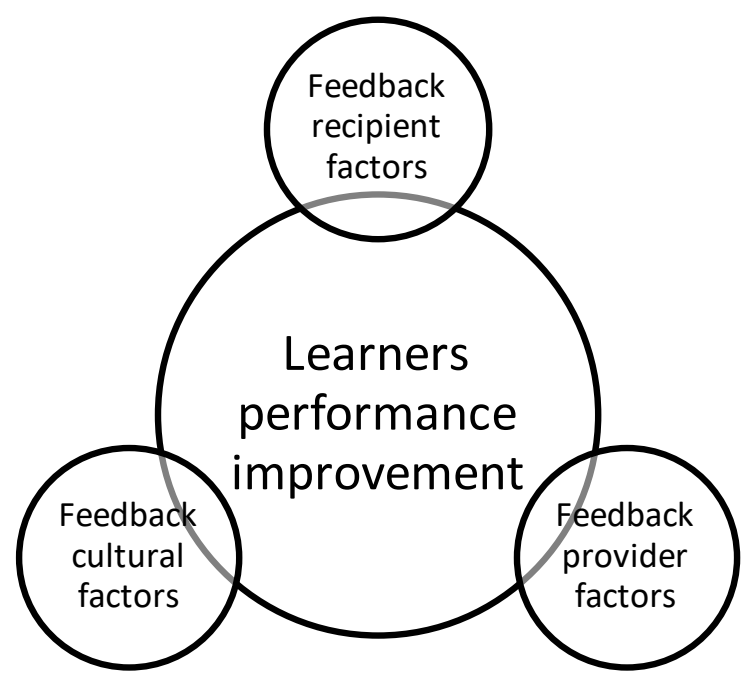

Figure 2: A learner-centred feedback loop and factors influencing learners' performance improvement

\section{Feedback recipients}

The feedback literature has been criticised for casting learners as passive recipients and teachers as the active participants. This model is particularly ineffective in postgraduate medical education, where trainees provide direct patient care and need to actively engage in self-reflection and appraisal of their practice. ${ }^{58}$ Learner factors that could enhance receptivity and incorporation of feedback include feedback seeking behaviours, goal setting, accurate self-assessment and a perception of threat to ego or self-esteem. ${ }^{21,45,59,60}$ Feedback seeking behaviour among learners has been the subject of several studies which report that goal orientation has a strong impact on feedback-seeking behaviour. ${ }^{14,40,58}$ Two types of goal orientation have been described, performance and learning goal orientation. ${ }^{46}$ Individuals with the performance goal orientation seek feedback because they want to showcase their clinical competence and receive positive judgements, thus they avoid situations where they anticipate negative judgements. Those with a learning goal orientation focus on improving their knowledge and skills with the aim of developing their clinical competence and growing as a professional. Feedback that is perceived as a threat to self-efficacy may also be rejected by recipients, especially in learners with a performance goal orientation. ${ }^{3,54}$ Therefore, it is important to promote and encourage a learning goal orientation among clinical learners as they develop into independent and reflective practitioners. 


\section{Feedback providers}

The medical education environment has traditionally viewed feedback as a unidirectional transmission of feedback from teachers to learners and teachers receive training in the 'skills' of providing feedback to learners. 8,11,31,61-64 Exploring how and whether it is received, accepted or incorporated into performance has been a more recent trend. ${ }^{7,10,65}$ Moving away from a 'how to' approach towards a dynamic approach requires attention to the learning climate, relationship between teachers and learners, observation of performance, and opportunities for behaviour change. The impact of feedback on learner behaviour change and professional growth will likely be greater if feedback initiatives target enhancement of teacher skills in promoting a positive learning climate, discussion of learning goals with their learners and action plans for performance improvement. ${ }^{44,45,47}$ In addition, clinical teachers need to observe segments of their learners' performance in a variety of domains and try to debrief these observations in a timely manner. Finally, it is important for teachers to facilitate self-assessment and reflection by their learners as a mechanism to diagnose learner insight, validate what was done well and discuss areas that need improvement.

\section{Feedback culture}

Feedback culture can be defined as an institution's support for nonthreatening, behaviour-focussed feedback, implementing a coaching model to interpret and use feedback, and linking performance improvement and outcomes. ${ }^{66-68}$ Institutional or departmental feedback culture might include factors such as explicit expectations for feedback conversations by multiple stakeholders (educational leadership, faculty, trainees); relationships between feedback providers and recipients; barriers to feedback within the work and educational environment of busy clinical settings; emotional responses to constructive feedback; creating shared understanding between teachers and learners about the pro-

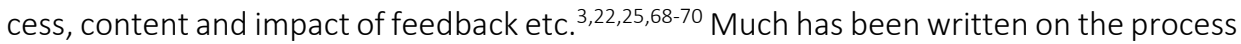
of feedback exchange including best practices, $7,8,11,30,31,61,62,71$ but the institutional culture and feedback have been less well studied. It has been said that feedback needs to move from static to a dynamic approach focussing more on seeking feedback, multisource feedback and improving performance. ${ }^{49,72-77}$ An understanding of these sociocultural factors in specific learning and work environments is essential prior to designing initiatives to improve feedback exchanges between faculty and residents and enhance the impact of feedback on professional development. 


\section{The unknowns in feedback culture research: What theories might apply?}

Experts have described a variety of effective techniques for giving feedback, $9,12,49,61,63$ however, viewing this conversation from the perspective of teachers' skills has not resulted in significant learner behaviour change. ${ }^{14,15,27,48}$ In the last decade, the focus of research into this topic has moved towards learner feedback seeking, acceptance and growth, thereby initiating and maintaining the conversation on sociocultural aspects of feedback. 3,10,22,23,48,59,65,67,76 These research reports have led to major shifts in the definition of effective feedback, yet expanded knowledge on factors that enhance feedback seeking, promote an effective feedback culture, and influence bidirectional feedback, would further advance the field. More is being understood on why learners reject feedback, after all, if feedback is not even accepted, what would be the point of providing feedback using skilled techniques? The concept of credibility has been discussed earlier. In addition, research indicates that learners also reject feedback if it is incongruent with self-assessment or perceived as a threat to self-esteem. Learner and teacher perspectives regarding an institutional culture that actively promotes self-appraisal and how self-assessment impacts the content or quality of a feedback conversation are less well studied. Finally, the content of actual feedback conversations between teachers and learners is a mostly unexplored area. It would be important to explore language used and behaviours during feedback conversations, and whether they are consistent with expressed opinions. Until the content and behaviour during real conversations are known, we only have opinions: opinions from experts, opinions from teachers, and opinions from learners.

In this section, we discuss key psychosocial theories, some individually-oriented and others collectively-oriented, that are applicable to and could add value to inquiries into the sociocultural aspects of the feedback exchange; the giving, receiving, acceptance and incorporation into performance. First, since much of the planned research relates directly to sociocultural influences on the quality and impact of feedback, it is important to discuss the Sociocultural theory and how this relates to competency-based assessment and feedback. ${ }^{78,79}$ Second, it is important for feedback conversations to address factors such as self-efficacy and autonomy, ${ }^{59}$ thus the descriptions of 'face' or self-image by Politeness theory experts are relevant to research on feedback. ${ }^{80}$ Finally, receptivity and acceptance of feedback are necessary for learners to incorporate data into their performance and change practice, therefore Self-determination theory is very relevant to include in this discussion. ${ }^{81}$

\section{Sociocultural theory and feedback}

Lev S. Vygotksy, a Russian psychologist, is most closely identified with Sociocultural theory, a psychological theory that describes how society contributes to individual development, and proposes that humans learn largely through social interactions. ${ }^{79}$ The theory also emphasises that cultural beliefs and attitudes influence how learning occurs. Thus, 
learning in a community and development would be interdependent. The "zone of proximal development" (ZPD) was put forth as a construct, which refers to the distance between actual development resulting from independent problem solving and potential development through problem solving under guidance or in collaboration with peers. While the ZPD is activated when working within a community of learners, it still refers to individual growth. The participation model of cultural development, on the other hand, describes the transformation of individuals through participation in sociocultural activity, referred to as becoming a member of a community of practice. ${ }^{78}$ Transformation occurs as learners assume increasing responsibility for their activities. Informed by a sociocultural perspective, learning is thought to occur through interaction and collaboration, and institutions and teachers should support students in these endeavours. Thus, institutions need to attend to the broader social system in which learning is occurring as well as development of individual learners within these communities of practice. When this theory is applied to educational assessment and feedback, the key goals would be to: (a) identify abilities, actual and potential, using a developmental approach, (b) focus on the gap between learners' current performance versus expected performance, and (c) provide meaningful formative feedback on learner performance to guide independent practice.

\section{Politeness theory and feedback}

Brown and Levinson's Politeness theory proposes that two types of 'face' play a role in most social interactions, positive and negative. ${ }^{80,82}$ Positive face reflects an individual's need to be appreciated in a social context. Negative face reflects an individual's need for freedom of action, freedom from imposition, and the right to make one's own decisions. The theory assumes that most conversations are potential face-threatening acts to either party. It is applicable to any profession where human communication is dominant, whether in individual interactions or the system in which these interactions occur. ${ }^{82}$ The clinical environment is characterised by interpersonal relationships between teachers and learners, and multiple team members. The patient care team invests in these relationships and depend on each other to achieve their respective professional goals. This is especially true when the learners are residents or junior doctors, who are not only trainees but also professionals directly responsible for patient care. In this context, exchanges viewed as "negative", such as constructive feedback, may be perceived as a breach of the norms of expected politeness. Honest constructive feedback is essential for longitudinal growth and mutual self-affirmation alone is not the path to professional improvement. Although politeness theory appears more applicable to individual interactions, it is likely that the work or learning culture promotes a degree of politeness that serves as a barrier to behaviour influencing feedback. Ginsburg and colleagues have alluded to politeness concepts in their research which found that faculty narrative comments on in-training evaluations were mostly vague and non-specific. ${ }^{83,84}$ During feedback exchanges, investigators have reported a tendency for clinical teachers to emphasise positive over negative 
performance, the conflict between trainees' desire for feedback and fear of critical feedback, and teacher concerns about damaging interpersonal relationships. ${ }^{22,23,28}$ The intersection of politeness and learning culture and their effects on feedback conversations warrant further exploration to advance the understanding of how feedback could impact positive face (self-efficacy) and negative face (autonomy).

\section{Self-determination theory and feedback}

Self-determination theory, described by Ryan and Deci, is a psychological theory that states that human beings tend to regulate behaviours autonomously and take on challenges and learn through intrinsic motivation. ${ }^{81,85}$ The theory proposes that humans have three basic psychologic needs: (1) competence, defined as the desire to control the environment and outcome, (2) relatedness, defined as the desire to interact with, be connected to and experience caring for others, and (3) autonomy, defined as having a sense of free will when acting out of own interests and values. Sources of motivation can be extrinsic or intrinsic. Extrinsic motivation is driven by external factors with the goal of achieving defined outcomes. ${ }^{81}$ Intrinsically motivated individuals wish to perform an activity for inherent satisfaction rather than to achieve a given result. ${ }^{81}$ Two types of motivation, described by Deci and Ryan, are autonomous and controlled, both of which are influenced by intrinsic and extrinsic sources of motivation to varying degrees. ${ }^{81,86}$ Intrinsic motivation is the major driver of autonomous motivation, where individuals gain selfsupport and self-efficacy through their own actions. Extrinsic motivation is the major driver of controlled motivation, where an individual's behaviour is likely a function of external values of reward and punishment. Intrinsic motivation is further amplified by factors such as challenge, curiosity, control or autonomy, cooperation and completion, and recognition. ${ }^{81}$ In applying motivation to performance-based feedback, we argue that intrinsic motivation would have a greater influence on feedback seeking, acceptance and assimilation, therefore performance improvement. Thus, the focus should be on autonomous rather than controlled learner motivation as medical education needs to provide increasing autonomy to learners during training. ${ }^{87}$ Ten Cate et al suggest approaches to boost motivation during feedback conversations: shifting the focus from the individual to the context; shifting from instructional messages to self-regulation; and shifting the focus from the perspective of feedback provider to recipient. ${ }^{88}$

All three theories intersect at many points and equally relevant to research into the role of culture in enhancing the impact of feedback. Figure 3 shows how the three theories described above overlap and the overlapping areas have specific implications for a conducive feedback culture. Eventually, principles from all three theories could be incorporated into the design of new feedback initiatives that target learner feedback seeking, acceptance and professional growth. In the remaining section of the Introduction, the research context, purpose, research questions and an overview of the methodology will be discussed in detail. 


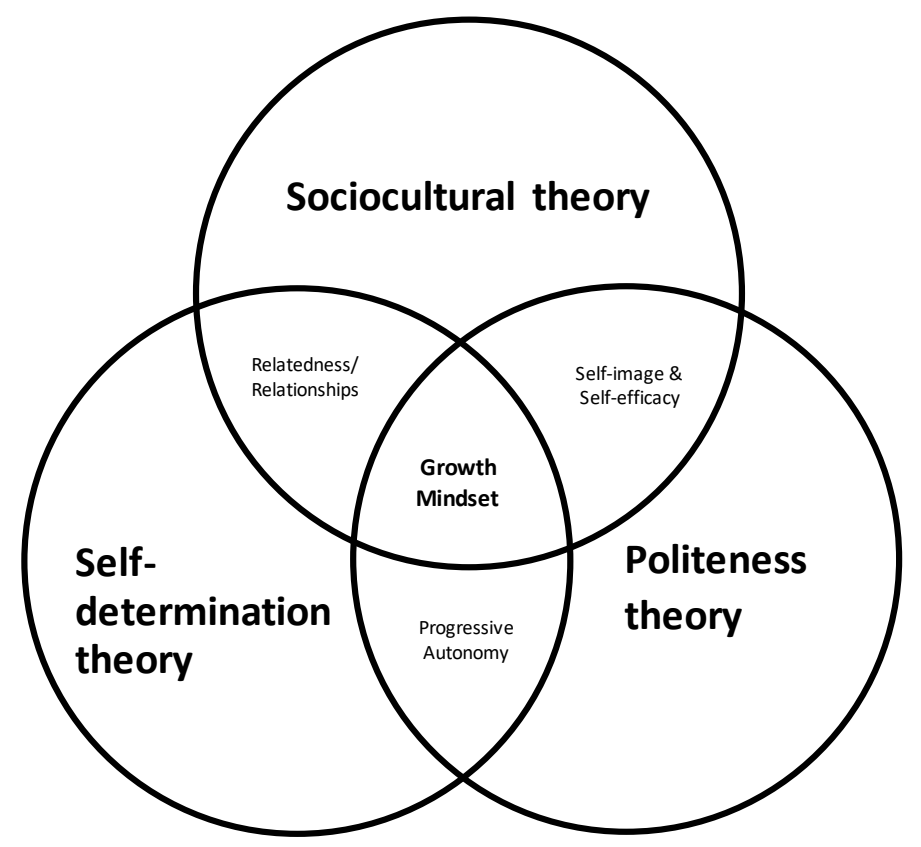

Figure 3: Intersection of three theories and their influence on a feedback culture

\section{Research context and questions}

While much has been written on techniques of giving feedback to learners, ${ }^{9,12,61,63}$ the sociocultural aspects of feedback are only beginning to be understood. ${ }^{3,22,48,67}$ Therefore, this thesis aimed to examine what institutional cultural factors influence the quality and impact of feedback conversations in postgraduate medical education settings. Through study of the overall question, "What are perceptions of residents and faculty regarding the institutional feedback culture and its influence on its quality and impact?", we aimed to add to research conducted by previous investigators on the sociocultural aspects of feedback. Additionally, since there is little knowledge of actual participant behaviours during feedback conversations, we also wanted to examine how faculty and residents interacted during feedback conversations, and whether their words and actions correlated with expressed beliefs and opinions. We chose the continuity clinic setting for the observations since it is the only clinical setting where longitudinal relationships between faculty and residents exist and the faculty are invested in learners' ongoing performance improvement and growth. For the purposes of this research, we chose not to study inpatient settings where the duration of working relationships can range from 5-10 days based on shift timings and days off. We acknowledge that it is important to conduct observations in inpatient settings in the future, especially examining the quality of feedback conversations in a setting with much turnover of team members. 
Our research project can be viewed in two parts, (1) open-ended and in-depth explorations of faculty and resident opinions and perceptions regarding resident, faculty and institution related cultural factors that could influence the quality and impact of feedback and serve as facilitators or barriers; (2) observations of real-time feedback conversations between residents and faculty in continuity clinic settings to explore verbal and non-verbal behaviours on both sides and whether perceptions of the effectiveness of the encounter were matched or mismatched.

\section{Research context}

The Internal Medicine Residency Program at Brigham and Women's Hospital, a teaching affiliate of Harvard Medical School, is a large, urban training program with approximately 160 residents. Inpatient teams typically consist of one or two postgraduate year (PGY) 2, 3, or 4 residents; two or three PGY1 residents; one or two attending physicians; and one or two medical students. All categorical residents (i.e., those who are not on a 1-year preliminary track) work in continuity clinics with a primary faculty preceptor throughout their residency. Preliminary residents, those on a 1-year track prior to other specialty residencies such as neurology or anaesthesiology, do not work in continuity clinics but work on inpatient medicine services. Residents are formally assessed by their supervising faculty and peers at the end of each inpatient rotation and twice a year by their continuity clinic preceptors. Faculty are also required to give verbal formative feedback to each resident at the midpoint and summative feedback at the end of each inpatient rotation and periodically in continuity clinics.

A major redesign of the residency assessment system was instituted in accordance with the ACGME (Accreditation Council for Graduate Medical Education) mandated milestones-based assessment in 2012. As part of the redesign new assessment tools were developed, but the end of year resident surveys by the graduate medical education committee indicated a subpar frequency of feedback conversations as well as non-specific and vague comments when such conversations occurred. As stated previously, competency-based assessment requires that meaningful data about their performance be fed back to residents so that they progress towards expected performance and independent practice by the end of their training.

Residents are exposed to a variety of faculty levels from novice to seasoned clinicians. For some of the clinician investigator faculty, their teaching commitments for an entire year might be limited to a 2-week rotation on a house staff team. Sporadic feedback workshops are offered at the institution, but there is no requirement that all teaching faculty receive formal training in feedback. There are also limited opportunities for faculty to discuss challenges and refine best practices. Faculty perceptions of the process of feedback, challenges in giving feedback and strategies employed during the feedback encounter are largely unknown. 


\section{Research questions}

The overall aims of this research are to explore perceptions of faculty and residents about the institutional feedback culture and its influence on feedback conversations, as well as behaviours during actual feedback conversations. Specific research questions are:

1. What are the perceptions of residents and faculty regarding a definition of feedback culture and what elements constitute this culture?

2. How do residents and faculty view the current departmental culture and its influence on the quality of feedback conversations between residents and faculty

3. What language and behaviours are used by teachers and learners during formal feedback conversations between faculty and residents who have a longitudinal relationship in continuity clinics?

4. Can video-facilitated reflection and reflexivity enhance faculty awareness of effective and ineffective behaviours and promote future behaviour change?

\section{Methodology}

As little evidence was available in these specific areas, we believed that exploratory qualitative approaches would be most appropriate to shed light on these study questions, and conducted a series of studies. ${ }^{89-96}$

In answering research questions 1 and 2, we opted to use a grounded theory approach. In this approach, researchers aim to construct a theory grounded in participant data, through systematic and concurrent data collection and analysis. Grounded theory (GT), which attempts to interpret meaning in social interactions, is grounded in participants' own words and observations rather than investigators' inherent assumptions. ${ }^{97}$ Specifically, constructivist GT, states that data and theories are not discovered but coconstructed by the researcher and participants and influenced by researchers' perspectives, values, positions and interactions with participants. ${ }^{98}$ The advantages of GT in our research include: (1) open-ended explorations of participant perceptions and behaviours; (2) systematic strategies for conducting the research and data analysis; (3) integration of data collection and analysis; and (4) providing rigour to qualitative research and enhancing the discipline of scientific inquiry. ${ }^{92}$

In answering research questions 3 and 4, we used the qualitative framework of ethnography to explore actual behaviours during and content of feedback conversations, supplemented by a video-reflexive approach. ${ }^{94,99}$ We were particularly interested in applying a reflexive approach to engage faculty participants in making sense of their own actions during a feedback encounter and reflect on whether their strategies were successful or not. It is worth explaining reflection and participant reflexivity, both applied in this research approach. Reflection refers to the practice of thinking back to an event and 
assessing one's practice and behaviours in relation to the event. It is focussed, personal and enables individuals to intervene in specific aspects of their own behaviour. Participant reflexivity in ethnographic studies, on the other hand, occurs when they review, discuss and assess their own behaviours to determine what was effective and what was not. ${ }^{93}$ It is collaborative, open-ended and participants can recognize challenges or potential problems that can be addressed on the spot. Additionally, video feedback reveals to them their own habits, often enacted unconsciously, may reveal a degree of disconnect between their intentions and others' perceptions of their practice. In gaining awareness of their behaviours, practitioners also gain the capacity to intervene in their habits. It links what they do in real time, how they do it, whether their actions match espoused goals or not, and what can be done to improve. ${ }^{99}$ Extensive debriefing of the observed feedback conversations can help faculty and residents to reflect on the effectiveness as well as impact (if any) of the exchange.

\section{Reflexivity for qualitative researchers}

Researcher reflexivity, defined as the ability to reflect on one's own behaviour and thoughts as well as the phenomenon under study, is considered essential for investigators conducting rigorous qualitative research. ${ }^{100}$ Researcher reflexivity is different than participant reflexivity discussed in the previous section and is an essential measure to ensure rigour. Reflexive researchers are aware of their beliefs and assumptions on a subject and acknowledge how their position and relationship to the research topic and participants could influence research findings. Through deep reflection, our research team wished to gain awareness of what allows us to see, as well as what inhibits us from seeing. ${ }^{100}$ Therefore, our goals were to engage in careful consideration of the phenomenon under study, i.e. feedback and its sociocultural influences, and how our assumptions and behaviour may impact the inquiry. Since all research studies used qualitative methodology to answer the study questions, we showcase the concept of reflexivity that is essential for qualitative researchers. We list key steps of qualitative studies and describe how reflexivity could be ensured in each step. This is written in the format of an Academic Medicine Last Page to be published in 2018, featured in Chapter 2.

\section{Overview of studies}

Research questions 1 and 2, regarding resident and faculty perceptions of the departmental feedback culture, are addressed in Chapters 3-5. Research questions 3 and 4 are addressed in Chapter 6, an ethnographic study of behaviours during actual resident-faculty feedback conversations.

Chapter 3 describes a qualitative study seeking to discover perceptions and opinions of residents using a grounded theory approach. We seek to explore resident opinions on what institutional factors affect the quality of feedback provided, their receptivity to 
feedback and its impact. Data sources include participant perspectives during four focus group discussions ( $n=38$ ) comprising residents at all levels (postgraduate year $1-3$ ) and investigator field notes. Through semi structured focus group discussions, residents are prompted to express their opinions freely regarding all aspects of feedback- its value in their training, the quality of feedback provided by their teachers and their perceptions of institutional expectations.

In the study described in Chapter 4, we conduct in-depth explorations of faculty as well as resident opinions regarding their definitions of the institutional feedback culture, elements that constitute this culture, perceptions of the culture of politeness within the institution, how this culture could facilitate or impede meaningful feedback and their recommendations for enhancing the feedback culture. Data sources include five focus group discussions with residents ( $n=29$ ), three focus group discussions with General Medicine faculty $(n=22)$ and 8 individual interviews with subspecialist faculty and field notes from interviewer and a neutral research assistant.

Chapter 5 is a qualitative study that uses the Johari window framework to analyse all data from three faculty focus groups, eight one-on-one faculty interviews and eight resident focus groups. This study focusses only on discovering themes related to self-awareness, self-assessment and self-reflection, important factors that impact feedback seeking and receptivity. Themes related to each of the Johari window quadrants are identified.

In our final study, described in Chapter 6, we use an ethnographic approach, with the addition of a video-reflexive element, to explore the content of real-life feedback conversations, as indicated in the study questions 3 and 4 . We are particularly interested in applying a reflexive approach to engage participants in making sense of their own actions during the encounter and reflect on the effectiveness of their strategies. The video-reflexive approach aims to reveal to participants their own habits, sometimes enacted without conscious awareness; reveal any disconnect between intention and perception of their practice; and potentially change their behaviour.

\section{Bringing it all together}

Chapter 7 summarises all the research findings and proposes twelve tips for educators to foster feedback exchanges and promote a growth-oriented culture. These twelve tips are written from multiple perspectives, that of feedback providers, recipients, the relationship between providers and recipients, and the institutional context.

Synthesising the findings from studies 1-4, we have also proposed five models showcasing the relationship of feedback culture and impact of feedback: (1) demonstrating the central role of institutional culture in influencing the quality and impact of feedback (Chapter 2), (2) intersection of teacher and learner factors leading to four different climates for a feedback culture, and strategies to promote feedback seeking, receptivity and growth (Chapter 3), (3) individual and institutional strategies under each quadrant of 
the Johari window to assist learners, teachers and institutions in enhancing self-assessment, reflection, feedback seeking, self-disclosure and self-discovery (Chapter 5), (4) application of a relationship-centred communication model to feedback conversations with description of strategies under each step (Chapter 6) and (5) strategies to promote a feedback culture with a growth mindset through multiple perspectives (Chapter 7 ).

In Chapter 8, Conclusions and Discussion, we summarise our findings in response to each of the study questions, describe the limitations of the research and areas for future research, and propose how our findings can be applied to real feedback practice by medical educators and in designing initiatives at educational institutions. Since the thesis includes multiple but separate publications, there is bound to be repetition of some concepts across chapters. 


\section{REFERENCES}

1. Norcini J. The power of feedback. Med Educ 2010;44:16-7.

2. Veloski J, Boex JR, Grasberger MJ, Evans A, Wolfson DB. Systematic review of the literature on assessment, feedback and physicians' clinical performance: BEME Guide No. 7. Med Teach 2006;28:117-28.

3. Watling $C$, Driessen $E$, van der Vleuten CP, Vanstone M, Lingard L. Beyond individualism: professional culture and its influence on feedback. Med Educ 2013;47:585-94.

4. Boud D, Molloy E. Feedback in higher and professional education: understanding it and doing it well. London ; New York: Routledge; 2013.

5. Holmboe ES, Yamazaki K, Edgar L, et al. Reflections on the First 2 Years of Milestone Implementation. J Grad Med Educ 2015;7:506-11.

6. Tekian A, Watling CJ, Roberts TE, Steinert Y, Norcini J. Qualitative and quantitative feedback in the context of competency-based education. Med Teach 2017;39:1245-9.

7. van de Ridder JM, Stokking KM, McGaghie WC, ten Cate OT. What is feedback in clinical education? Med Educ 2008;42:189-97.

8. Ende J. Feedback in clinical medical education. JAMA 1983;250:777-81.

9. Anderson PA. Giving feedback on clinical skills: are we starving our young? J Grad Med Educ 2012;4:1548.

10. Boud D. Feedback: ensuring that it leads to enhanced learning. Clin Teach 2015;12:3-7.

11. Krackov SK. Expanding the horizon for feedback. Med Teach 2011;33:873-4.

12. Krackov SK, Pohl H. Building expertise using the deliberate practice curriculum-planning model. Med Teach 2011;33:570-5.

13. Delva D, Sargeant J, Miller S, et al. Encouraging residents to seek feedback. Med Teach 2013;35:e1625-31.

14. Bing-You RG, Trowbridge RL. Why medical educators may be failing at feedback. JAMA 2009;302:1330-1.

15. Bing-You RG, Paterson J, Levine MA. Feedback falling on deaf ears: residents' receptivity to feedback tempered by sender credibility. Med Teach 1997;19:40-4.

16. De SK, Henke PK, Ailawadi G, Dimick JB, Colletti LM. Attending, house officer, and medical student perceptions about teaching in the third-year medical school general surgery clerkship. J Am Coll Surg 2004;199:932-42.

17. Sender Liberman A, Liberman M, Steinert Y, McLeod P, Meterissian S. Surgery residents and attending surgeons have different perceptions of feedback. Med Teach 2005;27:470-2.

18. Brukner HA, D.L.; Cook, S.; Quinn, M.T.; McNabb, W.L. Giving effective feedback to medical students: a workshop for faculty and house staff. Med Teach 1999;21:161-5.

19. Kogan JR, Conforti LN, Bernabeo EC, Durning SJ, Hauer KE, Holmboe ES. Faculty staff perceptions of feedback to residents after direct observation of clinical skills. Med Educ 2012;46:201-15.

20. Dudek NL, Marks MB, Regehr G. Failure to fail: the perspectives of clinical supervisors. Acad Med 2005;80:S84-7.

21. Eva KW, Armson $\mathrm{H}$, Holmboe $\mathrm{E}$, et al. Factors influencing responsiveness to feedback: on the interplay between fear, confidence, and reasoning processes. Adv Health Sci Educ Theory Pract 2012;17:15-26.

22. Sargeant J, McNaughton E, Mercer S, Murphy D, Sullivan P, Bruce DA. Providing feedback: exploring a model (emotion, content, outcomes) for facilitating multisource feedback. Med Teach 2011;33:744-9.

23. Mann K, van der Vleuten C, Eva K, et al. Tensions in informed self-assessment: how the desire for feedback and reticence to collect and use it can conflict. Acad Med 2011;86:1120-7.

24. Sargeant J, Mann K, Sinclair D, van der Vleuten C, Metsemakers J. Challenges in multisource feedback: intended and unintended outcomes. Med Educ 2007;41:583-91.

25. Sargeant J, Mann K, Sinclair D, Van der Vleuten C, Metsemakers J. Understanding the influence of emotions and reflection upon multi-source feedback acceptance and use. Adv Health Sci Educ Theory Pract 2008;13:275-88.

26. Sargeant JM, Mann KV, van der Vleuten CP, Metsemakers JF. Reflection: a link between receiving and using assessment feedback. Adv Health Sci Educ Theory Pract 2009;14:399-410. 
27. Watling CJ. Unfulfilled promise, untapped potential: feedback at the crossroads. Med Teach 2014;36:6927.

28. Watling $C$, Driessen $E$, van der Vleuten $C P$, Vanstone $M$, Lingard L. Understanding responses to feedback: the potential and limitations of regulatory focus theory. Med Educ 2012;46:593-603.

29. Delva D, Sargeant J, MacLeod T. Feedback: a perennial problem. Med Teach 2011;33:861-2.

30. Linzer M. Feedback in medical education. JAMA 1984;251:1277.

31. Hewson MG, Little ML. Giving feedback in medical education: verification of recommended techniques. J Gen Intern Med 1998;13:111-6.

32. Dohrenwend A. Serving up the feedback sandwich. Fam Pract Manag 2002;9:43-6.

33. Parkes J, Abercrombie S, McCarty T. Feedback sandwiches affect perceptions but not performance. Adv Health Sci Educ Theory Pract 2013;18:397-407.

34. Pendleton D. The Consultation : an approach to learning and teaching. Oxford Oxfordshire; New York: Oxford University Press; 1984

35. Archer J. Feedback: it's all in the CHAT. Med Educ 2013;47:1059-61.

36. Archer J, McGraw M, Davies H. Assuring validity of multisource feedback in a national programme. Arch Dis Child 2010;95:330-5.

37. Jensen AR, Wright AS, Kim S, Horvath KD, Calhoun KE. Educational feedback in the operating room: a gap between resident and faculty perceptions. Am J Surg 2012;204:248-55.

38. Bing-You RG. Internal medicine residents' attitudes toward giving feedback to medical students. Acad Med 1993;68:388.

39. Watling CJ, Kenyon CF, Zibrowski EM, et al. Rules of engagement: residents' perceptions of the in-training evaluation process. Acad Med 2008;83:S97-100.

40. Teunissen PW, Stapel DA, van der Vleuten C, Scherpbier A, Boor K, Scheele F. Who wants feedback? An investigation of the variables influencing residents' feedback-seeking behavior in relation to night shifts. Acad Med 2009;84:910-7.

41. Milan FB, Dyche L, Fletcher J. "How am I doing?" Teaching medical students to elicit feedback during their clerkships. Med Teach 2011;33:904-10.

42. Sargeant J, Mann K, Ferrier S. Exploring family physicians' reactions to multisource feedback: perceptions of credibility and usefulness. Med Educ 2005;39:497-504.

43. Watling $C$, Driessen $E$, van der Vleuten $C P$, Lingard $L$. Learning from clinical work: the roles of learning cues and credibility judgements. Med Educ 2012;46:192-200.

44. van de Ridder JM, Peters CM, Stokking KM, de Ru JA, Ten Cate OT. Framing of feedback impacts student's satisfaction, self-efficacy and performance. Adv Health Sci Educ Theory Pract 2015;20:803-16.

45. van de Ridder JM, McGaghie WC, Stokking KM, ten Cate OT. Variables that affect the process and outcome of feedback, relevant for medical training: a meta-review. Med Educ 2015;49:658-73.

46. Bok HG, Teunissen PW, Spruijt A, et al. Clarifying students' feedback-seeking behaviour in clinical clerkships. Med Educ 2013;47:282-91.

47. van de Ridder JM, Berk FC, Stokking KM, Ten Cate OT. Feedback providers' credibility impacts students' satisfaction with feedback and delayed performance. Med Teach 2014:1-8.

48. Watling C. Cognition, culture, and credibility: deconstructing feedback in medical education. Perspect Med Educ 2014;3:124-8.

49. Lefroy J, Watling C, Teunissen PW, Brand P. Guidelines: the do's, don'ts and don't knows of feedback for clinical education. Perspect Med Educ 2015;4:284-99.

50. Shute V. Focus on formative feedback. Rev Educ Res 2008;78:153-89.

51. Kluger A, DeNisi A. Effects of feedback intervention on performance: a historical review, a meta-analysis, and a preliminary feedback intervention theory. Psychol Bull 1996;119:254-84.

52. Harrison CJ, Konings KD, Molyneux A, Schuwirth LW, Wass V, van der Vleuten CP. Web-based feedback after summative assessment: how do students engage? Med Educ 2013;47:734-44

53. Harrison CJ, Könings KD, Schuwirth L, Wass V, van der Vleuten C. Barriers to the uptake and use of feedback in the context of summative assessment. Adv Health Sci Educ Theory Pract 2015;20:229-45. 
54. Gaunt A, Patel A, Rusius V, Royle TJ, Markham DH, Pawlikowska T. 'Playing the game': How do surgical trainees seek feedback using workplace-based assessment? Med Educ 2017;51:953-62.

55. Bok HG, Jaarsma DA, Spruijt A, Van Beukelen P, Van Der Vleuten CP, Teunissen PW. Feedback-giving behaviour in performance evaluations during clinical clerkships. Med Teach 2015:1-8.

56. Hoff TJ, Pohl H, Bartfield J. Creating a learning environment to produce competent residents: the roles of culture and context. Acad Med 2004;79:532-9.

57. Stinson L, Pearson D, Lucas B. Developing a learning culture: twelve tips for individuals, teams and organizations. Med Teach 2006;28:309-12.

58. Teunissen PW, Bok HG. Believing is seeing: how people's beliefs influence goals, emotions and behaviour. Med Educ 2013;47:1064-72.

59. ten Cate OT. Why receiving feedback collides with self-determination. Adv Health Sci Educ Theory Pract 2013;18:845-9.

60. Gaunt A, Patel A, Fallis S, et al. Surgical Trainee Feedback-Seeking Behavior in the Context of WorkplaceBased Assessment in Clinical Settings. Acad Med 2017;92:827-34.

61. Ramani S, Krackov SK. Twelve tips for giving feedback effectively in the clinical environment. Med Teach 2012;34:787-91.

62. Branch WT, Jr., Paranjape A. Feedback and reflection: teaching methods for clinical settings. Acad Med 2002;77:1185-8.

63. Cantillon P, Sargeant J. Giving feedback in clinical settings. BMJ 2008;337:a1961.

64. Milan FB, Parish SJ, Reichgott MJ. A model for educational feedback based on clinical communication skills strategies: beyond the "feedback sandwich". Teach Learn Med 2006;18:42-7.

65. Molloy E, Boud D. Seeking a different angle on feedback in clinical education: the learner as seeker, judge and user of performance information. Med Educ 2013;47:227-9.

66. London M, Smither JW. Feedback orientation, feedback culture, and the longitudinal performance management process. Human Resource Management Review 2002;12:81-100.

67. Watling $C$, Driessen $E$, van der Vleuten CP, Lingard L. Learning culture and feedback: an international study of medical athletes and musicians. Med Educ 2014;48:713-23.

68. Watling $C$, Driessen $E$, van der Vleuten CP, Vanstone M, Lingard L. Music lessons: revealing medicine's learning culture through a comparison with that of music. Med Educ 2013;47:842-50.

69. Archer JC. State of the science in health professional education: effective feedback. Med Educ 2010;44:101-8.

70. Kraut A, Yarris LM, Sargeant J. Feedback: Cultivating a Positive Culture. J Grad Med Educ 2015;7:262-4.

71. Menachery EP, Knight AM, Kolodner K, Wright SM. Physician characteristics associated with proficiency in feedback skills. J Gen Intern Med 2006;21:440-6.

72. Ilgen DR, Fisher CD, Taylor MS. Consequences of individual feedback on behavior in organizations. Journal of Applied Psychology 1979;64:349-71.

73. Sargeant J, Lockyer JM, Mann K, et al. The R2C2 Model in Residency Education: How Does It Foster Coaching and Promote Feedback Use? Acad Med 2018, Jan 16 (Epub ahead of print).

74. Sargeant J, Mann K, Manos S, et al. R2C2 in Action: Testing an Evidence-Based Model to Facilitate Feedback and Coaching in Residency. J Grad Med Educ 2017;9:165-70.

75. Sargeant J, Lockyer J, Mann K, et al. Facilitated Reflective Performance Feedback: Developing an Evidenceand Theory-Based Model That Builds Relationship, Explores Reactions and Content, and Coaches for Performance Change (R2C2). Acad Med 2015;90:1698-706.

76. Telio S, Ajjawi R, Regehr G. The "educational alliance" as a framework for reconceptualizing feedback in medical education. Acad Med 2015;90:609-14.

77. Telio S, Regehr G, Ajjawi R. Feedback and the educational alliance: examining credibility judgements and their consequences. Med Educ 2016;50:933-42.

78. Lave J, Wenger E. Situated learning : legitimate peripheral participation. Cambridge England; New York: Cambridge University Press; 1991.

79. Wertsch JV. Voices of the mind: a sociocultural approach to mediated action. Cambridge, Mass.: Harvard University Press; 1991. 
80. Brown P, Levinson SC. Politeness: some universals in language usage. Cambridge Cambridgeshire; New York: Cambridge University Press; 1987.

81. Ryan RM, Deci EL. Self-determination theory and the facilitation of intrinsic motivation, social development, and well-being. The American psychologist 2000;55:68-78.

82. Brown P, Levinson S. Universals in language usage: Politeness phenomena. Cambridge: Cambridge University Press; 1978.

83. Ginsburg S, van der Vleuten C, Eva KW, Lingard L. Hedging to save face: a linguistic analysis of written comments on in-training evaluation reports. Adv Health Sci Educ Theory Pract 2016;21:175-88.

84. Ginsburg S, Regehr G, Lingard L, Eva KW. Reading between the lines: faculty interpretations of narrative evaluation comments. Med Educ 2015;49:296-306.

85. Ryan R. Thoughts on the genesis of self-determination theory. Am J Health Promot 2013;27:TAHP8.

86. Mann KV. Thinking about learning: implications for principle-based professional education. J Contin Educ Health Prof 2002;22:69-76.

87. Ten Cate TJ, Kusurkar RA, Williams GC. How self-determination theory can assist our understanding of the teaching and learning processes in medical education. AMEE guide No. 59. Med Teach 2011;33:961-73.

88. Patton MQ. Qualitative research and evaluation methods. 3 ed. Thousand Oaks, Calif.: Sage Publications; 2002.

89. Creswell JW, Creswell JW. Qualitative inquiry and research design: choosing among five approaches. 3rd ed. Los Angeles: SAGE Publications; 2013.

90. Starks H, Trinidad SB. Choose your method: a comparison of phenomenology, discourse analysis, and grounded theory. Qual Health Res 2007;17:1372-80.

91. Watling CJ, Lingard L. Grounded theory in medical education research: AMEE Guide No. 70. Med Teach 2012;34:850-61.

92. ledema R, Mesman J, Carroll K. Visualising health care practice improvement: innovation from within. London; New York: Radcliffe Pub.; 2013.

93. Carroll K, ledema R, Kerridge R. Reshaping ICU ward round practices using video-reflexive ethnography. Qual Health Res 2008;18:380-90.

94. Gordon L, Rees C, Ker J, Cleland J. Using video-reflexive ethnography to capture the complexity of leadership enactment in the healthcare workplace. Adv Health Sci Educ Theory Pract 2016.

95. Wolcott HF. Ethnography: a way of seeing. 2nd ed. Lanham, MD: Altamira Press; 2008.

96. Glaser BG, Strauss AL. The discovery of grounded theory: strategies for qualitative research. London,: Weidenfeld and Nicolson; 1968.

97. Charmaz K. Constructing grounded theory. 2nd edition ed. London; Thousand Oaks, Calif.: Sage; 2014.

98. ledema R. Creating safety by strengthening clinicians' capacity for reflexivity. BMJ Qual Saf 2011;20 Suppl 1:i83-6.

99. Watt D. On Becoming a Qualitative Researcher: The Value of Reflexivity. The Qualitative Report 2007;12:82-101. 



\section{Chapter}

\section{A Guide to Reflexivity for Qualitative Researchers in Education}

Published as: Ramani S, Könings KD, Mann, K, van der Vleuten CPM. A Guide to

Reflexivity for Qualitative Researchers in Education Academic Medicine 2018, AM Last Page, April 24.

[Epub ahead of print] 
Qualitative researchers must engage in reflexivity - at all stages of the qualitative research process. They must recognize their beliefs and assumptions, acknowledge their relationship to the research topic and participants, and consider how these influence their study. Below, we describe two categories of reflexivity: personal and epistemological. For each category, we suggest key strategies that researchers can adopt to improve the quality and rigor of their research.

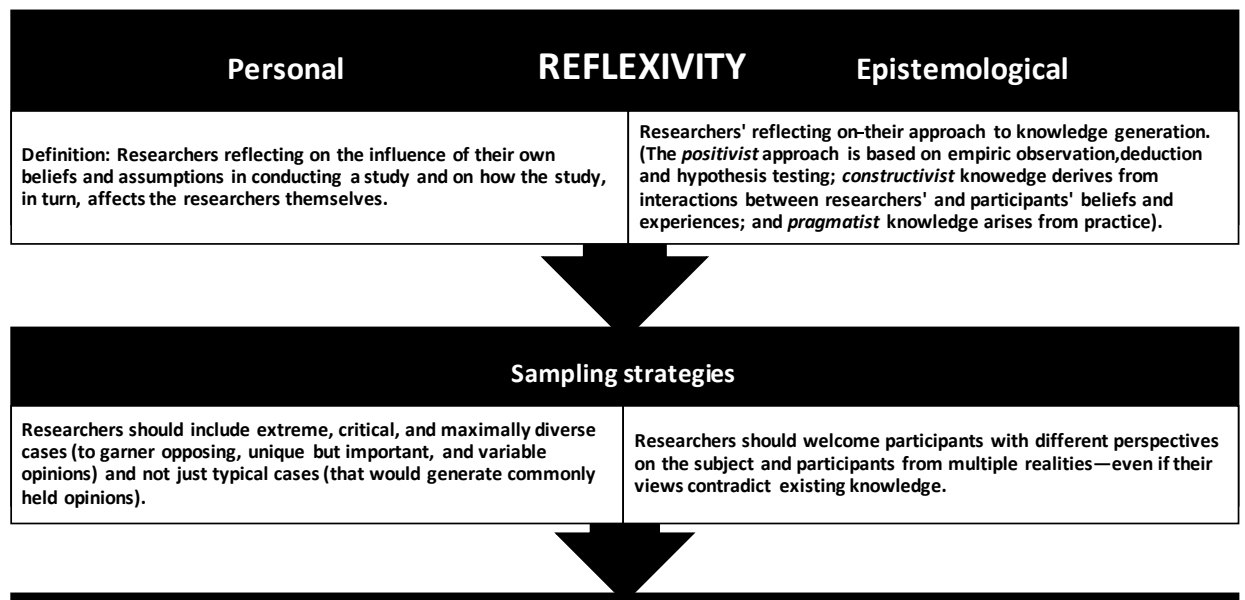

Data sources and collection: Questions to ask

Is the inquiry open-ended? Is a power differential or hierarchy inhibiting expression of alternative perspectives? Are any questions or data being overlooked due to personal beliefs and opinions?
Is data collection triangulated (i.e., from multiple data sources) so that investigator interpretations of findings are justified and to allow for discovery of new concepts linked to study questions?

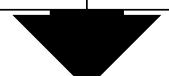

\section{Data analysis and interpretation}

Researchers immerse themselves in the data, actively look for complementary and divergent opinions, code using participants' words, and use memos to document assumptions.
Multiple investigators undertake independent analysis, ensuring that data interpretation is based on participants' narratives; then they verify their interpretation with participants (i.e., engage in member checking).

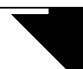

Findings and story

Researchers report how their preconceptions, beliefs, values, assumptions, and position may have influenced the research process.

Researchers report how participants' voices raised awareness of existing knowledge of the central concept, allowed discovery of new concepts, and influenced the storyline.

Notably, the dichotomy between personal and epistemological reflexivity is not absolute; the two categories overlap in many areas. The strategies here constitute a framework, 
not a set of rules, since the design for each qualitative study must ultimately be guided by the study questions.

Educ. 2015;49:1-148

\section{Further reading}

1. Jootun D, McGhee G, Marland GR. Reflexivity: promoting rigour in qualitative research. Nurs Stand 2009;23:42-46.

2. Verdonk P. When I say ... reflexivity. Med Educ 2015;49:147-148.

3. Enosh G, Ben-Ari A. Reflexivity: The Creation of Liminal Spaces--Researchers, Participants, and Research Encounters. Qual Health Res 2016;26:578-584.

4. Watt $D$. On becoming a qualitative researcher: The value of reflexivity. The Qualitative Report 2016; 12 (1): 82-101. 



\section{Chapter}

\section{"It's Just Not The Culture": \\ A qualitative study exploring residents' perceptions of the impact of institutional culture on feedback.}

Published as: Ramani S, Post SE, Könings K, Mann K, Katz JT, van der Vleuten CPM. "It's just not the culture": A qualitative study exploring residents' perceptions of the impact of institutional culture on feedback. Teaching and Learning in Medicine 2017; 29 (2): 153-61. 


\section{Abstract}

Phenomenon: Competency-based medical education requires ongoing performancebased feedback for professional growth. In several studies, medical trainees report that the quality of faculty feedback is inadequate. Sociocultural barriers to feedback exchanges are further amplified in graduate and postgraduate medical education settings, where trainees serve as front line providers of patient care. Factors that affect institutional feedback culture, enhance feedback seeking, acceptance, and bidirectional feedback warrant further exploration in these settings.

Approach: Using a constructivist grounded theory approach, we sought to examine residents' perspectives on institutional factors that affect the quality of feedback, factors that influence receptivity to feedback, and quality and impact of faculty feedback. Four focus group discussions were conducted, with two investigators present at each. One facilitated the discussion, the other observed the interactions and took field notes. We audiotaped and transcribed the discussions, and performed a thematic analysis. Measures to ensure rigor included, thick descriptions, independent coding by two investigators and attention to reflexivity.

Findings: We identified five key themes, dominated by resident perceptions regarding the influence of institutional feedback culture. The theme labels are taken from direct participant quotes: (1) the cultural norm lacks clear expectations and messages around feedback; (2) the prevailing culture of niceness does not facilitate honest feedback; (3) bidirectional feedback is not part of the culture; (4) faculty-resident relationships impact credibility and receptivity to feedback; (5) there is a need to establish a culture of longitudinal professional growth.

Insights: Institutional culture could play a key role in influencing the quality, credibility, and acceptability of feedback. A polite culture promotes a positive learning environment, but can be a barrier to honest feedback. Feedback initiatives focusing solely on techniques of feedback-giving may not enhance meaningful feedback. Further research on factors that promote feedback seeking, receptivity to constructive feedback, and bidirectional feedback would provide valuable insights. 


\section{Introduction}

The hallmark of competency-based training in medical education is the optimal combination of regular formative feedback and learning opportunities for trainees to practice skills and improve performance. ${ }^{1-5}$ A developmental approach to assessment, such as the milestones-based approach recommended by the Accreditation Council for Graduate Medical Education (www.acgme.org) requires provision of ongoing meaningful feedback, preferably from multiple sources, to help clinical trainees calibrate their performance at various time points and ensure that goals are met. Yet, research reports in medical education indicate that faculty feedback is vague and ineffective in changing behavior. ${ }^{6-8} \mathrm{Re}-$ luctance to provide constructive feedback to avoid damaging teacher-trainee relationships, ${ }^{9-13}$ can be magnified by the fact that residents are both trainees and frontline professionals progressing towards independent practice.

Key factors that influence the process and outcomes of feedback, particularly with more advanced professional trainees, include observation of task performance, feedback provision on performance and acceptance of the feedback by the recipient. ${ }^{10,11,14,15}$ Feedback seeking behaviour is also thought to enhance acceptance of feedback provided, goal setting, and performance improvement, ${ }^{16-18}$ this behaviour can be driven by self-motives (self-assessment, self-improvement, self-enhancement or self-verification); personal and interpersonal factors (intentions and the characteristics of the feedback provider, relationship between the feedback seeker and provider); and perceived positive or negative effect on self-esteem. ${ }^{13,16-24}$ Finally, if feedback is perceived to be credible, it is more likely to be accepted and processed with resulting change in behavior. ${ }^{3,15,25} 14,26$ While these reports have triggered a major shift in the thinking about feedback, little is yet known about factors that trigger feedback seeking, enhance institutional feedback culture, increase consistent performance observation, and promote bidirectional feedback ${ }^{27}$ especially in graduate and postgraduate medical education settings.

Concepts from the politeness theory have been emphasised in studies by Ginsburg and colleagues, who found that faculty narrative comments on written evaluations were frequently vague and generic. ${ }^{28,29}$ It is possible that faculty lack in-depth knowledge about their trainees' performance, or they perceive that their institutional culture discourages language potentially threatening to trainees' self-image; both of which could result in non-specific and unhelpful comments. ${ }^{28,29}$ The authors also described a politeness concept, 'conventional indirectness', referring to the use of phrases that imply one meaning in a professional culture, but are very different from their literal meanings, thus leading to teachers and learners reading between the lines. For example, descriptions such as 'good', 'solid' and 'meets expectations' are polite on the surface, but may actually indicate that the performance is borderline or below average. However, learners may not interpret these terms accurately or appreciate that their performance indeed requires improvement. How politeness affects in-person feedback conversations between teachers and trainees in medical education would be important to explore. 
We wished to explore some of these issues seeking to understand residents' ideas regarding institutional and their own values about feedback and the quality of feedback from faculty. In addition, we wanted to examine why residents consistently reported in end of the year surveys conducted by the graduate medical education office that feedback in our department was inadequate and unhelpful overall. This study focussed on the following questions:

1. What are resident perspectives regarding institutional work and learning climate related factors that could impact the quality of feedback exchanged between faculty and residents?

2. What factors could increase the credibility of and residents' receptivity to feedback provided by faculty?

3. What are the perceptions of residents regarding the quality of feedback provided by faculty, and specifically whether they think it can be acted upon?

\section{Methods}

Using qualitative methodology and study design, ${ }^{30}$ we conducted focus groups of residents to examine their opinions on the value and purpose of feedback in general, institutional messages about the value of and expectations for feedback conversations, facilitators and barriers to honest feedback conversations, and suggestions to enhance actionable feedback.

\section{Setting}

The Internal Medicine (IM) Residency Program at Brigham and Women's Hospital (BWH), a teaching affiliate of Harvard Medical School, is a large urban training program with approximately 160 residents. Inpatient teams typically consist of 1-2 Postgraduate year (PGY) 2, 3 or 4 residents, 2-3PGY1 residents, 1-2 attending physicians and 1-2 medical students. All categorical residents, i.e. those who are not on a 1-year preliminary track, work in continuity clinics with a primary faculty preceptor throughout their residency. Preliminary residents, those on a 1-year track prior to other specialty residencies such as Neurology or Anaesthesiology, do not work in continuity clinics but work on inpatient medicine services.

Residents are formally assessed by their supervising faculty and peers at the end of each inpatient rotation and twice a year by their continuity clinic preceptors, using milestones-based assessment forms. Faculty are also required to give verbal formative feedback to each resident at the mid-point and summative feedback at the end of each inpatient rotation and periodically in continuity clinics. On most inpatient general medicine 
or subspecialty rotations, faculty work with their team of 3-6 residents for 2-4 weeks. Only in continuity clinics, residents have a longitudinal one-on-one working relationship with their preceptor. Residents are exposed to a variety of faculty levels from novice to seasoned clinicians. For some of the clinician investigator faculty, their teaching commitments for an entire year might be limited to a 2-week rotation on a house staff team. Sporadic feedback workshops are offered at the institution, but there is no requirement that all teaching faculty receive formal training in feedback. There are also limited opportunities for faculty to discuss challenges and refine best practices.

\section{Framework and sampling}

We used a constructivist grounded theory approach to explore opinions of participants. ${ }^{31-}$ 33 In this approach, narratives of participants allow researchers to reconstruct experiences and their meaning using an interactive process. ${ }^{34} \mathrm{~A}$ purposive sampling strategy was used to recruit residents for the focus groups. Purposive sampling strategies target representative groups or groups with specific characteristics. ${ }^{32}$ In this study, we sampled groups of categorical residents (on a 3 or 4-year residency track and not in the 1-year preliminary track) in our program seeking to obtain a range of opinions regarding the value, quality of feedback provided by faculty, impact on performance as well as their perceptions of the departmental feedback culture. This sample was selected from a possible pool of 140 residents, the number enrolled in a 3 to 4 -year Internal Medicine track. We intentionally used heterogenous groups of postgraduate year (PGY) 1, 2 and 3 residents to obtain opinions from different levels of trainees, aiming to facilitate rich interactions among the different levels of residents, given that they work closely together and learn from each other.

\section{Data collection}

The principal data collection was through focus group discussions, ${ }^{33,35}$ supplemented by investigator observations and field notes during the discussions. Focus groups were selected to enhance the richness of data through group interactions, for feasibility reasons given residents' busy clinical schedules, and to maximise the number of participants in a shorter timeframe.

Participant opinions regarding the value of feedback, institutional expectations and messages around feedback, quality of feedback, and barriers to receptivity were explored. Focus group questions were semi structured to maintain the flexibility to discover unanticipated issues. Four focus group discussions were scheduled between December 2013 and February 2014, all groups consisted of PGY-1, 2 and 3 residents during their scheduled ambulatory conference time for convenience. The dedicated conference time was selected because of residents' busy schedules and to maximise participation. 
All prospective participants received e-mail invitations describing the purpose of the study, emphasizing that participation was voluntary and ensuring confidentiality of opinions. Verbal consent was obtained from participants, with the opportunity to opt out at any point. The study was granted exempt status by the Partners Institutional Review Board, the review board for Brigham and Women's Hospital (Protocol \#2013P002270/BWH).

Focus group discussions were 60 minutes in duration. Two investigators, a faculty member, and a resident, were present at each discussion. To minimise any power differences, discussions were led by the resident while the faculty member observed the interactions and made field notes. The faculty investigator (SR) was not a program director or responsible for promotion or graduation decisions. To maximise reflexivity, focus group facilitators were trained in using prompts and probes, facilitating participant interactions and avoiding injecting their own biases into the discussions. ${ }^{36}$ Post-discussion debriefing of the research team reemphasised these principles.

The interviewer used open-ended questions as initial prompts (listed below), followed up on responses, and sought clarification or elaboration as required. Trigger questions, discussed in advance by the research team, were used to initiate conversations, responses were further probed and further open-ended questions were posed to ensure that the content of the discussions covered the study questions. Whenever conversations spontaneously covered topics relating to the study questions, the interviewer did not interrupt. Sample triggers included:

- Does feedback provided by faculty facilitate performance improvement?

- What are the strengths and weaknesses of the current feedback system in our residency program?

- Can you describe challenges encountered when you give or receive feedback?

- Can you suggest strategies to improve the feedback culture in our department?

\section{Data analysis}

We audiotaped all discussions and used a transcription service to transcribe them, no identifying information was retained in the transcripts. We used the principles of grounded theory to identify themes through analysis of participants' conversations (rather than through a priori hypotheses) and generate a theory or concept about the process of feedback. ${ }^{31}$ Analysis, performed manually, occurred concurrently with and informed ongoing data collection. Trigger questions and probes were modified as appropriate for future discussions. Data collection was stopped when it appeared that no additional themes related to our study questions emerged and there was adequate information to construct a theoretical understanding of the problem being studied. Participants in our fourth focus group did not raise any new concepts about the feedback culture and we considered data gathered as sufficient to answer our study questions. Two 
investigators independently reviewed and coded transcripts and established coding categories. We analysed the data and interpreted their significance concurrently, a strategy known as "immersion and crystallization". 30,37 During open coding, each data unit referring to a specific issue was assigned a code consistent with participants' terminology to minimise subjective bias. We then performed thematic analysis to identify major themes reflecting words and phrases used by participants. Ambiguities or disagreements in coding and generation of themes were resolved by consensus at research team meetings, which involved two additional investigators reviewing the analysis. Our interpretation of data was further validated by informal checking-in discussions with some of the participating residents a few weeks later.

\section{Results}

A total of 38 residents participated in our focus groups: 12 in group 1, 10 in group 2 and 8 in each of groups 3 and 4. PGY-1, 2 and 3 levels of training were well represented within each group. The 38 residents were a sample of volunteers from among 140 residents on a 3 or 4-year training track.

We identified five major themes from our data analysis. Residents' discussions appeared to emphasise the feedback culture of the institution and relationships between faculty and residents, even though these were not directly probed by the investigators. : The themes were: (1) The cultural norm lacks clear expectations and messages around feedback; (2) The prevailing culture of niceness does not facilitate honest feedback; (3) Bidirectional feedback is not part of the culture; (4) Faculty-resident relationships affect credibility and receptivity to feedback; (5) There is a need to establish a culture of ongoing professional growth.

These themes, which appeared to represent fundamental beliefs held by residents on the role of feedback in their training, are described in more detail below with representative quotes.

The five themes related to a specific study question: the first three themes to study question (1), theme 4 to study question (2) and theme 5 to study question (3).

\section{The cultural norm lacks clear expectations and messages around feedback}

Participants indicated that the departmental feedback culture demonstrated a disconnect between stated expectations and actual events. According to them, there was an assumption that effective feedback would occur as a result of monthly reminder emails, but clear expectations about the content, strategies for delivery, and action items for follow up are deficient. Additionally, time is not set aside for formal feedback conversations nor are feedback givers and receivers guided by a suggested structure for these 
conversations. Those residents who had attended courses at the business school reported that expectations of feedback were much more clearly communicated, backed up by robust training for teachers and learners on providing, soliciting, and receiving feedback respectively.

I just don't think that that's the cultural norm here. When I was in business school, there was so much feedback, and so many sessions on how to give feedback, and how to give feedback on the feedback, it became like a joke. But, it did ingrain a culture of learning to deliver feedback in specific ways, and there was an expectation that you would give it and know how to receive it. Whereas I think here, maybe that would be well-received, but maybe a person would be taking a risk. (R3)

Residents commented on faculty who rotate on the teaching service only for 2-4 weeks each year. With limited time dedicated to supervising and teaching, they were perceived as less prepared to engage in learner-cantered teaching, provide timely and specific feedback or reflect on their own teaching. Participants queried whether the department explicitly communicated to faculty that the key purpose of such teaching rotations is learner growth, which requires meaningful performance-based feedback.

I've had a bunch of attendings that only attend for two weeks out of the year. The rest of the time, they're in a lab or they don't do any clinical stuff. I think they sort of forget that the purpose of this is that we're in training, it's not just to like get the work done and get out, which has felt more like the culture in those particular rotations. (R3)

\section{The prevailing culture of niceness does not facilitate honest feedback}

Residents stated that there was a "culture of niceness" within the program which they perceived as a barrier to honest feedback. They emphasised that faculty, peers, and the program leadership are "nice" and appreciative of hard work, but tend to avoid constructive feedback altogether. Participants did not explicitly blame hierarchy or power relationships for this lack, but related this to faculty empathy for hard working residents, unwillingness to hurt their feelings and a desire to maintain a nurturing work environment. However, they stated that constructive feedback is essential to enable awareness of specific areas requiring improvement as well as concrete next steps.

People are so encouraging, you're already sweating and scared, so they want to just help you along. And I think they're being nurturing and great. And it's wonderful and I wouldn't change that, but there have been times where I've been like, am I doing OK, do you have any thoughts, and people are like yeah yeah yeah! (R2) 
This "niceness" extended to peer feedback as well. Senior residents tended to omit any comments that could be construed as negative when they provided feedback to their junior peers.

The culture of feedback from us is not to give bad feedback, we don't want to give feedback because we don't want to hurt anyone's feelings. It's not doing anyone any favours. Changing the culture will be really important moving forward. (R3)

It was suggested that the departmental culture of niceness could potentially be harnessed to encourage honest feedback conversations by overt emphasis that feedback is integral for professional success and teachers and trainees should help each other grow.

It's still in line with the 'culture of niceness' to help someone succeed and reach their goals...that's the mentality all of us should bring to giving and accepting feedback...we want to see people succeed. (R2)

\section{Bidirectional feedback is not part of the culture}

Participants perceived that the departmental culture did not encourage bidirectional feedback. Residents rarely provide feedback to attending physicians, similarly junior residents hesitate to or avoid verbal feedback to their senior peers. Senior residents who had experienced feedback from their junior trainees identified these experiences as valuable, and felt that such feedback often focussed on different skills that the feedback from their supervisors.

I haven't actually gotten verbal feedback from any of my interns, but some of the written ones I've gone over with our program director. And I found it helpful, I wish they had done more, like how my teaching went off, stuff like that. And it's different feedback than I would get from an attending. (R3)

I found it helpful. I wish my intern had done more...interns give more feedback on the teaching, running rounds, how supportive I am, how it is working with us, the nitty-gritty. (R2)

Overall, there was a perception that faculty would not welcome constructive feedback and such requests may be just lip service. There was also some anxiety whether offering "negative" feedback to attending physicians would carry some risk, though unclear what this risk entailed. Such perceptions resulted in near absence of bidirectional feedback.

It's pretty awkward to give feedback to attendings. I tend to just not say anything constructive. I think they rarely ask (R2).

When I've been asked to give feedback (to faculty) ... I don't really know what to say. When asked 'how do you think things are going', I don't know if they want specifics or just going through the motions. (R3) 
Only extremely negative circumstances such as overly long rounds causing disruption of the work routine seemed to trigger residents' feedback to attending physicians and such conversations tended to be confrontational. Only one senior resident reported engaging in a in a collegial, honest yet supportive dialogue with her attending which she perceived was intended for mutual professional growth.

I gave some feedback to an attending once, because I felt like rounds were just totally horrible. I think he was a little taken aback, but I think he really appreciated it. Sort of, I don't think he had thought so much about where we are in the year, and how rounds should be different maybe at different points. It was well received. $(R 2)$

On rare occasions it's been useful. It was a good back and forth, kind of thinking about how things had changed over the past week, what ways I had grown, and she invited the same feedback for her. It was an open dialogue. Six months, one occasion. (R1)

\section{Faculty- resident relationships affect credibility and receptivity to feedback}

According to participants, current feedback conversations are dominated by "good job" comments. They stated that feedback is less credible when expectations of required performance are not clear, the feedback giver has not set the stage by allowing learners to discuss their goals.

It would be really helpful to know the things expected of you ... 'the ten skills you should have by the end of the year.' It helps you identify where you are weak and helps others identify where you need growth. (R1)

When interns picked one or two areas of weakness that they want to focus on, I found I was giving more feedback, more frequently, and more in-depth. It guided me in terms of how to help them. And that also makes the experience more enriching for me. (R3)

Feedback not based on first-hand observation appeared to lack credibility. When used as the basis of a feedback conversation, the comments neither provided specific information on performance nor were they likely to be acceptable to residents.

I've been given feedback on things that weren't observed...it's confusing to me how an attending can comment on my physical exam skills if he or she has never seen me... I think that is fundamental to providing any sort of feedback. (R3)

Summative feedback provided solely at the end of a rotation appeared to be less well received as opportunities are not provided for residents to change their behaviour and 
there is no follow up. According to participants, this could lead to a mismatch of perceptions between feedback givers and receivers, with the former ticking a box that feedback occurred and the latter perceiving that feedback never occurred.

At the end of a rotation, you're given feedback, like 'this went poorly.' It's awkward and difficult, you can't really do anything to change it. (R2)

Finally, feedback comments need to be actionable with conversations concluding with concrete performance improvement plans.

What's useful is a tangible strategy to improve. ...Anybody that has concrete ways of helping you get there; I've found that to be so helpful. (R1)

\section{There is a need to establish a culture of longitudinal and professional growth}

Participants suggested that efforts at changing the institutional culture might include explicit encouragement of a goal setting conversation at the start of any rotation and further emphasis on professional growth of teachers and learners alike as a foundation for meaningful feedback.

What needs to happen is a change in culture. The way to do that isn't necessarily a mandate. Whereas, if it's a culture around self-improvement or trying to identify what needs to happen-instead of saying, give feedback every day, it's establish the expectations as a team at the beginning of every rotation. Invite a meeting that first day, one on one with the interns or residents or among everybody, saying, this is what we want out of this rotation. That way, you can gear the feedback to that. (R2)

It was suggested that faculty should have an orientation on the educational mission of the institution and the culture of ongoing improvement. This orientation is essential whether the faculty are core educators, frequent, or sporadic teachers.

Attendings are being trained to be educators. They do deserve a session on how to give good feedback. I think as a whole, the concept of growth just needs to be much more ingrained in the culture. Making sure that every attending that's on service here, whether that's an attending who's on service four months a year or an attending on service for two weeks, I think they all need to be reminded that we're here for education. (R1)

Another suggestion was that the institution actively facilitate longitudinal relationships between faculty and residents. While continuity clinics are structured with each resident assigned to a longitudinal preceptor throughout their training, they believed that 2-week inpatient rotations do not foster relationships or facilitate adequate performance observation, accurate performance assessment, exchange of behaviour influencing feedback, and bidirectional feedback. 
I think in general the best feedback comes out of longitudinal relationships. Because if it's a two-week block, you just have a snippet, and although there's growth there.... Any sort of relationship that happens over time offers better opportunities for feedback. (R3)

\section{Discussion}

Our study provides several insights into residents' perspectives on key factors that influence the exchange of feedback at one large residency program. These findings are depicted in Figure 1. Residents' frequent emphasis of the department's feedback culture leads us to speculate that institutional culture is central to most of the reported themes and appeared to affect residents' perceptions of the quality, credibility, and acceptability of feedback, hence its impact. The culture was described as polite or nice; ironically the politeness served as a barrier to honest feedback conversations even though it was seen to promote a positive learning environment and appreciated by most residents. Participants believed that faculty may be overprotective of residents' feelings with a tendency to omit any constructive feedback that might be perceived as criticism. The culture was also not conducive to bidirectional feedback, either from residents to faculty or from junior to senior residents. While residents did not wish to detract from the friendly learning environment, they suggested strategies to preserve it while moving to a behaviour changing feedback culture, which promotes professional growth.

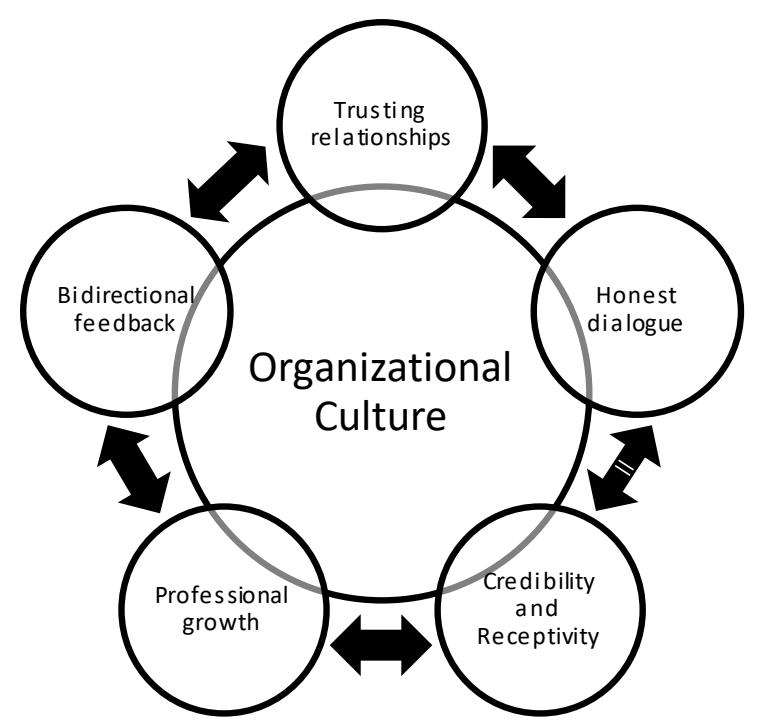

Figure 1: Organisational culture at the heart of the process and impact of feedback 
Legend: This figure depicts organisation culture at the centre of an effective feedback cycle. A culture that promotes trusting relationships, and honest dialogue between teachers and learners, can enhance credibility of and receptivity to feedback provided. Additionally, trusting relationships can encourage bidirectional feedback which in turn leads to professional growth on both sides.

Our residents' statements about politeness being a barrier to honest feedback conversations resonate well with facets of the Politeness theory. Politeness refers to a battery of social skills that ensures self-affirmation for those engaged in social interactions. ${ }^{38}$ This theory, described by Brown and Levinson, is relevant to the clinical training environment where learning occurs through social interactions and team members are dependent on each other to achieve their teaching, learning, or patient care goals. ${ }^{39}$ Residents are trainees as well as front line professionals and it is not surprising that faculty and residents wish to be "nice" to each other and avoid exchanges that could be perceived as impolite. Constructive feedback may well be viewed as a breach of the norms of expected politeness. ${ }^{40,41}$ This point was raised by Ginsburg and colleagues in their research into the quality of written comments by faculty on evaluation forms. ${ }^{28,29}$ It is very likely that politeness concepts impact in-person feedback conversations even more, especially with advanced professional trainees, and is not unique to written feedback or to our institution. This culture of politeness within an institution and between individuals working and learning in that system needs to be addressed openly in feedback training initiatives, especially since it was flagged as a barrier by many study participants.

Many aspects of organisational culture, which influences how its members think, feel, and act, are likely to be relevant to the process, quality, and impact of feedback conversations. Schein defines organisational culture as "a pattern of shared basic assumptions invented, discovered, or developed by a given group as it learns to cope with its problems of external adaptation and internal integration." 42 Such assumptions are taken for granted, and taught to new members as the correct way to perceive, think, and feel. The competing values framework refers to how an organisational culture balances two key dimensions that influence its effectiveness: organisational focus (internal or external) and organisational preference for structure (the balance between stability, control, flexibility and change). ${ }^{43}$ It has been reported that an organisational culture that consists of a certain level of risk taking, flexible policies, and procedures, strong leadership and strict hierarchy, a high concern for new ideas and teamwork, and a focus on growth and innovation can positively impact successful curriculum reform in medical education. ${ }^{44}$ In some organisations, members tend to challenge each other openly, while in others members are polite and avoid disagreeing or criticizing openly. It appears that our institutional culture falls under the latter category at least where feedback conversations are concerned. Thus, change management involves understanding of the culture of an organisation, cultural barriers to change, developing strategies to deal with potential sources of resistance and creating a shared vision.

The process and impact of feedback relies on interpersonal interactions and relationships between feedback givers and recipients, situated within an institutional culture. ${ }^{45}$ 
Sargeant et al., described a facilitated feedback model using the sociocultural lens that could enhance its acceptance and lead to performance improvement. They described four phases in this model: build relationships, explore reactions, explore content, coach for performance change. ${ }^{46}$ Könings et al., indicated that a participatory design, which integrates multiple perspectives from learners, teachers, and leaders is more likely to enhance learning and the effectiveness of learning environments and this view has implications for co-construction of bidirectional feedback. ${ }^{47}$ Thus, training on techniques for delivering feedback alone, which dominates much of faculty development on this topic, is unlikely to enhance its impact on behaviours or performance or promote honest conversations and bidirectional feedback.

This study has a few limitations which may have affected our findings. Opinions of residents from a single department at a single institution limit the transferability of findings. Though the exploration yielded significant quantity of narrative data, we may not have captured fully a wide range of opinions. The focus group discussions lasted 60 minutes and we cannot be sure that all participants had sufficient time to express opinions in detail. Our study focussed on resident perspectives and did not explore opinions of faculty, which are likely to reflect additional challenges not perceived by trainees. The issue of politeness was unanticipated and what the residents perceive to be the components of a feedback culture is unclear. Both topics warrant further exploration as a next step, particularly as they relate to the sociocultural aspects of feedback. Finally, we did not define in detail or distinguish formative and summative feedback. It is entirely possible that each of the types have their own challenges and we cannot be sure which of the two types specific themes relate to.

\section{Implications for practice and future research}

Future research should seek to gain a better understanding of the sociocultural factors that facilitate or challenge feedback exchanges. Such understanding could lead to strategies to address these barriers and promote the understanding that feedback is not solely about the skills of providing it, but more about co-construction by both participants and related to professional goals which would enhance acceptance, incorporation, and behaviour change.

We plan to further explore perspectives of residents and faculty about the culture of politeness that was alluded to, factors influencing this culture, the various professionals who contribute to it, and how this can be harnessed to enhance meaningful feedback. Institutional leaders, faculty, and trainees will all need to be involved in designing feedback initiatives to encourage feedback seeking and promote bidirectional performanceimproving conversations. ${ }^{48}$ Facilitating longitudinal relationships between faculty and residents would also likely increase the credibility and acceptance of feedback. ${ }^{11,49}$ Short rotations with limited direct interactions between faculty and trainees may have a dele- 
terious effect on direct observation and feedback. ${ }^{50,51}$ Faculty need to be actively encouraged to solicit feedback on their clinical and teaching performance and residents need to be trained and persuaded that there is an institutional expectation that feedback would be bidirectional. We anticipate that attempts to encourage bidirectional feedback will prove challenging given the hierarchical nature of the clinical environment, but hope to understand ways to harness the culture of politeness to promote honest, reflective conversations aimed at professional growth, and thus an open feedback culture. ${ }^{49}$

\section{Conclusions}

Before implementing yet another feedback initiative, it is essential to acknowledge and explicitly address cultural, social, emotional, and interpersonal factors that impact feedback. Ultimately, residents and faculty should view feedback as a bidirectional exchange within a social culture that encourages reflective practice and ongoing professional development for both, as they work towards the common goal of excellence in patient care. 


\section{REFERENCES}

1. Hodges B. Assessment in the post-psychometric era: learning to love the subjective and collective. Med Teach 2013;35:564-8.

2. Govaerts $M$, van der Vleuten CP. Validity in work-based assessment: expanding our horizons. Med Educ 2013;47:1164-74.

3. Boud D. Feedback: ensuring that it leads to enhanced learning. Clin Teach 2015;12:3-7.

4. Boud D, Molloy E. Feedback in higher and professional education : understanding it and doing it well. London; New York: Routledge; 2013.

5. Krackov SK. Expanding the horizon for feedback. Med Teach 2011;33:873-4.

6. Bing-You RG, Trowbridge RL. Why medical educators may be failing at feedback. JAMA 2009;302:1330-1.

7. Branch WT, Jr., Paranjape A. Feedback and reflection: teaching methods for clinical settings. Acad Med 2002;77:1185-8.

8. Anderson PA. Giving feedback on clinical skills: are we starving our young? J Grad Med Educ 2012;4:1548.

9. van de Ridder JM, Stokking KM, McGaghie WC, ten Cate OT. What is feedback in clinical education? Med Educ 2008;42:189-97.

10. Sargeant J, McNaughton E, Mercer S, Murphy D, Sullivan P, Bruce DA. Providing feedback: exploring a model (emotion, content, outcomes) for facilitating multisource feedback. Med Teach 2011;33:744-9.

11. Watling CJ. Unfulfilled promise, untapped potential: feedback at the crossroads. Med Teach 2014;36:6927 .

12. Delva D, Sargeant J, Miller S, Holland J, Brown PA, Leblanc C, et al. Encouraging residents to seek feedback. Med Teach 2013;35:e1625-31.

13. Harrison CJ, Könings KD, Schuwirth L, Wass V, van der Vleuten C. Barriers to the uptake and use of feedback in the context of summative assessment. Adv Health Sci Res 2015;20:229-45.

14. Watling C, Driessen E, van der Vleuten CP, Vanstone M, Lingard L. Beyond individualism: professional culture and its influence on feedback. Med Educ 2013;47:585-94.

15. van de Ridder JM, McGaghie WC, Stokking KM, ten Cate OT. Variables that affect the process and outcome of feedback, relevant for medical training: a meta-review. Med Educ 2015;49:658-73.

16. Bok HG, Jaarsma DA, Spruijt A, Van Beukelen P, Van Der Vleuten CP, Teunissen PW. Feedback-giving behaviour in performance evaluations during clinical clerkships. Med Teach 2015;38:88-95.

17. Bok HG, Teunissen PW, Spruijt A, Fokkema JP, van Beukelen P, Jaarsma DADC, et al. Clarifying students' feedback-seeking behaviour in clinical clerkships. Med Educ 2013;47:282-91.

18. Teunissen PW, Stapel DA, van der Vleuten C, Scherpbier A, Boor K, Scheele F. Who wants feedback? An investigation of the variables influencing residents' feedback-seeking behavior in relation to night shifts. Acad Med 2009;84:910-7.

19. Crommelinck M, Anseel F. Understanding and encouraging feedback-seeking behaviour: a literature review. Med Educ 2013;47:232-41.

20. Watling CJ, Lingard L. Toward meaningful evaluation of medical trainees: the influence of participants' perceptions of the process. Adv Health Sci Educ 2012;17:183-94.

21. Mann K, van der Vleuten C, Eva K, Armson H, Chesluk B, Dornan T, et al. Tensions in informed self-assessment: how the desire for feedback and reticence to collect and use it can conflict. Acad Med 2011;86:1120-7.

22. Eva KW, Armson H, Holmboe E, Lockyer J, Loney E, Mann K, et al. Factors influencing responsiveness to feedback: on the interplay between fear, confidence, and reasoning processes. Adv Health Sci Educ 2012;17:15-26.

23. Hattie J, Timperley H. The power of feedback. Rev Educ Res 2007;77:81-112.

24. Menachery EP, Knight AM, Kolodner K, Wright SM. Physician characteristics associated with proficiency in feedback skills. J Gen Int Med 2006;21:440-6.

25. Molloy E, Boud D. Seeking a different angle on feedback in clinical education: the learner as seeker, judge and user of performance information. Med Educ 2013;47:227-9. 
26. London M, Smither JW. Feedback orientation, feedback culture, and the longitudinal performance management process. Human Resource Management Review 2002;12:81-100.

27. Bose MM, Gijselaers WH. Why supervisors should promote feedback-seeking behaviour in medical residency. Med Teach 2013;35:e1573-83.

28. Ginsburg S, Regehr G, Lingard L, Eva KW. Reading between the lines: faculty interpretations of narrative evaluation comments. Med Educ 2015;49:296-306.

29. Ginsburg S, van der Vleuten C, Eva KW, Lingard L. Hedging to save face: a linguistic analysis of written comments on in-training evaluation reports. Adv Health Sci Educ 2016;21:175-88.

30. Patton MQ. Qualitative research and evaluation methods. 3 ed. Thousand Oaks, Sage Publications, 2002.

31. Kennedy TJ, Lingard LA. Making sense of grounded theory in medical education. Medical Education 2006;40:101-8.

32. Hanson JL, Balmer DF, Giardino AP. Qualitative research methods for medical educators. Acad Ped 2011;11:375-86.

33. Kitzinger J. Qualitative research. Introducing focus groups. BMJ 1995;311:299-302.

34. Charmaz K. Constructing grounded theory. London, Thousand Oaks, Sage Publications 2006.

35. Stalmeijer RE, McNaughton N, Van Mook WN. Using focus groups in medical education research: AMEE Guide No. 91. Med Teach 2014;36:923-39.

36. Watt D. On Becoming a Qualitative Researcher: The Value of Reflexivity. The Qualitative Report 2007;12:82-101.

37. Creswell JW. Educational research : planning, conducting, and evaluating quantitative and qualitative research. 4th ed. Boston: Pearson; 2012.

38. Foley WA. Anthropological linguistics : an introduction. Malden, MA: Blackwell Publishers; 1997.

39. Brown P, Levinson SC. Politeness : Some Universals In Language Usage. Cambridge Cambridgeshire; New York: Cambridge University Press; 1987.

40. Fraser B. Perspectives on politeness. Journal of Pragmatics 1990;14:219-36.

41. Brown P, Levinson S. Universals in language usage: Politeness phenomena. Cambridge: Cambridge University Press; 1978.

42. Schein EH. Organizational culture and leadership. 4th ed. San Francisco: Jossey-Bass; 2010.

43. Quinn R, Spreitzer $\mathrm{G}$. The psychometrics of the competing values culture instrument and an analysis of the impact of organizational culture on the quality of life. Research in Organizational Change and Development 1991;5:115-42.

44. Jippes M, Driessen EW, Broers NJ, Majoor GD, Gijselaers WH, van der Vleuten CP. Culture Matters in Successful Curriculum Change: An International Study of the Influence of National and Organizational Culture Tested With Multilevel Structural Equation Modeling. Acad Med 2015;90:921-9.

45. Mann KV. Theoretical perspectives in medical education: past experience and future possibilities. Med Educ 2011;45:60-8.

46. Sargeant J, Lockyer J, Mann K, Holmboe E, Silver I, Armson H, et al. Facilitated Reflective Performance Feedback: Developing an Evidence- and Theory-Based Model That Builds Relationship, Explores Reactions and Content, and Coaches for Performance Change (R2C2). Acad Med 2015;90:1698-706.

47. Könings KD, Seidel T, van Merriënboer JJ. Participatory design of learning environments: integrating perspectives of students, teachers, and designers. Instructional Science 2014;42:1-9.

48. Könings KD, Brand-Gruwel S, van Merriënboer JJ. Towards more powerful learning environments through combining the perspectives of designers, teachers, and students. Br J Educ Psych 2005;75:645-60.

49. Dudek NL, Dojeiji S, Day K, Varpio L. Feedback to Supervisors: Is Anonymity Really So Important? Acad Med 2016;91:1305-12.

50. Bernabeo EC, Holtman MC, Ginsburg S, Rosenbaum JR, Holmboe ES. Lost in transition: the experience and impact of frequent changes in the inpatient learning environment. Acad Med 2011;86:591-8.

51. Holmboe E, Ginsburg S, Bernabeo E. The rotational approach to medical education: time to confront our assumptions? Med Educ 2011;45:69-80. 



\section{Chapter}

\section{About Politeness, Face, And Feedback: Exploring resident and faculty perceptions of how institutional feedback culture influences feedback practices}

Published as: Ramani S, Karen D. Könings KD, PhD, Karen V. Mann KV, Pisarski EE, van der Vleuten CPM. About Politeness, Face and Feedback: Exploring perceptions of residents and faculty regarding institutional cultural factors that influence feedback. Acad Med 2018, Mar 6. [Epub ahead of print] 


\section{Abstract}

Purpose To explore resident and faculty perspectives on what constitutes feedback culture, their perceptions of how institutional feedback culture (including politeness concepts) might influence the quality and impact of feedback, feedback seeking, receptivity, and readiness to engage in bidirectional feedback.

Method Using a constructivist grounded theory approach, five focus group discussions with internal medicine residents, three focus group discussions with general medicine faculty, and eight individual interviews with subspecialist faculty were conducted at Brigham and Women's Hospital between April and December 2016. Discussions and interviews were audiotaped and transcribed verbatim; concurrent data collection and analysis were performed using the constant comparative approach. Analysis was considered through the lens of politeness theory and organisational culture.

Results Twenty-nine residents and twenty-two general medicine faculty participated in focus group discussions, and eight subspecialty faculty participated in interviews. The institutional feedback culture was described by participants as: (1) a culture of politeness, in which language potentially damaging to residents' self-esteem was discouraged, and (2) a culture of excellence, in which the institution's outstanding reputation and pedigree of trainees inhibited constructive feedback. Three key themes situated within this broader cultural context were discovered: normalizing constructive feedback to promote a culture of growth, overcoming the mental block to feedback seeking, and hierarchical culture impeding bidirectional feedback.

Conclusions An institutional feedback culture of excellence and politeness may impede honest, meaningful feedback and may impact feedback seeking, receptivity, and bidirectional feedback exchanges. It is essential to understand the institutional feedback culture before it can be successfully changed. 


\section{Introduction}

Feedback is most effective when it informs learners' self-assessments and influences performance. ${ }^{1-5}$ Increasingly, the focus of feedback is shifting away from providers' feedback-giving skills toward receivers' acceptance, incorporation, and behaviour change. ${ }^{2,6,7}$ However, feedback conversations are complex interpersonal exchanges, where the lack of a shared mental model between the provider and receiver may result in defensiveness, anger, or even rejection of the information. ${ }^{8-11}$ Sociocultural factors-including perceived threats to self-esteem and autonomy, fear of damaging relationships, scepticism about the credibility of the source, and incongruence of feedback data with self-assessments, ${ }^{11-}$ ${ }^{18}$ as well as the institutional learning culture ${ }^{9,19,20}$ — can also impact how feedback is given and received. In a previous study, residents reported that an existing institutional culture of politeness impeded honest feedback, while simultaneously enhancing the work and learning environment. ${ }^{21}$ In this study, we aim to further explore resident and faculty perspectives on what constitutes feedback culture, their perceptions of how institutional feedback culture (including politeness concepts) might influence the quality and impact of feedback, feedback seeking, receptivity, and readiness to engage in bidirectional feedback.

\section{Organisationa/ Culture, Image, and Identity}

Organisational culture refers to the beliefs of a community, which guide their perceptions and behavior. ${ }^{22,23}$ Schein $^{22}$ described three levels of culture that influence organisational behaviour: assumptions and beliefs that form the foundation of the culture (level 1), espoused values that underscore the organisation's purpose and desired image (level 2), and visible day-to-day behaviour, which is often a compromise between stated values and practical needs (level 3). Organisational culture also interacts with identity (members' feelings about their organisational mission) and image (how the organisation is viewed by others) to direct community behavior. ${ }^{24}$

In addition to an overall organisation culture, educational institutions have a learning culture, defined by Watling and colleagues ${ }^{20}$ as the shared beliefs, practices, and values that underpin how the profession designs the education of its learners. They report that medical educators tend to avoid constructive feedback and postulate that a learning culture that lacks longitudinal relationships and emphasises learner autonomy contributes to this behaviour. Thus far, only one study has reported that medical students were willing to exchange and accept constructive feedback from peers with whom they had prior positive learning relationships. ${ }^{25}$ How relationships with faculty could influence the quality and impact of feedback in residency education needs further inquiry. ${ }^{25}$ 


\section{The Concept of Face and Relevance to Feedback}

Goffman coined the term "face" to describe how an image of oneself is constructed per approved social norms, hence professional behaviour may be guided by the desire to project a positive image to others. ${ }^{26}$ Brown and Levinson ${ }^{27}$ expanded on the concept of face, defining positive face as a desire for self-affirmation or self-efficacy and negative face as a desire for freedom of action or autonomy. Politeness theory, as described by Brown and Levinson, ${ }^{27}$ assumes that most conversations can be face-threatening to either the hearer or speaker and views politeness as an attempt to mitigate face-threatening acts. Language and politeness may also be influenced by social distance, power differences, and the cultural context. ${ }^{27}$ Face has also been described as relational rather than individual, where one's sense of self develops through relationships with others. ${ }^{28}$ Positive face, negative face, and the relational conceptualization of face are relevant to clinical settings where patient care and learning occur on teams and members of the team rely on each other to grow professionally.

Ginsburg and colleagues ${ }^{29,30}$ invoke the politeness concept of conventional indirectness as one possible explanation for vague language used by faculty in written comments about trainee performance. They report that faculty narratives on in-training evaluation reports frequently contain vague and nonliteral language, and that other faculty often decode this language by "reading between the lines." For example, another study found that "good" may refer to underperforming trainees and "excellent" may not refer to the highest performers. ${ }^{31}$ However, the use of nonspecific language in assessments could result in trainees misinterpreting the assessment language. ${ }^{29}$ If learners take the comments literally, they may miss the message and preserve their self-image; if they read between the lines, they could lose face. ${ }^{30}$ Since positive framing of feedback enhances learner satisfaction and self-efficacy, ${ }^{32}$ feedback providers may avoid language that could threaten learners' self-esteem, while learners could reject information that threatens their selfefficacy (positive face) or autonomy (negative face). ${ }^{26}$ The concepts of positive and negative face are also direct threats to bidirectional feedback in a hierarchical learning environment. Hidden codes, hedging, and indirectedness may well be amplified during faceto-face conversations. ${ }^{30}$ Further, feedback language may also be influenced by institutional or professional culture with conflicting implicit and explicit expectations for such conversations. ${ }^{22,33}$

Despite increasing knowledge about sociocultural aspects of feedback, much is still unknown about resident and faculty perspectives on what constitutes feedback culture, their perceptions of how institutional feedback culture may impact feedback, feedback seeking, receptivity, and readiness to engage in bidirectional feedback. ${ }^{34-36}$ To better understand these, we explored the following questions:

1. How do residents and faculty define feedback culture and what are their views regarding the impact of institutional feedback culture (including politeness concepts) on meaningful feedback? 
2. What factors influence feedback seeking and receptivity, as perceived by residents and faculty?

3. What are resident and faculty perspectives regarding the value of bidirectional feedback, defined as two-way feedback from faculty to residents and residents to faculty, as well as junior to senior residents and senior to junior residents? (For the purposes of this study, the terms junior and senior refer to residents' position on a clinical team [see below].)

Insights into these issues can help medical educators design feedback initiatives that incorporate feedback seeking, receiving, and bidirectional feedback exchanges and emphasise professional growth.

\section{Methods}

Using a constructivist grounded theory approach, ${ }^{37-39}$ we conducted focus group discussions with residents, and focus group discussions and individual interviews with faculty to explore their views on institutional feedback culture.

\section{Setting}

The internal medicine residency program in the Department of Medicine at Brigham and Women's Hospital, a teaching affiliate of Harvard Medical School, is a large urban training program consisting of approximately 160 residents across many training tracks (e.g., research, global health, primary care, management and leadership, medical education, medicine-paediatrics). Inpatient teams consist of 1-2 postgraduate year (PGY) 2 or PGY3 residents (referred to as senior residents in this study), 2-4 PGY-1 residents (referred to as junior residents in this study), 1-2 attending physicians, and 1-2 medical students. Weekly e-mails remind residents and supervising faculty to exchange regular feedback with each other. All categorical residents (i.e., those not on a 1-year preliminary track) work in continuity clinics. Residents have a longitudinal working relationship with their continuity clinic preceptor, but their working relationships with inpatient attending physicians are typically two-weeks long and may be shorter depending on the block schedule. Attendings range from novice to seasoned clinicians, clinician-educators, and clinicianinvestigator faculty with limited teaching commitments. There is no mandate that teaching faculty receive formal feedback training, though faculty development opportunities for feedback training exist. Thus, residents receive feedback from a number of supervising faculty with variable teaching and feedback skills, with the duration and quality of these working relationships varying as well. 


\section{Framework, participants, and sampling}

We believed that a constructivist grounded theory approach, which iteratively deconstructs and reconstructs meaning from participant narratives, was most appropriate to develop a theory regarding the influence of institutional culture on feedback. ${ }^{40-42}$ Using a purposive sampling strategy, in April-December 2016, we invited (see below) 62 residents who had continuity clinic at the principal outpatient site for the residency program and 30 continuity clinic preceptors who supervised residents at this site, 20 hospitalist attendings, and 12 subspecialist faculty. Faculty were selected for focus group discussions and interviews based on the fact that all of them supervise residents in clinics or on the inpatient service. Faculty who had no contact with residents were not recruited. No feedback training was offered to any of the participants. We explored their opinions and perspectives in an open-ended manner.

E-mail invitations to participate in the focus groups or interviews described the purpose of the study and emphasised that participation was voluntary, opinions were confidential, participants had the ability to opt out at any point, and all data would be deidentified. Verbal consent was obtained by S.R. prior to focus group discussions or interviews. None of the residents or faculty we contacted refused to participate, but final scheduling was based on availability on specific dates. Since we aimed to explore perspectives of residents and faculty on the institutional feedback culture and their perceptions of how it might influence the quality and impact of feedback, we believed that this sampling strategy would yield participants who could provide rich insights on this topic and help develop a theory. ${ }^{39}$ Mixed groups of PGY-1, PGY-2, and PGY-3 residents were intentionally targeted to stimulate rich interactions across the different levels of residents. No incentives were offered for participation.

We conducted focus group discussions with general medicine faculty (continuity clinic preceptors and hospitalist attendings) during regularly scheduled noon faculty meetings and with residents during scheduled post-clinic conferences. Focus groups are a useful strategy to study organisational culture and behaviour and when enrichment of data through interactive discussions is anticipated. ${ }^{43}$ It was not feasible to convene focus groups with subspecialist faculty, so we conducted individual interviews at times when faculty were available to meet (for sample questions, see Supplemental Digital Appendix $1 .{ }^{44,45}$

\section{Data collection}

Five resident focus group discussions were conducted between April and June 2016. Three focus group discussions with general medicine faculty (two with continuity clinic preceptors and one with hospitalist attendings) and eight individual interviews with subspecialist faculty were conducted between September and December 2016. Data sources 
included transcripts from focus groups and interviews, as well as field notes and observations by a research assistant.

Using open-ended questions, we explored participant perspectives on what constitutes feedback culture, their perceptions of how institutional feedback culture (including politeness concepts) might influence the quality and impact of feedback, feedback seeking, receptivity to feedback, and bidirectional feedback. Semi-structured discussions allowed us to examine participant opinions without introducing investigator assumptions and allowed us to be open to discovering unanticipated issues and opinions that differed from commonly held ones.

Focus group discussions were approximately 60 minutes and interviews were approximately 30 minutes. The primary investigator (S.R.) led the discussions while a research assistant observed group interactions and made field notes. Trigger questions, discussed in advance by the research team, were used to initiate conversations (List 1). Responses were probed, and further open-ended questions were posed to ensure that the content of the discussions covered the study questions. Further questions were not posed if participants spontaneously covered three main areas: feedback culture, feedback seeking and receptivity, and bidirectional feedback.

\section{List 1}

Trigger Questions ${ }^{\mathrm{a}}$ for Focus Group Discussions With Residents, Continuity Clinic Preceptors, ${ }^{b}$ and Hospitalist Attendings, ${ }^{c}$ Internal Medicine Residency Program, Department of Medicine, Brigham and Women's Hospital, April-December $2016^{\mathrm{d}}$

\section{Feedback culture}

o When the term feedback culture is used, what does it mean to you?

o How would you describe our institutional feedback culture?

o In previous discussions, residents had expressed that our department has a culture of politeness which inhibits honest feedback conversations, what are your opinions regarding this?

\section{Feedback seeking and receptivity}

1. How important is feedback seeking behaviour in obtaining meaningful feedback?

2. What factors could increase receptivity to constructive feedback?

\section{Bidirectional feedback}

1. In your opinion, is bidirectional feedback important? 
2. Can you tell us more about your thoughts on this topic?

3. What might be some strategies to stimulate bidirectional feedback?

${ }^{a}$ This is a sample list of focus group trigger questions and not all of the questions were used. Further questions were posed based on group responses if clarifications or further elaborations were needed. Further questions were not used if participants spontaneously engaged in discussions that were related to the study questions.

${ }^{b}$ General internists who served as resident continuity clinic preceptors, some also attended on general medicine wards for 2-4 weeks a year.

${ }^{c}$ Attending physicians who primarily worked on general medicine wards on the teaching service.

${ }^{d}$ In a qualitative study exploring resident and faculty perspectives on what constitutes feedback culture, their perceptions of how institutional feedback culture (including politeness concepts) might influence the quality and impact of feedback, feedback seeking, receptivity, and readiness to engage in bidirectional feedback.

Since reflexivity is essential for a constructivist approach, we reflected on the influence of researcher roles and assumptions in our approach to sampling, data collection, and analysis. ${ }^{42,46}$ The lead author (S.R.), a faculty physician in the department, is neither a program director responsible for promotion or graduation decisions for residents nor in a position of power over fellow faculty. Her collaborators are non-physicians and include expert health professions educators and researchers from outside institutions (C.P.M.V., K.V.M., K.D.K.). The team also included two research assistants (one observed the focus groups and took field notes and the other participated in independent data analysis [E.E.P.]). We held post-discussion debriefings between the observer and investigator and examined each transcript to ensure that questions were open-ended and allowed for the expression of a wide range of opinions.

\section{Data analysis}

We audiotaped and transcribed focus group discussions and interviews verbatim without inclusion of any names, and performed concurrent data collection and analysis using the constant comparative approach required for grounded theory research. ${ }^{37,38,40-42}$ Trigger questions and probes were modified as needed for future discussions as relevant themes were identified. Data collection was stopped when we did not obtain significant additional themes related to our study questions and there was adequate information to construct a theoretical understanding. ${ }^{47}$ Two investigators (S.R., E.E.P.) independently reviewed and coded the first three transcripts. These three transcripts were also coded by one of the other investigators (C.P.M.V., K.V.M, K.D.K.). By comparing and discussing their codes, the team reached consensus on a coding system for the rest of the dataset, which was analysed and organized using NVivo 10 Pro software for Windows (QSR International Pty Ltd, Melbourne, Australia) by S.R. and E.E.P. Field notes and investigator observations were coded using a similar strategy and contributed to the generation of themes, these interpretations were confirmed by member checking and backed by participant quotes. During first level coding, each data unit referring to a specific issue was assigned an in vivo (using participants' words) code. During second level coding, the number of codes 
was reduced by establishing coding categories which grouped codes by major subject areas. We then performed thematic analysis to identify major themes grounded in participant narratives rather than through a priori hypotheses.$^{48}$ Identified themes were discussed with the entire research team and influenced subsequent data collection through additional focus group discussion and interview questions. Once we coded the complete dataset, we moved from the categorical level (exploring opinions and beliefs) to the conceptual level (exploring relationships between categories and understanding meaning). ${ }^{41,42}$ Ambiguities or disagreements in coding and generation of themes were resolved by consensus at research team meetings. Finally, we considered our analysis through the lens of politeness theory ${ }^{26}$ and organisational culture, ${ }^{22,23}$ exploring how our findings aligned with or challenged these constructs.

This study was granted exempt status by the Partners Institutional Review Board, the review board for Brigham and Women's Hospital (Protocol \#2013P002270/BWH). The board deemed that verbal consent was adequate provided narratives were deidentified.

\section{Results}

Of those we invited, 29 residents and 22 general medicine faculty participated in focus group discussions, and 8 subspecialty faculty participated in interviews (Table 1). 
Table 1 Participants (Residents and Faculty), ${ }^{a}$ Internal Medicine Residency Program, Department of Medicine, Brigham and Women's Hospital, April-December 2016

\begin{tabular}{lll}
\hline $\begin{array}{l}\text { Focus group/Individual } \\
\text { interviews }\end{array}$ & Participants & No. of participants \\
\hline Focus group & Residents & 6 (2 PGY-1, 1 PGY-2, and 3 PGY-3) \\
Focus group & Residents & 7 (2 PGY-1, 2 PGY-2, and 3 PGY-3) \\
Focus group & Residents & 5 (1 PGY-1, 2 PGY-2, and 2 PGY-3) \\
Focus group & Residents & 5 (2 PGY-1, 2 PGY-2, and 1 PGY-3) \\
Focus group & Residents & 6 (2 PGY-1, 3 PGY-2, and 1 PGY-3) \\
Focus group & General medicine faculty (continuity & 4 \\
& clinic preceptors) & \\
Focus group & General medicine faculty (hospitalist & 10 \\
& attendings) & \\
Focus group & $\begin{array}{l}\text { General medicine faculty (continuity } \\
\text { clinic preceptors) }\end{array}$ & 8 \\
Individual interviews & Subspecialist faculty (oncology) & \\
Individual interviews & Subspecialist faculty (cardiology) & 4 \\
\hline
\end{tabular}

Abbreviation: PGY indicates postgraduate year.

an a qualitative study exploring resident and faculty perspectives on what constitutes feedback culture, their perceptions of how institutional feedback culture (including politeness concepts) might influence the quality and impact of feedback, feedback seeking, receptivity, and readiness to engage in bidirectional feedback.

${ }^{b}$ General internists who served as resident continuity clinic preceptors, some also attended on general medicine wards for 2-4 weeks a year.

${ }^{c}$ Attending physicians who primarily worked on general medicine wards on the teaching service.

dSubspecialty attending physicians who worked on the inpatient subspecialty teaching service.

We discovered three key themes situated within the broader cultural context: normalizing constructive feedback to promote a culture of growth, overcoming the mental block to feedback seeking, and hierarchical culture impeding bidirectional feedback. These themes as well as reported barriers and facilitators for each theme are depicted in Figure 1. 


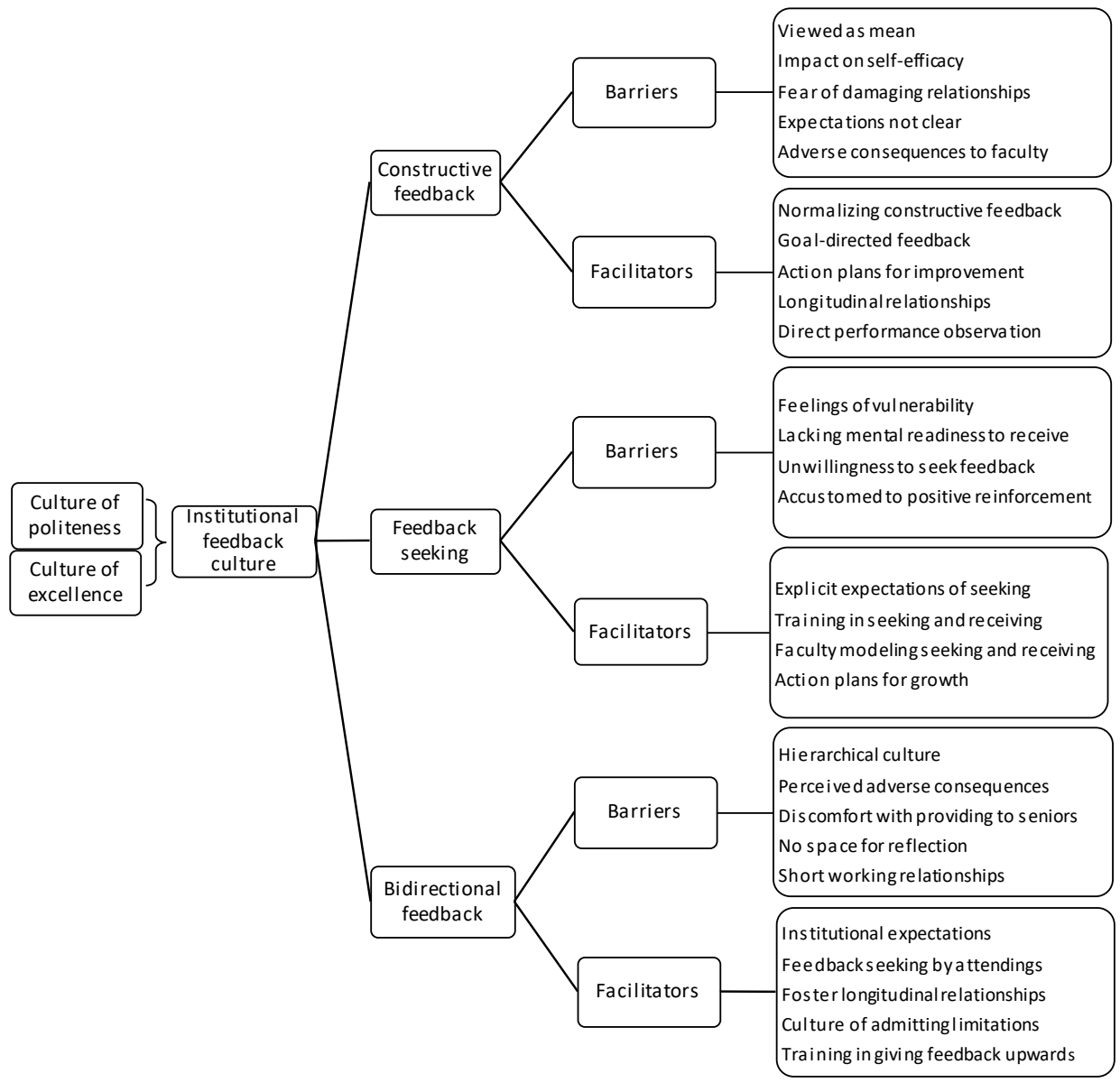

Figure 1

Legend: Flow diagram generated from focus group discussions and interviews with residents and faculty, internal medicine residency program, Department of Medicine, Brigham and Women's Hospital (April-December 2016), showing their perceptions of the impact of institutional feedback culture. Three themes were identified from the narrative data related to constructive feedback, feedback seeking, and bidirectional feedback. For each theme, participants listed facilitators and barriers that would enhance or impede the institutional feedback culture. This study explored resident and faculty perspectives on what constitutes feedback culture, their perceptions of how institutional feedback culture (including politeness concepts) might influence the quality and impact of feedback, feedback seeking, receptivity, and readiness to engage in bidirectional feedback.

In the remainder of this section, we will first look at participants' definitions of feedback culture and perceptions of the institutional feedback culture at Brigham and Women's Hospital, then we will discuss each of the three themes noted above.

Throughout this section, in the labels following each quote, $\mathrm{R}$ denotes resident comments (with the number following the R referring to the resident's PGY (e.g., PGY-2 resident $=\mathrm{R} 2$ ) and $\mathrm{F}$ denotes faculty comments. 


\section{Cultural context: The institutional feedback culture}

Many participants defined a feedback culture as one that communicated clear institutional expectations promoting regular two-way feedback conversations. As further elaborated on below in the section on theme 3 , both faculty and residents emphasised the bidirectional aspect in their definition of feedback culture.

Feedback culture is a part of our existence here, to observe other people and give them feedback, but also to have people observe and give us feedback. I feel it's an expectation that it's a part of our daily life. (R2)

It means ... we have a culture where feedback is expected and accepted with open arms and where it just is normal to be providing feedback regularly (F).

Culture of politeness. There was general agreement among most residents and faculty that the institution had a strong culture of politeness that implicitly discouraged feedback language that might be potentially threatening to residents' self-esteem. It was described by faculty as a "warm and fuzzy cocoon" for residents and by residents as a "family-like atmosphere."

We do have a culture here of being like a family and support each other. People are hesitant to give any criticism. There's usually not a lot of specifics. (R1)

We all sort of pat each other on the back, and don't have an open culture in terms of giving constructive criticism to each other. (R2)

The concept is being able to give a range of feedback, positive and negative. But what a lot of this comes back to is, "Yes, yes, fine. You're doing great." Nobody gets things to work on. (F)

In contrast to the clinical teaching environment, a few faculty stated that it was less challenging to provide constructive feedback to research trainees. It was felt that since feedback to clinical trainees involves complex competencies, such as communication skills and professionalism, giving constructive feedback on these skills could be more threatening for these trainees and harder for them to accept than is feedback for research trainees.

The culture is very supportive of the residents, but they almost never get corrected. I'm thinking about my research life, if someone presents something, people say, "that just doesn't work." It's a different environment. (F)

The tension between the desire to provide meaningful, constructive feedback and the fear of damaging interpersonal relationships was alluded to frequently.

I struggle with trying to figure out how to deliver effective, constructive feedback without alienating interns, without overwhelming them. (R2) 
There is a culture of not wanting to hurt each other's feelings and being awkward in delivery. (F)

Culture of excellence. The culture was also described by residents and faculty as one where the institution's outstanding academic reputation and the pedigree of its trainees inhibited constructive feedback.

Even though people here are amazing, we all have areas to improve on and weaknesses. The culture here may hinder the type and the quality of feedback that we give. (R3)

It's tougher to give difficult feedback to someone who has, all their life, been treated with superlatives. It's a barrier to giving good feedback in this place. (F)

Faculty expressed concern about being taken to task if they provided constructive comments that could be threatening to residents' self-efficacy.

It's a fabulous institution with fabulous residents at the top of the game, but sometimes, there are things not done correctly. If we tell them, what does that mean to the team dynamic ... what [does] this [mean] for retaliation, which has happened to some faculty. There are cultural issues around everyone here being exceptional that are important to acknowledge. (F)

Faculty also alluded to the possibility that residents at prestigious institutions may suffer from an imposter complex and that "negative" comments could threaten their already fragile self-esteem.

On the flip side is this impostor complex that everyone in this place has. It's not only that they base their self-esteem on excellence, but on the other side, they're like, I don't belong here. That also makes the whole thing higher stakes, I think. (F)

The "pedigree" of residents and unquestioned assumptions of their excellence were viewed by faculty as significant barriers to providing constructive feedback.

\section{Theme 1: Normalizing constructive feedback to promote a culture of growth}

Though the institutional feedback culture was noted to be a barrier to constructive feedback, both residents and faculty participants felt that it was important to have those conversations without negative connotations.

If we strive for excellence, we should constantly be vigilant about the things we're better and worse at. Normalizing that we all have weaknesses and strengths is the most important part of making sure that constructive feedback happens and should happen from the top. (R3) 
Short working relationships, common during residency training, were viewed as a major obstacle to constructive, goal-directed feedback conversations. Faculty also indicated that they felt a decreased sense of ownership for a resident's growth without a longitudinal relationship.

How do I become better as a leader, how do I become better as a physician overall? I think having more longitudinal feedback would be helpful. We work with people for a week or two weeks. By the time you even learn how to work with them, you're on to the next thing and they don't get to see you grow over time. (R3)

I've struggled with continuity. For ambulatory precepting to be effective in terms of feedback, you need a lot of data points. You need to be able to have-whatever the equivalent of [plan-do-study-act] cycles is. Give them something to work on, see how they're doing. (F)

The degree to which direct performance observation could contribute to meaningful feedback seemed to surprise many residents and faculty.

When somebody watched me in clinic and gave feedback, I was just relieved. I had no idea if what I was doing in the room with patients was right, because no one had ever watched me. (R1)

I never would've picked that up had I not actually been sitting there. I actually like this idea of the observation, because I think you're seeing something different than "you present well and you seem to be nice and everybody likes you." (F)

However, a few residents saw the presence of a faculty observer as intrusive and a potential threat to autonomy.

Because you're so busy and it feels artificial when we have direct observation. It's an autonomy thing, and a fine balance. (R1)

Suggestions for promoting constructive feedback exchanges and an overall culture of growth included: attention to language and tone of feedback, longitudinal relationships, direct performance observation without threatening autonomy, and normalizing constructive feedback exchanges.

\section{Theme 2: Overcoming the mental block to feedback seeking}

Active feedback seeking was a relatively rare occurrence overall. PGY-1 residents were mentally unprepared to seek feedback, which they generally equated to criticism, because they were overwhelmed by hectic clinical commitments.

Intern year is tough and you don't have the bandwidth to receive it. You're holding on for dear life, and it's like, "I'm just going to get through the day." (R1) 
The more senior residents empathized with these sentiments as they too approached feedback conversations with some trepidation.

You make yourself vulnerable. I now think about asking for feedback in a way I wouldn't have before, because I had a mental block. I didn't want to make myself vulnerable. (R3)

However, PGY-2 and PGY-3 residents also wished that they had been more proactive at seeking feedback during internship. Ironically, uncertainty regarding their skills and competence seemed to rise especially as they approached PGY-3 and were heading toward independent practice and thus sought feedback more frequently to assess their strengths and areas in which they could improve.

It shouldn't just be on the attendings. The best feedback I've gotten is when I've been proactive. I've tried to do more of that this year, asking my attendings after rounds, and seeking out feedback more regularly. (R3)

Several faculty welcomed feedback seeking from residents as they felt it allowed them to provide specific feedback related to learning goals.

We're not always focussed on giving feedback or thinking about what each resident needs the feedback on. To be directed by the resident, I think is terrific. It doesn't happen much, but it's wonderful when it does. (F)

Residents indicated that direct performance observation and goal-directed feedback would enhance the credibility and acceptability of feedback.

I really think they should be expected to observe us more. Because they have things they can draw on to form concrete opinions about how we take care of patients, how we think. Versus the overall, "Gosh, I liked you." (R2)

It was recommended that feedback training include strategies for seeking and receiving feedback, and framing feedback to enhance receptivity rather than focusing solely on the techniques of providing feedback.

Just teach people to seek out constructive criticism, so that they grow. (R3)

A lot of us [faculty] don't know how to frame constructive feedback in a way that allows them [residents] to receive it well and [act on it]. I think that takes lots of time and experience to figure out how to be direct with somebody and have them thank you for it. (F)

PGY1 residents seemed mentally unprepared to seek and receive constructive feedback. According to participants, this lack of cognitive and emotional space to engage in performance-related feedback could benefit from explicit institutional expectations, training in feedback seeking and receiving, dedicated time for reflection, and opportunities to implement performance improvement plans. 


\section{Theme 3: Hierarchical culture impeding bidirectional feedback}

Most residents stated that even the most nurturing clinical environment is fundamentally hierarchical, which impedes the provision of constructive feedback to upper levels.

Just thinking as an intern, it's even hard to give feedback to your resident, let alone your attending. (R1)

As much as we like to think that this is a non-hierarchical environment, it is hierarchical. Maybe less than other places, but it's a natural tendency of humans to want to be deferential to those who influence their trajectories in life. (R3)

There was a common perception among residents that attendings would not be receptive to constructive feedback or willing to change their behaviours.

I think there are times where you decide it's not worth the effort. I'm only going to be with this person for five more days. Yeah, the way they do this one thing is annoying, but it's just going to be five days. Let me just go on to the next thing. (R3)

On those occasions when faculty sought feedback, residents still did not know how to approach the conversation.

I've been asked for feedback and not really given it to an attending. I don't know how to give feedback to a superior. That's an unfortunate part of the culture. (R2)

Someone asked me, "Well, what could I do better?" My mind went blank. I'm like, "I don't really think about you in that way. You're my superior and I accommodate my daily routine to meet your activity." (R2)

There were many residents in favour of promoting a culture of bidirectional feedback provided faculty initiated the dialogue.

Having that attending say to me, "Hey, I would really appreciate more feedback. Why don't we sit down tomorrow?" I think that breaks that "personality" or "relationship" barrier. (R3)

The personality of attending physicians and the manner of their team interactions were believed to influence bidirectional feedback. Residents also stated that knowing institutional teaching expectations could help them to provide more specific feedback to their faculty.

I feel that the personality of an attending who can create a more light-hearted atmosphere makes giving feedback a little bit easier. (R2)

Maybe making expectations of attendings more transparent... then we can give more accurate feedback. "Well, you were supposed to be here to do this, this, and that, and I don't feel we're getting that from you." (R3) 
Faculty, on the other hand, stated that even when they sought feedback they did not get honest or specific comments.

People giving feedback to their supervisors is always a little dicey. You don't actually get their honest opinion. (F)

I get mostly suggestions about conferences, topics, and things even when I asked. I don't get any constructive criticism on my teaching. (F)

Faculty seemed willing to engage more in seeking feedback from residents. One faculty participant stated that admitting his own limitations tended to break down hierarchical barriers and allow residents to provide feedback:

It sets up this culture of bidirectional feedback. "I'm going to give you feedback. You're going to give me feedback. This is how we do things. This is how we get better. I can always get better. I've been doing this for 15 years, and I can still get better." If you send that message, I think it makes it that much easier to get feedback. (F)

There were varying degrees of openness to bidirectional feedback despite its inclusion in the definition of a feedback culture by residents and faculty. However, overall residents were willing to engage provided faculty actively sought feedback and there was an institutional feedback culture that encouraged and promoted feedback up the hierarchy.

\section{Discussion}

In this study, we sought to explore resident and faculty perspectives regarding what constitutes feedback culture, their perceptions of how institutional feedback culture (including politeness concepts) might influence the quality and impact of feedback, feedback seeking, receptivity, and readiness to engage in bidirectional feedback. In doing so, we hoped to learn more about the areas of congruence and incongruence in the two groups' mental models of the feedback culture that could be helpful for designing culture-enhancing initiatives.

Several faculty and resident participants used the terms culture of excellence and culture of politeness. The culture of excellence refers to the outstanding academic reputation of the institution and pedigree of its trainees, which can inhibit constructive feedback. The culture of politeness refers to the collegial and supportive work environment that could prevent the use of language that has the potential to adversely affect selfesteem. As depicted in Figure 1, these two facets of the cultural context act as the starting point for the three key themes we found (see above); Figure 1 also shows participant descriptions of facilitators and barriers pertaining to each category of the feedback culture. Using these descriptions and themes, we developed the framework shown in Figure 2 , based on varying degrees of resident and faculty openness to constructive feedback 
exchanges, feedback seeking, and bidirectional feedback (see the figure legend for an explanation of the axes and quadrants).

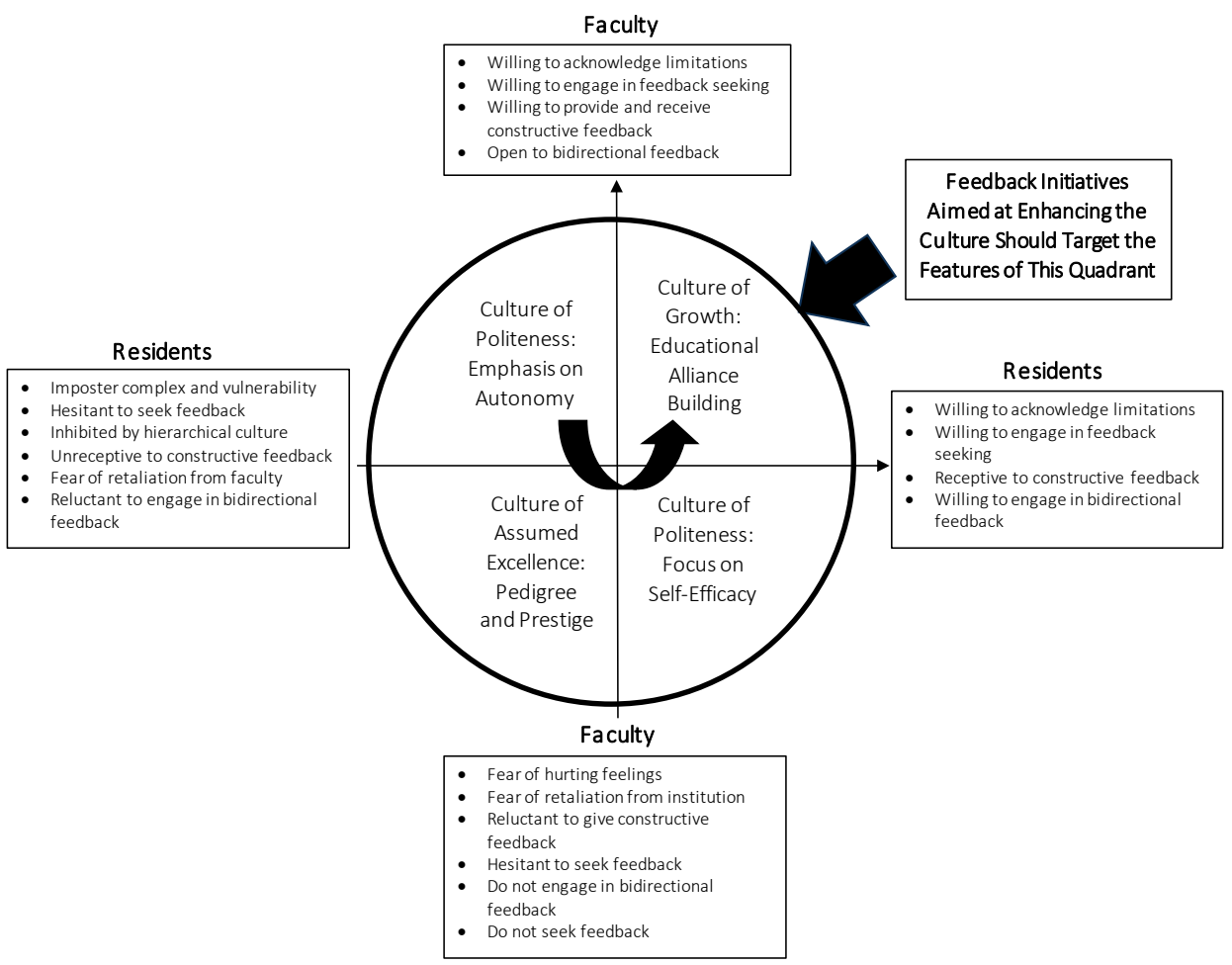

Figure 2

Legend: Model developed from the narratives of residents and faculty, internal medicine residency program, Department of Medicine, Brigham and Women's Hospital, regarding what constitutes feedback culture, how institutional feedback culture (including politeness concepts) might influence the quality and impact of feedback, feedback seeking, receptivity, and readiness to engage in bidirectional feedback, April-December 2016. Resident feedback practices are represented along the $x$-axis and faculty feedback practices are represented along the $y$-axis. The intersection of these axes results in four quadrants, each denoting a certain cultural climate for feedback: (1) culture of politeness: emphasis on autonomy, (2) culture of excellence: pedigree and prestige, (3) culture of politeness: focus on self-esteem, and (4) culture of growth: educational alliance building. Each of these quadrant is linked to aspects of politeness theory and components of organisational culture. ${ }^{22,26,27} \mathrm{All}$ the terms and labels used in the figure reflect words that were used by the participants. The circular arrow indicates that feedback culture should ideally move toward a culture of growth.

In our framework, the bottom left quadrant, where faculty and residents hesitate to engage in feedback seeking, constructive feedback exchanges, and bidirectional feedback, is titled the culture of assumed excellence. In this type of culture, the institutional reputation for academic and clinical excellence appears to lead to assumptions that everyone is outstanding and that "negative" statements are not permitted in feedback conversations. A lack of longitudinal relationships and a hierarchical institutional culture 
would also be barriers to honest and meaningful dialogue in such a culture. ${ }^{4,9,49}$ Further, a fear of retaliation would inhibit feedback from residents to faculty and an underlying lack of self-confidence or the imposter complex could underlie the lack of feedback seeking and receptivity. These factors are important to explore and address to promote an open feedback culture.

The bottom right quadrant can be characterised by residents' openness to feedback seeking and bidirectional feedback but faculty reluctance to engage in constructive and bidirectional feedback. This combination could promote nonspecific conversations with a focus on preserving positive face or self-esteem. Preserving positive face, the desire to be approved by others, and how it shapes language use in feedback interactions are very relevant to the findings of this study. ${ }^{26,27}$ Other investigators have also reported the fear of hurting feedback receivers' feelings and damaging working relationships as major barriers to the exchange of constructive feedback, which would apply in this type of cul-

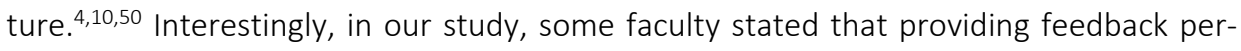
ceived as threatening to residents' self-esteem had led to admonishment from departmental leadership; this fear of retaliation would impede the provision of honest, constructive feedback.

The top left quadrant is characterised by faculty openness to engage in feedback seeking and bidirectional feedback but residents' reluctance to seek and receive constructive feedback. A hierarchical learning culture, real or perceived, and a lack of cognitive and emotional space to receive constructive feedback would also impede feedback seeking and receptivity in this type of culture. If residents are perceived as not receptive, faculty might initiate conversations that avoid any threat to resident autonomy, that is, negative face. ${ }^{26}$ Watling ${ }^{51}$ and Watling and colleagues ${ }^{4}$ reported that the emphasis on autonomy and independent practice in medical education often prevents direct observation of performance by faculty and acts as a barrier to an open feedback culture. If feedback providers encode their messages using polite language aimed at preserving self-esteem or autonomy, the feedback receiver may decode and construct a meaning that contradicts the original message. ${ }^{28}$ The hedging and hidden code described by Ginsburg and colleagues ${ }^{29,30}$ is very applicable to in-person feedback conversations in such a culture.

We titled the top right quadrant as the culture of growth, a term used by one resident participant, to indicate openness to feedback seeking and bidirectional feedback on both sides. These behaviours set the tone for educational alliance building, which stimulates discussion and exchange of professional goals, goal-directed feedback, and action plans for improvement. ${ }^{52}$ For this culture to work, both faculty and residents need to make themselves vulnerable and open to discussion of their weaknesses so that they can embrace professional growth.

Applying Schein's levels of culture to resident and faculty perceptions of the existing feedback culture, ${ }^{22}$ underlying assumptions may involve politeness and institutional pride in its reputation (level 1 ) and espoused values may be the written expectations of regular 
feedback and professional growth (level 2); however, the more visible day-to-day behaviours may be dominated by the desire to preserve face (level 3). This concept is reflected in a faculty comment, "the value and need for feedback is communicated but there is gap in translating the intent to action." Without addressing the mismatch between the three levels of culture, ${ }^{22}$ change strategies may not be successful.

\section{Limitations and strengths}

This study has limitations which may have affected our findings. It was conducted in a single department at a single academic health centre. Thus, these resident and faculty perceptions may not be completely transferable to other departments or institutions. Though focus group discussions and interviews explore participants' stated perceptions, these may differ greatly from their actions and behaviours. Despite a large quantity of narrative data, we may not have captured a full range of opinions. Nonparticipants could have strong and contradictory feelings about feedback and the institutional feedback culture which we may have missed. Moreover, the more junior residents may not have shared their opinions openly in a mixed focus group where senior residents were also present. Institutional feedback culture is likely to be different at different institutions and in different departments, thus these results may not be applicable without further explorations of the specific cultural context. Further, learning cultures in departments such as surgery and anaesthesiology would be markedly different from internal medicine. For example, in surgery, a key learning setting is the operating room where the culture is more hierarchical, contact between supervisors and trainees is limited to the duration of the procedure, and the focus would be on specific skills-based feedback that would likely mostly be constructive. ${ }^{53,54}$ Though surgical trainees engage in feedback seeking and are receptive to feedback from supportive supervisors, the complexities of relationship building in these settings would be entirely different than continuity clinics or even inpatient rotations and politeness concepts may not be applicable. ${ }^{55}$

We have tried to enhance the credibility of the findings by using multiple data sources to triangulate the findings and independent data analysis by two or more investigators to ensure that the discovered themes were not guided by a single investigator's assumptions or biases. The findings appear to resonate with existing feedback literature describing sociocultural factors that influence feedback. ${ }^{4,10,11,15,16,18,51}$ Our context is typical of large, urban medicine residency programs situated within major academic medical centres; therefore, many of the findings may be relevant and applicable to similar educational settings. Finally, attention was paid to reflexivity in formulating study questions, data collection, and data analysis. 


\section{Suggestions for further research}

In this study, we explored the perceptions of residents and faculty regarding the influence of the institutional feedback culture on the quality and impact of feedback conversations. It is also important to observe real time feedback conversations to examine whether the verbal and nonverbal behaviours used by faculty and residents are congruent with expressed opinions, challenges, and intentions. Such observations would benefit from an ethnographic approach where feedback conversations can be debriefed through reflection and reflexivity. It will also help us to understand the existing levels of institutional feedback culture and facilitate the design of robust initiatives that target a cultural shift in feedback practices at the institution, yet preserve the supportive work and learning environment. Even if feedback initiatives actively promote feedback-seeking behaviours, normalise constructive feedback exchanges, empower junior learners to give feedback to senior levels, and encourage acknowledgement of limitations at all levels, junior trainees still may not distinguish between summative feedback during assessment and formative feedback aimed at professional development. Thus, they may avoid giving formative feedback to faculty for fear of ruining future fellowship or career prospects in competitive work settings. Additionally, further research could explore resilience training for both residents and faculty, the potential use of narrative data in enhancing feedback cultures, and differences between feedback in clinical and research settings. Finally, assessments of organisational cultures may be useful to determine whether change management initiatives are successful. ${ }^{56}$

\section{Conclusions}

An institutional feedback culture of excellence and politeness may impede honest and meaningful feedback and may influence feedback seeking, receptivity, and bidirectional feedback exchanges. Understanding the assumptions and values that constitute an institutional feedback culture and recognizing the barriers to change, as well as aligning proposed new initiatives with the existing mission and showcasing their benefits, are essential to guide successful culture change. 
Dedication: The late Dr. Karen V. Mann was a major source of inspiration and guidance to the research team and a personal role model to $S$. Ramani. She was instrumental in guiding each step of this research project, including the literature review, study design, data analysis, and initial manuscript writing. Her mentoring, compassion, wisdom, patience, and guidance will be sorely missed. It was a privilege for the authors to have worked with her. This is a tragic loss to the world of medical education.

Acknowledgments: The authors gratefully acknowledge the residents and faculty who enthusiastically participated in the study and shared their perceptions, challenges, and suggestions for best practices related to feedback, as well as the leadership of the Department of Medicine at Brigham and Women's Hospital for their active support of educational research in general and this research is particular. The authors would also like to acknowledge Dr. Shiphra Ginsburg for her thoughtful review and feedback on the manuscript.

Funding/Support: This study was funded by the Department of Medicine Clinical Education Research Scholars Grant at Brigham and Women's Hospital.

Other disclosures: None reported.

Ethical approval: The study was granted exempt status by the Partners Institutional Review Board, the review board for Brigham and Women's Hospital (Protocol \#2013P002270/BWH). The board deemed that verbal consent was adequate provided narratives were deidentified.

Previous presentations: This research study was presented as a short communication at the 2017 Annual AMEE (Association of Medical Education in Europe) Meeting, Helsinki, Finland, August 28, 2017. 


\section{Supplemental Digital Appendix 1}

Sample Interview Questions for Subspecialist Faculty ${ }^{a}$ Interviews, Internal Medicine Residency Program, Department of Medicine, Brigham and Women's Hospital, April-December $2016^{\mathrm{b}}$

Thank you so much for meeting with me today. As I had described in my email to you, I am interested in exploring your perspectives on feedback in our department. I will be focusing on 3 main areas: the culture of feedback at our institution, feedback seeking by our trainees, and feedback from trainees to faculty. I would like to audiotape our conversation to record your perspectives accurately and to help me with data analysis. I hope this is okay. The transcripts will be completely de-identified. I intend to present and publish interesting findings from our conversation, please let me know if there is anything you said that you would prefer not to share. There are no right or wrong answers, so please share your opinions freely.

I would like to start the conversation with your thoughts on the feedback culture at our institution.

\section{Feedback culture}

- When I use the term feedback culture, what does it mean to you?

o What factors do you think influence this feedback culture?

o How would you describe our institutional feedback culture?

o In previous discussions, residents had expressed that our department has a culture of politeness which inhibits honest feedback conversations. What are your opinions regarding this?

\section{Feedback seeking and receptivity}

- Do residents and fellows seek out feedback from you often?

o How important is feedback seeking behaviour in obtaining meaningful feedback?

o Probe as needed: Do you have suggestions to encourage feedback seeing?

- What factors could increase receptivity to constructive feedback?

Bidirectional feedback (defined as feedback from trainees to faculty or junior to senior levels)

- Do you think it is important for attending physicians to receive feedback from their learners?

o Further probe for yes or no responses: Can you tell us more about your thoughts on this topic?

- How often do you think this happens?

o Probe: Why or why not?

o Probe for yes response: What might be strategies to stimulate bidirectional feedback? 
Concluding question: Do you have suggestions for enhancing our institutional feedback culture overall?

Thank you for your time and sharing your thoughts.

asubspecialty attending physicians who worked on the inpatient subspecialty teaching service.

${ }^{b}$ In a qualitative study exploring resident and faculty perspectives on what constitutes feedback culture, their perceptions of how institutional feedback culture (including politeness concepts) might influence the quality and impact of feedback, feedback seeking, receptivity, and readiness to engage in bidirectional feedback. 


\section{REFERENCES}

1. van de Ridder JM, Stokking KM, McGaghie WC, ten Cate OT. What is feedback in clinical education? Med Educ. 2008;42:189-197.

2. Boud D. Feedback: Ensuring that it leads to enhanced learning. Clin Teach. 2015;12:3-7.

3. Delva D, Sargeant J, MacLeod T. Feedback: A perennial problem. Med Teach. 2011;33:861-862.

4. Watling C, Driessen E, van der Vleuten CP, Vanstone M, Lingard L. Beyond individualism: Professional culture and its influence on feedback. Med Educ. 2013;47:585-594.

5. Ramani S. Reflections on feedback: Closing the loop. Med Teach. 2016;38:206-207.

6. Molloy E, Boud D. Seeking a different angle on feedback in clinical education: The learner as seeker, judge and user of performance information. Med Educ. 2013;47:227-229.

7. Parkes J, Abercrombie S, McCarty T. Feedback sandwiches affect perceptions but not performance. Adv Health Sci Educ Theory Pract. 2013;18:397-407.

8. Watling C. Cognition, culture, and credibility: Deconstructing feedback in medical education. Perspect Med Educ. 2014;3:124-128.

9. Watling C, Driessen E, van der Vleuten CP, Lingard L. Learning culture and feedback: An international study of medical athletes and musicians. Med Educ. 2014;48:713-723.

10. Sargeant J, McNaughton E, Mercer S, Murphy D, Sullivan P, Bruce DA. Providing feedback: Exploring a model (emotion, content, outcomes) for facilitating multisource feedback. Med Teach. 2011;33:744-749.

11. Mann K, van der Vleuten C, Eva K, et al. Tensions in informed self-assessment: How the desire for feedback and reticence to collect and use it can conflict. Acad Med. 2011;86:1120-1127.

12. Sargeant J, Armson $H$, Chesluk B, et al. The processes and dimensions of informed self-assessment: A conceptual model. Acad Med. 2010;85:1212-1220.

13. Sargeant J, Eva KW, Armson H, et al. Features of assessment learners use to make informed self-assessments of clinical performance. Med Educ. 2011;45:636-647.

14. Sargeant J, Mann K, Sinclair D, van der Vleuten C, Metsemakers J. Challenges in multisource feedback: Intended and unintended outcomes. Med Educ. 2007;41:583-591.

15. Sargeant JM, Mann KV, van der Vleuten CP, Metsemakers JF. Reflection: A link between receiving and using assessment feedback. Adv Health Sci Educ Theory Pract. 2009;14:399-410.

16. van de Ridder JM, Berk FC, Stokking KM, Ten Cate OT. Feedback providers' credibility impacts students' satisfaction with feedback and delayed performance. Med Teach. 2015;37:767-774.

17. Harrison CJ, Könings KD, Schuwirth L, Wass V, van der Vleuten C. Barriers to the uptake and use of feedback in the context of summative assessment. Adv Health Sci Educ Theory Pract. 2015;20:229-245.

18. Eva KW, Armson $\mathrm{H}$, Holmboe $\mathrm{E}$, et al. Factors influencing responsiveness to feedback: On the interplay between fear, confidence, and reasoning processes. Adv Health Sci Educ Theory Pract. 2012;17:15-26.

19. Watling C, Driessen E, van der Vleuten CP, Vanstone M, Lingard L. Music lessons: Revealing medicine's learning culture through a comparison with that of music. Med Educ. 2013;47:842-850.

20. Watling C. When I say ... learning culture. Med Educ. 2015;49:556-557.

21. Ramani S, Post SE, Könings K, Mann K, Katz JT, van der Vleuten C. "It's just not the culture": A qualitative study exploring residents' perceptions of the impact of institutional culture on feedback. Teach Learn Med. 2017;29:153-161.

22. Schein EH. Organizational Culture and Leadership. 4th ed. San Francisco, Calif: Jossey-Bass; 2010.

23. Kotter JP. Leading Change. Boston, Mass: Harvard Business Review Press; 2012.

24. Hatch MJ, Schultz M. Relations between organizational culture, identity and image. Eur J Marketing. 1997;31:356-365.

25. Chou CL, Masters DE, Chang A, Kruidering M, Hauer KE. Effects of longitudinal small-group learning on delivery and receipt of communication skills feedback. Med Educ. 2013;47:1073-1079.

26. Goffman E. On face-work; an analysis of ritual elements in social interaction. Psychiatry. 1955;18:213-231.

27. Brown P, Levinson SC. Politeness: Some Universals in Language Usage. Cambridge, UK: Cambridge University Press; 1987. 
28. Arundale RB. An alternative model and ideology of communication for an alternative to politeness theory. Pragmatics. 1999;9:119-153.

29. Ginsburg S, Regehr G, Lingard L, Eva KW. Reading between the lines: Faculty interpretations of narrative evaluation comments. Med Educ. 2015;49:296-306.

30. Ginsburg S, van der Vleuten C, Eva KW, Lingard L. Hedging to save face: A linguistic analysis of written comments on in-training evaluation reports. Adv Health Sci Educ Theory Pract. 2016;21:175-188.

31. Kiefer C S, Colletti J E, Bellolio MF, Hess EP, Woolridge DP, Thomas KB, Sadosty AT. The "good" dean's letter. Acad Med. 2010;85:1705-1708.

32. van de Ridder JM, Peters CM, Stokking KM, de Ru JA, Ten Cate OT. Framing of feedback impacts student's satisfaction, self-efficacy and performance. Adv Health Sci Educ Theory Pract. 2015;20:803-816.

33. Cameron KS, Quinn RE. Diagnosing and Changing Organizational Culture: Based on the Competing Values Framework. 3rd ed. San Francisco, Calif: Jossey-Bass; 2011.

34. van de Ridder JM, McGaghie WC, Stokking KM, ten Cate OT. Variables that affect the process and outcome of feedback, relevant for medical training: A meta-review. Med Educ. 2015;49:658-673.

35. Crommelinck M, Anseel F. Understanding and encouraging feedback-seeking behaviour: A literature review. Med Educ. 2013;47:232-241.

36. Teunissen PW, Bok HG. Believing is seeing: How people's beliefs influence goals, emotions and behaviour. Med Educ. 2013;47:1064-1072.

37. Patton MQ. Qualitative Research and Evaluation Methods. 3rd ed. Thousand Oaks, Calif: Sage; 2002.

38. Creswell JW. Educational Research: Planning, Conducting, and Evaluating Quantitative and Qualitative Research. 4th ed. Boston, Mass: Pearson; 2012.

39. Ramani S, Mann K. Introducing medical educators to qualitative study design: Twelve tips from inception to completion. Med Teach. 2016;38:456-463.

40. Charmaz K. Constructing Grounded Theory. 2nd ed. London, UK: Sage; 2014.

41. Kennedy TJ, Lingard LA. Making sense of grounded theory in medical education. Med Educ. 2006;40:101108.

42. Watling CJ, Lingard L. Grounded theory in medical education research: AMEE Guide No. 70. Med Teach. 2012;34:850-861.

43. Krueger RA, Casey MA. Focus Groups: A Practical Guide for Applied Research. 5th ed. Thousand Oaks, Calif: Sage; 2015. [Moved to match move in main text]

44. Stalmeijer RE, McNaughton N, Van Mook WN. Using focus groups in medical education research: AMEE Guide No. 91. Med Teach. 2014;36:923-939.

45. Kitzinger J. Qualitative research. Introducing focus groups. BMJ. 1995;311:299-302.

46. Watt D. On becoming a qualitative researcher: The value of reflexivity. Qualitative Report. 2007;12:82101.

47. Morse JM. "Data were saturated ...." Qual Health Res. 2015;25:587-588.

48. Morse JM. Analytic strategies and sample size. Qual Health Res. 2015;25:1317-1318.

49. Bok HG, Teunissen PW, Spruijt A, et al. Clarifying students' feedback-seeking behaviour in clinical clerkships. Med Educ. 2013;47:282-291.

50. Sargeant J, Mann K, Sinclair D, Van der Vleuten C, Metsemakers J. Understanding the influence of emotions and reflection upon multi-source feedback acceptance and use. Adv Health Sci Educ Theory Pract. 2008;13:275-288.

51. Watling CJ. Unfulfilled promise, untapped potential: Feedback at the crossroads. Med Teach. 2014;36:692-697.

52. Telio S, Ajjawi R, Regehr G. The "educational alliance" as a framework for reconceptualizing feedback in medical education. Acad Med. 2015;90:609-614.

53. Jensen AR, Wright AS, Kim S, Horvath KD, Calhoun KE. Educational feedback in the operating room: A gap between resident and faculty perceptions. Am J Surg. 2012;204:248-255.

54. Ahmed M, Arora S, Russ S, Darzi A, Vincent C, Sevdalis N. Operation debrief: A SHARP improvement in performance feedback in the operating room. Ann Surg. 2013;258:958-963. 
55. Gaunt A, Patel A, Rusius V, Royle TJ, Markham DH, Pawlikowska T. 'Playing the game': How do surgical trainees seek feedback using workplace-based assessment? Med Educ. 2017;51:953-962.

56. Rougas S, Clyne B, Cianciolo AT, Chan TM, Sherbino J, Yarris LM. An extended validity argument for assessing feedback culture. Teach Learn Med. 2015;27:355-358. 



\section{Chapter}

\section{Uncovering the Unknown: A grounded theory study exploring the impact of self-awareness on the culture of feedback in residency education}

Published as: Ramani S, Könings KD; Mann KV, van der Vleuten CPM. Uncovering the Unknown: A Grounded Theory Study Exploring the Impact of Self-Awareness on the 


\section{Abstract}

Self-assessment and reflection are essential for meaningful feedback. We aimed to explore whether the well-known Johari window model of self-awareness could guide feedback conversations between faculty and residents and enhance the institutional feedback culture.

Methods: We had previously explored perceptions of residents and faculty regarding sociocultural factors impacting feedback. We re-analysed data targeting themes related to self-assessment, reflection, feedback seeking and acceptance, aiming to generate individual and institutional feedback strategies applicable to each quadrant of the window.

Results: We identified the following themes for each quadrant: (1) Behaviours known to self and others - Validating the known; (2) Behaviours unknown to self but known to others - Accepting the blind; (3) Behaviours known to self and unknown to others - Disclosure of hidden; and (4) Behaviours unknown to self and others - Uncovering the unknown. Normalising self-disclosure of limitations, encouraging feedback seeking, training in nonjudgemental feedback and providing opportunities for longitudinal relationships could promote self-awareness, ultimately expanding the 'open' quadrant of the Johari window.

Conclusions: The Johari window, a model of self-awareness in interpersonal communications, could provide a robust framework for individuals to improve their feedback conversations, and institutions to design feedback initiatives that enhance its quality and impact. 


\section{Introduction}

Effective feedback, integral to continuing professional development, needs to be credible, and informed by self-reflection to facilitate performance improvement. ${ }^{1-5}$ Feedback exchanges also need to address factors such as self-efficacy and autonomy which could impact internal motivation and lead to loss of 'face'. ${ }^{1,6}$ Accurate self-calibration of performance requires reflection in and on action, self-assessment and feedback from others. ${ }^{7-9}$ Thus, changing the institutional feedback culture would require concerted efforts to stimulate these strategies. ${ }^{1,3,10,11} \mathrm{~A}$ framework such as the Johari window could guide educators and institutions in establishing a learning culture that actively encourages self-awareness, thereby raising the credibility and acceptability of feedback and promoting commitment to behaviour change. Below, we describe how the Johari window could be used to incorporate self-assessment and reflection into feedback conversations.

The Johari Window is a psychological matrix developed by Joseph Luft and Harry Ingham in 1955, to enable awareness and understanding of own behaviours, feelings and motivation during interpersonal interactions. ${ }^{12}$ The model also applies to person-environment interactions, and explains the role of self-awareness in professional development. There are four quadrants, each depicting a different level of self-awareness: (1) known to self and others (open), (2) unknown to self but known to others (blind), (3) known to self and unknown to others (hidden), and (4) unknown to self and others (unknown). ${ }^{13-15}$ The Johari window has been infrequently used in medical education. Since feedback conversations are complex interactions between two persons, or between persons and their work or learning environment, we propose this matrix as an effective framework to guide systematic inquiries on the culture of feedback, feedback seeking, receptivity and impact on performance. In the next section, self-assessment and reflection are described as two important pedagogical strategies relevant to the Johari model and essential to the effective exchange of feedback.

The first strategy is self-assessment, traditionally viewed as an unguided, self-generated strategy to assess one's own abilities. However, professionals' ability to self-assess has been reported as less accurate than external observations, with suboptimal performers tending to overestimate their competence due to lack of insight into their errors. ${ }^{2,8,16-}$ 20 This incongruence is amplified when data from others conflict with impressions of self or if learners view the source as lacking credibility. ${ }^{2,21}$ More recent definitions of selfassessment strongly emphasise inclusion of data from external sources. Boud describes self-assessment as a process that requires internal and external data about one's performance and comparing these with a standard to make a judgment about one's performance. ${ }^{7}$ Mann et al coined the term informed self-assessment, defining it as the incorporation of internal and external data into self-appraisal. ${ }^{21}$ The term self-directed assessment seeking refers to the pedagogical activity of looking outward for formative and summative assessments of one's current level of performance. ${ }^{8}$ These descriptions of self- 
assessment as an interactive rather than individual strategy are more relevant to feedback seeking, acceptance and impact on behaviour.

The second important strategy is reflection, which can be categorised as reflective learning and practice. Reflective learning refers to critical thinking and analysis of own experience and performance to inform growth in knowledge, skills and attitudes. ${ }^{22-24} \mathrm{Re}-$ flective practice, a core tenet for healthcare professionals, is the ability to reflect on one's actions to enable continuing professional development. ${ }^{1}$ Reflection in action is the analysis of one's performance during the event potentially leading to immediate and beneficial behaviour change, while reflection on action is the review of one's performance after the event to change future behaviour. Boud and colleagues state that: "Reflection is an important human activity in which people recapture their experience, think about it, mull it over and evaluate it. It is this working with experience that is important in learning" ${ }^{25}$ Reflection has also been described as the link between receiving and assimilating feedback. ${ }^{3}$ Provision of feedback is thought to stimulate a reflective process among receivers which can be instrumental to acceptance and incorporation of data.

While informed self-assessment and facilitated reflection of performance have been the subject of many recent research reports, how these strategies influence feedback conversations between faculty and residents is largely unknown. Resident and faculty perceptions on the impact of institutional culture on these pedagogical strategies has also not been studied. Using qualitative methodology, we had previously conducted two studies in open-ended explorations of (1) perspectives of residents on the value of, barriers to, and best practices for feedback, 6 and (2) perspectives of residents and clinical teachers on the institutional feedback culture, feedback seeking, receptivity and bidirectional feedback.26 Key results from the previous studies indicated that institutional culture had a significant impact on the content and credibility of feedback exchanges. Residents and faculty also reported that the institutional culture of politeness was a barrier to honest, especially constructive feedback. In this study, we performed a focussed in-depth exploration of factors impacting feedback, solely through the lens of the Johari window. Thus, we only targeted themes related to self-assessment, reflection, feedback seeking and acceptance. Specifically, we aimed to discover individual and institutional strategies that could be applied to each quadrant of the window to enhance the culture of feedback. We describe how self-awareness, feedback seeking and receptivity could interact to inform learners about their performance, and the role of the institution in implementing strategies to enhance the culture of feedback.

\section{Methods}

Data from two previous studies were re-analysed using the Johari framework. The study setting, sampling, and data collection summarise the methods for studies 1 and 2, no new participants were recruited for this study. 


\section{Study setting}

The study was conducted at a large, urban training program with approximately 160 residents. Residents on a 3-4-year training track work in inpatient and outpatient settings. Ward teams consist of one or two postgraduate year (PGY) 2, 3, or 4 residents; two or three PGY1 residents; one or two attending physicians; and one or two medical students, who mostly work together for two weeks. Only in continuity clinics do residents have a longitudinal faculty supervisor. The quality of feedback would be variable as faculty level and experience in teaching vary. The institution outlines expectations for feedback but does not mandate feedback training.

\section{Qualitative approach and sampling}

A constructivist grounded theory approach, appropriate for hypothesis generation, was used to explore participant views on the role of feedback seeking, informed self-assessment, and reflection on clinical performance and professional growth. ${ }^{27-29}$ Using a purposive sampling strategy, we recruited residents and faculty for focus group discussions. Purposive sampling strategies target representative groups, in this case residents who rotated on inpatient and continuity clinic settings and generalist faculty who provide most of the clinical supervision and teaching. ${ }^{30,31}$ All prospective participants received e-mail invitations describing the purpose of the study, emphasising that participation was voluntary and ensuring confidentiality of opinions. Verbal consent was obtained from participants, with the opportunity to opt out at any point.

\section{Data collection}

The primary data collection was through focus group discussions supplemented by field notes. Focus groups were facilitated by the first author SR, a faculty trained in qualitative methodology, assisted by a research assistant who monitored the discussions and debriefed with the interviewer.

Open-ended questions explored participant opinions on the institutional feedback culture, factors impacting feedback seeking, receptivity, and bidirectional feedback. A total of nine resident focus group discussions (four for study 1 and five for study 2) were conducted between December 2013 and May 2016; all groups consisted of PGY-1, 2 and 3 residents. Three focus groups with general medicine faculty (continuity clinic preceptors and inpatient attendings) were conducted between June and October 2016 (study 2). All focus group discussions were 60 minutes in duration. Open-ended questions, discussed in advance by the research team, were used as triggers to initiate conversations, clarification and further elaboration were sought as required (Table 1). 
Table 1: Subjects and Focus group trigger questions in studies 1 and 2

\begin{tabular}{ll}
\hline Study Subjects & Trigger questions \\
\hline 138 residents & 1. Does feedback provided by faculty facilitate performance improvement? \\
2. What are the strengths and weaknesses of the current feedback system in our \\
residency program? \\
3. Can you describe challenges encountered when you give or receive feedback? \\
4. Can you suggest strategies to improve the feedback culture in our department? \\
1. Feedback culture: \\
- When the term feedback culture is used, what does it mean to you? \\
- How would you describe our institutional feedback culture? \\
- Can you suggest strategies to enhance the feedback culture in our department? \\
- In previous discussions, residents had expressed that our culture of politeness \\
- inhibits meaningful feedback, what are your opinions regarding this? \\
2. Feedback seeking and receptivity: \\
- How important is feedback seeking behaviour in obtaining meaningful feedback? \\
- Do you seek feedback? If yes, was it effective? If no, what are the reasons for not \\
- seeking it? \\
- What factors could increase receptivity to constructive feedback? \\
- In your opinion, is bidirectional feedback important? \\
- How often do you give feedback to seniors (faculty or residents)? \\
- How can we encourage bidirectional feedback?
\end{tabular}

\section{Data analysis}

Eleven focus group transcripts provided data for a new framework-based qualitative analysis, using the Johari window model. A conceptual thematic analysis was carried out to explore how our findings aligned with or challenged constructs for each quadrant of the Johari window. Only themes related to self-assessment and reflection and applicable to the framework were identified. A constant comparative approach required for grounded theory research was utilised. ${ }^{27-29,32,33}$ Two investigators independently performed a thematic analysis to identify major themes grounded in participant narratives using NVIVO software. Emerging themes were discussed with the entire research team, ambiguities or disagreements in coding and generation of themes were resolved by consensus at research team meetings.

To ensure reflexivity, we reflected on and acknowledged any influence of researchers in their approach to sampling, data collection and analysis. ${ }^{28,34}$ The lead author (SR), a faculty in the Department of Medicine, is not responsible for promotion or graduation decisions for residents or in a position of power over faculty. Her collaborators are nonphysicians, not affiliated with the institution where the research was conducted, and experts in health professions education research (CV, KK). The team also included 2 research assistants, one of whom observed the focus groups and took field notes and the other participated in independent data analysis (LW, EP). Each transcript was reviewed 
to ensure that questions remained open-ended and allowed for expression of a wide range of opinions.

\section{Ethical approval}

The study was granted exempt status by the Partners Institutional Review Board, the review board for Brigham and Women's Hospital (Protocol\#2013P002270/BWH).

\section{Results}

A total of 67 residents participated in 9 focus group discussions and 22 generalist faculty participated in 3 focus group discussions. These data were collected for studies 1 and 2 as described previously. In our new thematic analysis based solely on the framework of the Johari window, we identified the following themes most applicable to each quadrant:

1. Validating the known: Quadrant 1-Behaviours known to self and others

2. Accepting the blind: Quadrant 2- Behaviours unknown to self but known to others

3. Disclosure of hidden: Quadrant 3-Behaviours known to self but unknown to others

4. Uncovering the unknown: Quadrant 4- Behaviours unknown to self and others

\section{Validating the known}

The 'known' quadrant refers to competency domains or behaviours known to the resident as well as their supervising faculty and peers. Reviewing these areas during feedback conversations validates the feedback receiver that their self-assessment is accurate and reinforces that their performance improvement plans are on target. Reinforcing good clinical habits can ensure that the resident will continue to engage in such behaviour.

Feedback isn't code for criticism. It means, how are you doing? It could be good; it could be bad. The absence of feedback is bad... It doesn't have to be critical to be accurate. (R)

Sometimes you just want to hear, 'yes, you are where you're supposed to be.' Sometimes that's all you need to know. (R)

Feedback is useful not only to identify weaknesses but also to provide reassurance that one is on the right track. (F)

While known behaviours include strengths and deficiencies, faculty emphasised the role of positive feedback in establishing trust and setting the tone for ongoing conversations.

I think lots of positive feedback is important to developing their trust. If they only notice that you're picking out the bad stuff, they are going to think you're not really 
on their side. You need to catch them doing something right. Have them be called out for an excellent job so they get used to the idea that you're not out to get them. You want to help them and reinforce the good things that they're doing as well as help with the bad. (F)

Residents and faculty stated that discussing known behaviours is important to assess the accuracy of self-assessment, validate and reinforce strengths.

\section{Accepting the blind}

The 'blind' quadrant refers to areas of performance unknown to the resident but evident to supervising faculty and peers. It is likely easier to discuss strengths, but the challenge arises when the blind area involves constructive feedback on underperformance, often skipped to avoid hurting receivers' feelings. Engaging in active feedback seeking, grounding feedback conversations in learning goals and facilitating performance improvement plans, could make it more palatable to accept constructive comments.

I think that's (the responsibility) on the receiver a little bit. You have to say I'm not interested in hearing the things you think I'm doing great at, because that'll make me feel good, but that's not the point of this. It's to grow. (R)

To say you're not going to hurt my feelings. I want to know what things I can really improve on and how to do it. Then to push people when you feel like they're sugarcoating things a little bit. $(R)$

We're not always focussed on giving feedback or thinking about what each resident needs the feedback on, would be useful to have this information. (F)

Faculty expressed that modelling feedback seeking behaviour and demonstrating their own efforts at ongoing professional growth could encourage residents to do the same and enhance their acceptance of constructive feedback.

If you show them that you're trying to seek active feedback and continuing to learn, maybe the constructive feedback you're providing also carries a bit more weight. (F)

I always ask for feedback genuinely and say, "I'm always striving to improve my attending skills, my teaching skills, so I'm asking you for honest feedback." (F)

Additionally, it was suggested that feedback training should not just focus on the skills of giving, but also on receiving and accepting it.

I think we should be told at the beginning, how you seek out and how you react to the feedback that you're given. If you're defensive, if you don't push people to say tell me what I could be doing a better job at, it's very easy to get through residency without anybody ever telling you those things. (R) 
Just teach people to seek out constructive criticism, but criticism so that they grow. (F)

The comparison to sports coaching as well as parenting was brought up as strategies to defuse emotion and avoid the implication that the comments were an attack on the person.

As specific as you can get, it takes the emotional valence out of it. Giving tips on someone's golf swing is a lot easier than telling them that they are lacking as a person. It's also more actionable ....in general you're separating the person from the behaviour, which is something you learn from parenting all the time. (R)

Overall, participants indicated that strategies to encourage acceptance of constructive feedback pertaining to skills in the blind quadrant include active feedback seeking, training in feedback seeking and receiving, and a coaching culture similar to that seen in sports.

\section{Disclosure of hidden}

The 'hidden' quadrant comprises what is known to the resident but not to faculty or peers, and therefore requires disclosure by the resident. While expectations about weekly feedback exchanges were communicated regularly, participants stated that performance goals were rarely discussed, resulting in conversations not guided by self-disclosed goals, fears or limitations.

I have had interns who pick one or two areas of weakness that they want to focus on for that rotation. I found that incredibly helpful in terms of the entire rotation. I think that can do tons in terms of making the whole feedback experience much more useful. (R)

It helps if you ask the person you're working with, is there anything in particular you're working on or trying to get better at? That way, it doesn't feel like it's coming out of nowhere. It feels like 'okay, I asked you to watch me in this particular domain and see how I'm doing'. (F)

The credibility of feedback could be influenced by the relationship between the feedback provider and receiver. Residents may be willing to disclose their goals, and limitations to those they trust, allowing for more focussed and actionable feedback. Positive relationships can also stimulate more performance observation and make the feedback data more acceptable.

The most useful relationship was with my clinic preceptor who knows me best as a clinician and has given me the most formative feedback. I think they go together. Because I feel like she knows me so well, I really value what she says. It has a lot of merit. I think I've been very lucky in that sense. (R) 
How you evaluate someone, or think about someone growing, is really the question. Any sort of relationship that happens over time offers better opportunities for feedback. (R)

The more time the person that's getting feedback spends with you, the better able they should be to be able to give you that feedback. The less the receiver can say, in their head, they didn't see me in this situation. How do they know what I'm doing here? (F)

Development of trusting and longitudinal relationships between residents and faculty was thought to be important to allow for disclosure of performance goals, fears and insecurities.

\section{Uncovering the unknown}

The 'unknown' quadrant refers to domains unknown to the resident as well as supervising faculty. Therefore, seeking feedback from peers and other staff could be helpful. Residents indicated that their near-peers provided feedback on very different skills than faculty and wished peer-peer feedback conversations occurred more frequently. Some inpatient attendings emphasised the importance of feedback from non-physician team members whose perceptions of physician-patient interactions and teamwork are likely to be different and valuable.

I wish interns give more feedback on the teaching, running rounds, how supportive I am, how it is working with us, the nitty-gritty. And it's different feedback than I would get from an attending. (R)

I think the nurses, case managers and other team members should also be evaluating residents from a multidisciplinary team standpoint. They provide informal feedback on different skills than we do-professionalism, teamwork, interpersonal skills etc. $(F)$

Training in the skills of giving feedback, both top-down and bottom-up, was considered important by residents and faculty. Effective techniques to providing constructive feedback emphasising the goal of mutual professional growth were suggested. Residents who had participated in courses at the business school stated that medical education could borrow methods of feedback training from outside the profession.

I think formal feedback teaching with the goal being how to give negative feedback would be a very good thing. (F)

Attendings are being trained to be educators and deserve a session on how to give good feedback...the concept of [trainee] growth needs to be ingrained in the culture. (R) 
Go to McKenzie or Google. I'm sure they have a great apparatus for giving feedback, these companies focus on parallel feedback and top-down feedback. There are ways of teaching feedback in an efficient way so you show them how to do it before they start. (R)

Participant statements indicate that unknown behaviours could come to light through frequent performance observation, multisource feedback and feedback training that emphasises professional growth.

\section{Discussion}

In this study, we sought to explore perceptions of residents and faculty to help us determine the fit between sociocultural factors that impact feedback and a psychological model that emphasises self-awareness in professional development. Based on our findings, we believe that the Johari window model can effectively guide feedback conversations between faculty and residents, and the design of feedback initiatives by institutions. Originally described as a model of interpersonal communication and later adapted for leadership, teamwork, teaching skills etc., the model comprises self-awareness and perception of self as core components. ${ }^{13-15}$ Thus far, no studies have been published on the application or utility of this model in feedback conversations in medical education. The perception of self includes self-assessment and reflection, both of which can play a significant role in influencing the quality of feedback conversations. Stimulating these pedagogical strategies could influence behaviour change and performance improvement, through learners' willingness to self-discover strengths and weaknesses, feedback seeking behaviour and receptivity to multisource feedback. Our data suggest that both residents and faculty view effective feedback as an interpersonal communication facilitated or inhibited by the institutional culture, rather than a unidirectional top-down process. Additionally, the clinical environment is one where patient care is delivered by teams, where perception of self and perception of one's behaviours by other team members are essential for optimal functioning.

In the next sections, we describe feedback strategies to potentially expand the 'open' quadrant and shrink the 'hidden', 'blind' and 'unknown' quadrants, as depicted in Figure 1. Under each quadrant, we have listed strategies for individual feedback providers and receivers, followed by institutional initiatives that could maximise professional growth. 


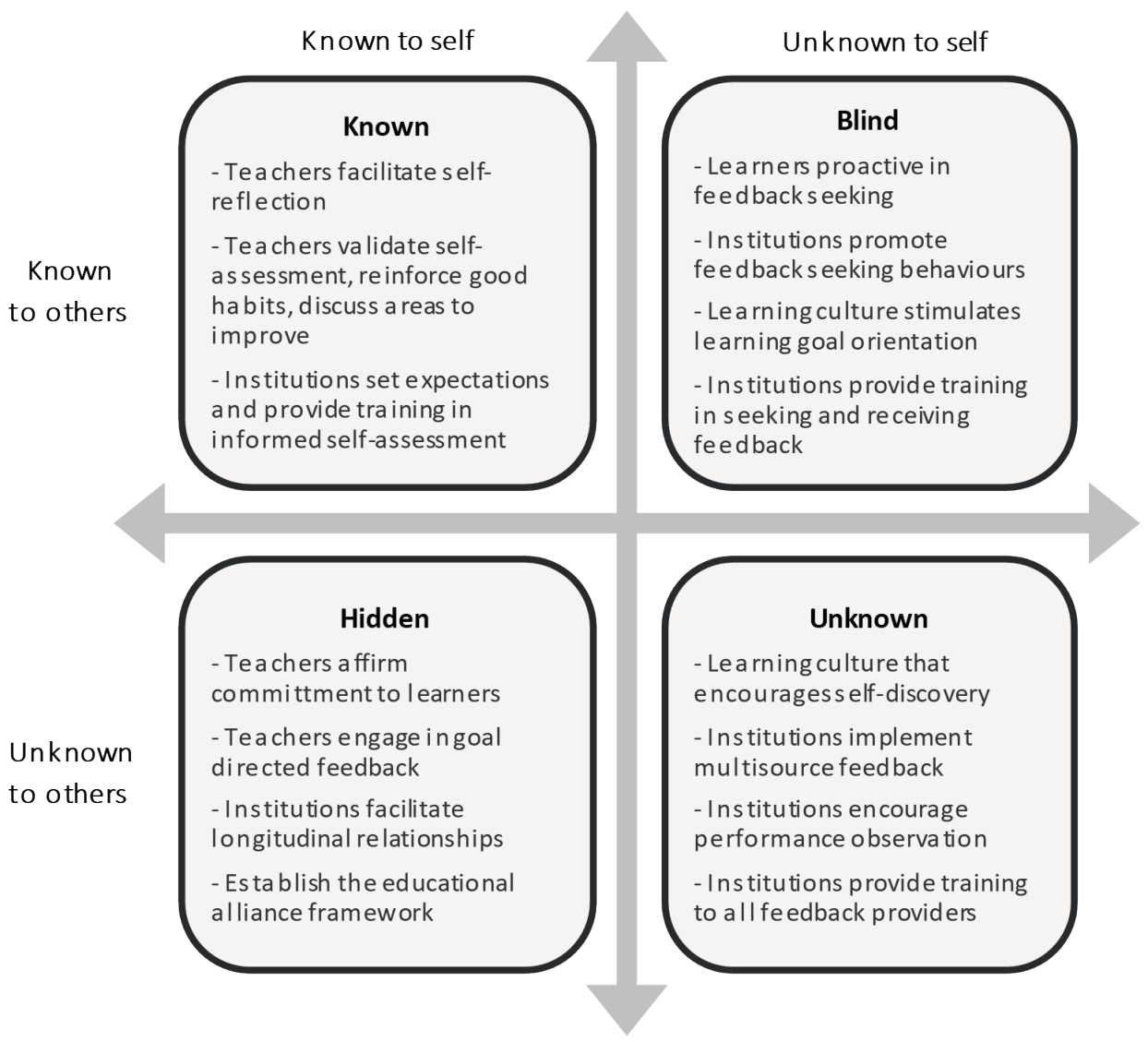

Figure 1: The Johari window and the culture of feedback

Legend: The four quadrants of the Johari window list strategies that individuals and institutions can use to enhance self-awareness and impact of feedback, thereby optimising the size of each quadrant.

The 'open' quadrant enables individual professionals and teams to be most productive. Strengths as well as deficiencies need to be discussed to stimulate a growth mind-set. For feedback providers, encouraging reflection and inviting self-assessment from receivers can expand this quadrant. However, research suggests that most people tend to possess inflated self-assessments as they pay more attention to positive data in reconstructing experiences, ${ }^{8,19}$ thus unguided reflection and self-assessment can lead feedback receivers to inaccurately calibrate their performance level. ${ }^{16}$ Self-reflection is more accurate when it incorporates performance data from external sources. $3,7,8,21,35,36$ Sargeant et al. recently described the R2C2 model, a facilitated reflective performance feedback model, comprising the following steps: building a relationship, exploring reactions to performance data, exploring learners' understanding of the content of feedback and coaching for performance change. ${ }^{37}$ Self-directed assessment seeking can be useful not only to validate perception of strengths and agreement on areas needing improvement, but also to assess 
accuracy of residents' self-awareness. ${ }^{8}$ Institutional leaders have a major role in promoting a culture where informed self-assessment becomes the norm, and providing training on these skills, thereby enlarging the 'open' quadrant for individuals and teams. Additionally, faculty supervisors should present frequent, affirmative feedback on performance along with a road map detailing where learners need to be at different stages and a plan to get there. These strategies can also address learners' sense of competence, relatedness and autonomy, needs that are crucial in residency education. ${ }^{6,38}$

The 'blind' quadrant arises out of ignorance about one's behaviours and performance. A multipronged approach is needed to shrink this space. Learners can gain awareness of their blind spots through active feedback-seeking, defined as one's conscious efforts to determine adequacy of performance in attaining required learning goals. ${ }^{39}$ Since feedback-seeking behaviour can be driven by the desire for useful information, to enhance one's ego, or maintain a positive image, it can be influenced by goal orientation of individuals. ${ }^{40-42}$ Trainees with a performance goal-orientation, focus on good performance and creating a good impression, may avoid feedback that could reveal limitations and threaten their image. Those with a learning goal-orientation, focus on gaining new knowledge and skills, are more likely to engage in feedback seeking to correct deficiencies and gain mastery in their field. Feedback-seeking can also be impacted by the attending physician's supervisory style and interpersonal skills. ${ }^{42,43}$ Institutions need to establish a learning culture that actively promotes feedback-seeking behaviour, emphasises learning goal rather than performance goal-orientation among its trainees and staff, communicate these as clear expectations, and provide feedback training that includes strategies for seeking, receiving and incorporating feedback. ${ }^{42}$

The 'hidden' quadrant represents information, feelings, fears, agendas or context that a resident may hesitate to reveal to supervising faculty or peers. Disclosure is necessary to narrow this space, though how much to reveal would depend on the person, the trust and relationship with others. Many potential negative effects of rapid transitions and short rotations in clinical medicine have been described including inability of trainees and faculty to establish trusting educational or working relationships, lack of knowledge about each other's motivation, commitment or goals, and lack of a shared mental model of performance appraisal and expectations for feedback. ${ }^{44-51}$ Modelled on the psychotherapeutic concept of a therapeutic alliance, the educational alliance framework may promote supportive relationships between learners and teachers resulting in meaningful feedback exchanges where learners feel comfortable disclosing their limitations and insecurities, and teachers ground their feedback in learner goals while being mindful of their fears and the context. ${ }^{52,53}$ Establishing such an alliance necessitates that residents and attendings have conversations that demonstrate the teacher's commitment to the learner and the learning process, establish a relationship that permits disclosure, thus narrowing the 'hidden' space. Faculty can acknowledge their own fears and limitations, demonstrate understanding of the learner's context, and provide goal-directed feedback. Institutional interventions 
to enhance self-disclosure can include opportunities for creating longitudinal relationships, a climate that encourages admission of limitations and training in giving non-judgmental feedback.

The last quadrant, the 'unknown' space is the most challenging to address because neither the resident nor their supervisors or peers are aware of these behaviours. These can include abilities or a limitation that a professional is unaware that they possess or skills that are underestimated. Shrinking this area would involve a multitude of approaches such as residents' readiness to discover new areas of self, direct performance observation by different supervisors, and multisource feedback. Supervisors, peers, nonphysician team members such as nurses or case managers and patients, are all likely to perceive and provide insights on different dimensions of performance, thus enhancing professional development of residents. ${ }^{36,54,55} 56$ 36,57 However, it has also been reported that physicians tend to view non-physician sources of feedback as less credible and beneficial, therefore less receptive to their feedback. ${ }^{54,55,58}$ Institutions can promote these strategies by implementing formal interprofessional feedback, providing training in receiving and incorporating feedback into performance, and creating a culture of openness to self-discovery. With time, the combination of these strategies could shrink the unknown space.

This study has limitations which may have affected our findings. The inquiry was based at a single residency program, and the data may not be completely transferable to other programs and institutions. The data were not collected with the goal of exploring opinions about self-awareness or reflection, rather the analysis was performed on pre-existing data using a framework-based qualitative approach. Focus groups aim to discover participants' opinions on a given subject, but such perceptions may differ from actions. While a large quantity of narratives was available, our participants were a sample of a larger resident population, we may not have captured a full range of opinions from non-participants. To ensure rigour, our data sources included focus group transcripts, field notes and observations by two people, and independent data analysis by two or more investigators. The findings also appear to be consistent with existing literature on sociocultural factors that influence feedback. ${ }^{3,21,59-62}$ Our context is typical of large medicine residency programs and the findings are potentially transferable to similar postgraduate education settings. Finally, attention was paid to reflexivity in formulating open-ended study questions, data collection that allowed for group interactions and triangulation of data analysis.

\section{Suggestions for further research}

In this study, we have explored the perceptions of residents and faculty regarding the importance and influence of factors such as self-assessment and reflection on feedback seeking, receptivity and professional growth, through the lens of the Johari window model of self-awareness. Further research is required to investigate whether and how 
these strategies come into play during real time feedback conversations. It is also important to explore if increasing direct performance observation and designing longitudinal mentoring relationships will improve accurate self-assessment, disclosure and willingness to engage in self-discovery. Our next steps will include observations of real-time feedback conversations between faculty and resident using an ethnographic approach, followed by reflexive debriefing of feedback behaviours. Finally, we aim to design feedback training incorporating the Johari framework and study its impact on feedback behaviours of faculty and residents.

\section{Conclusions}

Informed self-assessment and facilitated reflection are integral aspects of feedback conversations. These strategies should incorporate data from self and multiple external sources. The Johari window, an established model for self-awareness in interpersonal communications, can provide a robust framework for teachers to plan feedback conversations as well as institutions to design feedback initiatives that enhance its quality and impact on professional growth. Normalising disclosure of fears and limitations, encouraging feedback seeking, training in providing non-judgemental feedback and providing opportunities for longitudinal relationships can enhance self-awareness and promote self-discovery which can ultimately maximise the 'open' quadrant of the Johari window.

\section{Practice Points}

- The impact of feedback should be determined by its acceptance and incorporation by feedback receivers and subsequent behaviour change

- Unguided self-assessment is likely to lead to inaccurate calibration of own performance

- Informed self-assessment and facilitated reflection should be considered integral elements of feedback conversations

- The Johari window, a framework for self-awareness in interpersonal communications, can be a useful model to structure the content of feedback conversations and design feedback training

- Individual and institutional pedagogical strategies can expand the "open" space and shrink the "blind" and "hidden" spaces, and gradually uncover the "unknown" quadrant

\section{Acknowledgements}

This research was funded by the Department of Medicine CERS (Clinical Education Research Scholars) grant at the Brigham and Women's Hospital.

We express our appreciation to all the residents and faculty who participated in this study and provided valuable insights on this topic. 


\section{REFERENCES}

1. Developing as a clinical teacher. Clin Teach 2016;13:397-8.

2. Sargeant J. 'To call or not to call': making informed self-assessment. Med Educ 2008;42:854-5.

3. Sargeant JM, Mann KV, van der Vleuten CP, Metsemakers JF. Reflection: a link between receiving and using assessment feedback. Adv Health Sci Educ Theory Pract 2009;14:399-410.

4. Delva D, Sargeant J, MacLeod T. Feedback: a perennial problem. Med Teach 2011;33:861-2.

5. Boud D. Feedback: ensuring that it leads to enhanced learning. Clin Teach 2015;12:3-7.

6. Ramani S, Post SE, Konings K, Mann K, Katz JT, van der Vleuten C. "It's Just Not the Culture": A Qualitative Study Exploring Residents' Perceptions of the Impact of Institutional Culture on Feedback. Teach Learn Med 2017;29:153-61.

7. Boud D. Enhancing learning through self assessment. London; Philadelphia: Kogan Page; 1995.

8. Eva KW, Regehr G. "I'll never play professional football" and other fallacies of self-assessment. J Contin Educ Health Prof 2008;28:14-9.

9. Eva KW, Regehr G. Knowing when to look it up: a new conception of self-assessment ability. Acad Med 2007;82:S81-4.

10. Sargeant J, Mann K, Sinclair D, Van der Vleuten C, Metsemakers J. Understanding the influence of emotions and reflection upon multi-source feedback acceptance and use. Adv Health Sci Educ Theory Pract 2008;13:275-88.

11. Sargeant J. How external performance standards inform self-assessment. Med Teach 2012;34:267-8.

12. Luft J. Of human interaction. Palo Alto, Calif.,: National Press Books; 1969.

13. Numerof RE. How assertive are you? A look through the Johari Window. Health Serv Manager 1979;12:7-9.

14. Sutherland JA. The Johari Window: a strategy for teaching therapeutic confrontation. Nurse Educ 1995;20:22-4.

15. Verklan MT. Johari window: a model for communicating to each other. J Perinat Neonatal Nurs 2007; $21: 173-4$

16. Kruger J, Dunning D. Unskilled and unaware of it: how difficulties in recognizing one's own incompetence lead to inflated self-assessments. J Pers Soc Psychol 1999;77:1121-34.

17. Dunning D, Heath C, Suls JM. Flawed Self-Assessment: Implications for Health, Education, and the Workplace. Psychol Sci Public Interest 2004;5:69-106.

18. Eva KW, Regehr G. Self-assessment in the health professions: a reformulation and research agenda. Acad Med 2005;80:S46-54.

19. Davis DA, Mazmanian PE, Fordis M, Van Harrison R, Thorpe KE, Perrier L. Accuracy of physician selfassessment compared with observed measures of competence: a systematic review. JAMA 2006;296:1094-102.

20. Ehrlinger J, Johnson K, Banner M, Dunning D, Kruger J. Why the Unskilled Are Unaware: Further Explorations of (Absent) Self-Insight Among the Incompetent. Organ Behav Hum Decis Process 2008;105:98-121.

21. Mann K, van der Vleuten C, Eva K, et al. Tensions in informed self-assessment: how the desire for feedback and reticence to collect and use it can conflict. Acad Med 2011;86:1120-7.

22. Moon J. Using reflective learning to improve the impact of short courses and workshops. J Contin Educ Health Prof 2004;24:4-11.

23. Chaffey LJ, de Leeuw EJ, Finnigan GA. Facilitating students' reflective practice in a medical course: literature review. Educ Health (Abingdon) 2012;25:198-203.

24. Hayton A, Kang I, Wong R, Loo LK. Teaching Medical Students to Reflect More Deeply. Teach Learn Med 2015;27:410-6.

25. Boud D, Keogh R, Walker D. Reflection, turning experience into learning. London New York: Kogan Page; Nichols Pub.; 1985. 
26. Ramani S, Konings KD, Mann KV, Pisarski EE, van der Vleuten CPM. About Politeness, Face, and Feedback: Exploring Resident and Faculty Perceptions of How Institutional Feedback Culture Influences Feedback Practices. Acad Med 2018.in press.

27. Kennedy TJ, Lingard LA. Making sense of grounded theory in medical education. Med Educ 2006;40:1018.

28. Watling CJ, Lingard L. Grounded theory in medical education research: AMEE Guide No. 70. Med Teach 2012;34:850-61.

29. Charmaz K. Constructing grounded theory. 2nd edition ed. London ; Thousand Oaks, Calif.: Sage; 2014.

30. Creswell JW, Creswell JW. Qualitative inquiry and research design : choosing among five approaches. 3rd ed. Los Angeles: SAGE Publications; 2013.

31. Ramani S, Mann K. Introducing medical educators to qualitative study design: Twelve tips from inception to completion. Med Teach 2016;38:456-63.

32. Patton MQ. Qualitative research and evaluation methods. 3 ed. Thousand Oaks, Calif.: Sage Publications; 2002.

33. Creswell JW. Educational research : planning, conducting, and evaluating quantitative and qualitative research. 4th ed. Boston: Pearson; 2012.

34. Watt D. On Becoming a Qualitative Researcher: The Value of Reflexivity. The Qualitative Report 2007;12:82-101.

35. Epstein RM, Hundert EM. Defining and assessing professional competence. JAMA 2002;287:226-35.

36. Sargeant J. Reflecting upon multisource feedback as 'assessment for learning'. Perspect Med Educ 2015;4:55-6.

37. Sargeant J, Lockyer J, Mann K, et al. Facilitated Reflective Performance Feedback: Developing an Evidenceand Theory-Based Model That Builds Relationship, Explores Reactions and Content, and Coaches for Performance Change (R2C2). Acad Med 2015.

38. Schumacher DJ, Englander R, Carraccio C. Developing the master learner: applying learning theory to the learner, the teacher, and the learning environment. Acad Med 2013;88:1635-45.

39. Crommelinck M, Anseel F. Understanding and encouraging feedback-seeking behaviour: a literature review. Med Educ 2013;47:232-41.

40. VandeWalle D, Cron WL, Slocum JW, Jr. The role of goal orientation following performance feedback. J Appl Psychol 2001;86:629-40.

41. VandeWalle D, Ganesan S, Challagalla GN, Brown SP. An integrated model of feedback-seeking behavior: disposition, context, and cognition. J Appl Psychol 2000;85:996-1003.

42. Teunissen PW, Bok HG. Believing is seeing: how people's beliefs influence goals, emotions and behaviour. Med Educ 2013;47:1064-72.

43. Bok HG, Teunissen PW, Spruijt A, et al. Clarifying students' feedback-seeking behaviour in clinical clerkships. Med Educ 2013;47:282-91.

44. Bernabeo EC, Holtman MC, Ginsburg S, Rosenbaum JR, Holmboe ES. Lost in transition: the experience and impact of frequent changes in the inpatient learning environment. Acad Med 2011;86:591-8.

45. Holmboe E, Ginsburg S, Bernabeo E. The rotational approach to medical education: time to confront our assumptions? Med Educ 2011;45:69-80.

46. Sargeant J, Eva KW, Armson H, et al. Features of assessment learners use to make informed selfassessments of clinical performance. Med Educ 2011;45:636-47.

47. Sargeant J, McNaughton E, Mercer S, Murphy D, Sullivan P, Bruce DA. Providing feedback: exploring a model (emotion, content, outcomes) for facilitating multisource feedback. Med Teach 2011;33:744-9.

48. Watling C. Cognition, culture, and credibility: deconstructing feedback in medical education. Perspect Med Educ 2014;3:124-8.

49. Watling CJ. Unfulfilled promise, untapped potential: feedback at the crossroads. Med Teach 2014;36:6927.

50. Sargeant J, Lockyer J, Mann K, et al. Facilitated Reflective Performance Feedback: Developing an Evidenceand Theory-Based Model That Builds Relationship, Explores Reactions and Content, and Coaches for Performance Change (R2C2). Acad Med 2015;90:1698-706. 


\section{Chapter 5}

51. Dudek NL, Dojeiji S, Day K, Varpio L. Feedback to Supervisors: Is Anonymity Really So Important? Acad Med 2016;91:1305-12.

52. Telio S, Ajjawi R, Regehr G. The "educational alliance" as a framework for reconceptualizing feedback in medical education. Acad Med 2015;90:609-14.

53. Telio S, Regehr G, Ajjawi R. Feedback and the educational alliance: examining credibility judgements and their consequences. Med Educ 2016;50:933-42.

54. Sargeant J, Mann K, Ferrier S. Exploring family physicians' reactions to multisource feedback: perceptions of credibility and usefulness. Med Educ 2005;39:497-504.

55. Ten Cate O, Sargeant J. Multisource feedback for residents: how high must the stakes be? J Grad Med Educ 2011;3:453-5.

56. Holmboe ES, Ross K. Commentary: realizing the formative potential of multisource feedback in regulatorybased assessment programs. Acad Med 2012;87:1657-9.

57. van der Meulen MW, Boerebach BC, Smirnova A, et al. Validation of the INCEPT: A Multisource Feedback Tool for Capturing Different Perspectives on Physicians' Professional Performance. J Contin Educ Health Prof 2017.

58. Sargeant J, Mann K, Sinclair D, van der Vleuten C, Metsemakers J. Challenges in multisource feedback: intended and unintended outcomes. Med Educ 2007;41:583-91.

59. Shute V. Focus on formative feedback. Review of Educational Research 2008:153-89.

60. Eva $\mathrm{KW}$, Armson $\mathrm{H}$, Holmboe $\mathrm{E}$, et al. Factors influencing responsiveness to feedback: on the interplay between fear, confidence, and reasoning processes. Adv Health Sci Educ Theory Pract 2012;17:15-26.

61. Watling C, Driessen E, van der Vleuten CP, Vanstone M, Lingard L. Beyond individualism: professional culture and its influence on feedback. Med Educ 2013;47:585-94.

62. van de Ridder JM, Berk FC, Stokking KM, Ten Cate OT. Feedback providers' credibility impacts students' satisfaction with feedback and delayed performance. Med Teach 2014:1-8. 


\section{Chapter}

\section{It's all about the relationship - Exploring preceptor-resident feedback conversations}

Manuscript submitted to Medical Education as: Ramani S, Könings K, Ginsburg S, van der Vleuten CPM. It's all about the relationship: Exploring preceptor-resident feedback conversations. 


\section{Abstract}

Introduction: Though newer models of feedback emphasise sociocultural influences and the central role of learners in the feedback conversation, verbal and non-verbal behaviours of teachers and learners during real-life feedback exchanges are mostly unknown. Most studies to date have explored feedback perspectives through interviews or questionnaires. Direct observations of conversations could enhance existing knowledge of feedback behaviours. Our study objective was to observe feedback conversations between faculty supervisors and residents to explore strategies used to establish an educational alliance and behaviours that promote feedback seeking and acceptance of constructive feedback.

Methods: We observed and videotaped twelve feedback conversations between preceptors and residents who work together in continuity clinic settings. Post observation debriefing interviews explored participant insights into their behaviours and effectiveness of their strategies. Since preceptor-resident relationships dominated many of the debriefing conversations, data were analysed through the lens of REDE, a relationship-centred communication framework (relationship establishment, development and engagement).

Results: Six preceptors and twelve residents participated in the study. The central theme identified pertained to the influence of preceptor-resident longitudinal relationships on feedback exchanges. We identified the following subthemes under each of the three categories of the REDE model: (1) Relationship establishment-Collaborative agenda, Convey value and respect; (2) Relationship development -Elicit resident narrative, Engage in reflective listening, and Explore resident perspective; and (3) Relationship engagement Share information, Collaborative planning, and Provide closure.

Conclusions: Direct observation of feedback conversations is a valuable method to explore verbal and non-verbal behaviours during feedback conversations and the impact of longitudinal relationships on conversations between clinical supervisors and residents. Our study indicates that trusting and supportive teacher-learner relationships should form the foundation on which feedback conversations are based, for feedback to be received, accepted and lead to behaviour change. 


\section{Introduction}

Newer constructs of feedback emphasise educational alliances between teachers and learners and learner-centred approaches, ${ }^{1-4}$ however, the theoretical gains from this research have not yet adequately translated into outcomes such as seeking, acceptance and incorporation of feedback by learners. ${ }^{5-7}$ While research methodologies using questionnaires, interviews and audiotaping have provided rich insights into factors that impact feedback, teachers and learners often tell different stories about the feedback conversation. ${ }^{8-12}$ Thus, these methods may not adequately uncover the nuances of behaviours during such complex interactions. Direct observation and analysis of feedback conversations between teachers and learners could allow deeper understanding of behaviours, and yield rich clues to promote a feedback culture that influences educational alliances and behaviour change.

Feedback initiatives have swung from unidirectional transmission to bidirectional models that advocate alliance building and coaching. ${ }^{3,13-15}$ Sociocultural factors, such as teacher-learner relationships, perceptions of credibility and the institutional learning culture, may strongly influence feedback quality and impact on learners. ${ }^{16-20}$ The educational alliance ${ }^{4,13}$ and the R2C2 (relationship building, exploring reactions to feedback, exploring content and coaching for change) models, ${ }^{21}$ emphasise that effective feedback interactions are built on trusting relationships between teachers and learners with learner engagement in the entire feedback process. Residents have previously reported dissatisfaction with the quality of feedback from clinical supervisors, ${ }^{19,22-24}$ while faculty overestimate the frequency of feedback provided, hesitate to provide constructive feedback and rarely discuss action plans. ${ }^{24,25}$ Exploring feedback through the sociocultural lens may be one approach to addressing this mismatch.

Despite new knowledge gained from research to date, ${ }^{13,16,17,20,26-31}$ it is possible that full understanding of the impact of feedback cannot be achieved by methods such as questionnaires, interviews or even audiotaping. If theoretical models of feedback are constructed from perceptions of feedback conversations after the fact, such recollections could be subject to recall bias, mismatched decoding of the conversations by participants. Sargeant et al audiotaped feedback conversations between faculty and residents to explore the utility and acceptability of the R2C2 model, ${ }^{32,33}$ observation could yield further insights into non-verbal behaviours. Therefore, despite increasing emphasis on relationships and coaching as essential aspects of effective feedback, whether these happen in real-time conversations warrants further exploration.

Ethnography combines data collection methods such as observations of people in 'natural' settings, artefact analysis and narrative interviews to interpret behaviours. ${ }^{34}$ This approach could reveal intangible aspects of feedback interactions, with debriefing interviews allowing participants to reflexively discuss and potentially transform their own practice. ${ }^{35,36}$ It is worth emphasizing that successful ethnographic approaches rely on the researcher gaining the trust of participants, and familiarity with the practice setting. 
The purpose of this study was to observe and videotape feedback conversations between faculty supervisors and residents in continuity clinic settings followed by interviews, aiming to explore the following questions:

1. Is there evidence of an educational alliance between faculty and residents during observed feedback conversations?

2. What general behaviours (verbal and non-verbal) and strategies are observed during formal feedback conversations between faculty and resident pairs who work together in continuity clinics?

3. What teacher behaviours do residents think would be most likely to promote feedback seeking, acceptance and incorporation of constructive feedback?

\section{Methods}

Using an ethnographic approach, we attempted to gain insights into behaviours during feedback conversations between resident-faculty pairs who have a longitudinal relationship in a continuity clinic setting. The term preceptor is used to indicate faculty supervisors of residents.

\section{Study setting and sampling}

The study was conducted at Brigham and Women's Hospital, a large, urban teaching institution, and an affiliate of Harvard Medical School. The Internal Medicine training program comprises approximately 160 residents, who work in continuity clinics with a faculty supervisor throughout their training. The program communicates expectations that residents and faculty should have formal feedback conversations at least twice a year in the outpatient clinics, in addition to regular in-the-moment exchanges. The quality of feedback would vary based on faculty teaching experience. Teaching or feedback training is not a requirement and none of the faculty received training on newest insights from the educational alliance or R2C2 frameworks. ${ }^{21,32,33}$

Using purposive sampling, six faculty and twelve residents were recruited the major residency outpatient training site, as pairs with longitudinal relationships were best placed to provide insights into our inquiry. They were provided information about the study objectives via email and during conferences, emphasising voluntary participation and confidentiality of opinions. Sixty residents and twenty faculty work together at this outpatient training site, each faculty is the primary supervisor for 2-3 residents. The emails to preceptors did not include suggestions on feedback strategies, and no faculty development was provided. 


\section{Study framework}

We used a reflexive ethnographic approach where ethnography refers to preceptors and residents interacting in their 'natural' setting, i.e. the continuity clinic, and reflexivity refers to engaging participants in making sense of their actions and reflecting on the effectiveness of their strategies. ${ }^{34,36,37}$ Reflexivity is collaborative, open-ended and allows participants to anticipate problems that can be addressed on the spot or in future encounters. ${ }^{38,39}$ While traditional ethnographic methodology emphasises prolonged immersive observations of participants in their natural environments, many experts include shorter observations under this approach as long as investigators co-construct meaning of the encounter with participants through interviews, narratives, field notes etc. ${ }^{34,40}$ Our methodology is consistent with modern ethnographic approaches rather than pure observational methods, as it combines short observations with participant debriefing to construct the meaning and implications of each feedback conversation. ${ }^{40}$ Specifically, it enabled us to explore rapport between preceptors and residents, feedback strategies used, receptivity of residents and demonstration of a shared understanding of the purpose and impact.

\section{Data collection}

Data collection occurred between September 2017 and May 2018 in three phases: (1) observation and video recording of feedback conversations between preceptors and residents; (2) post-encounter debriefing interviews of preceptors; (3) post-encounter debriefing interviews of residents. All debriefing conversations were audiotaped and transcribed for analysis. These steps are depicted in Figure 1.

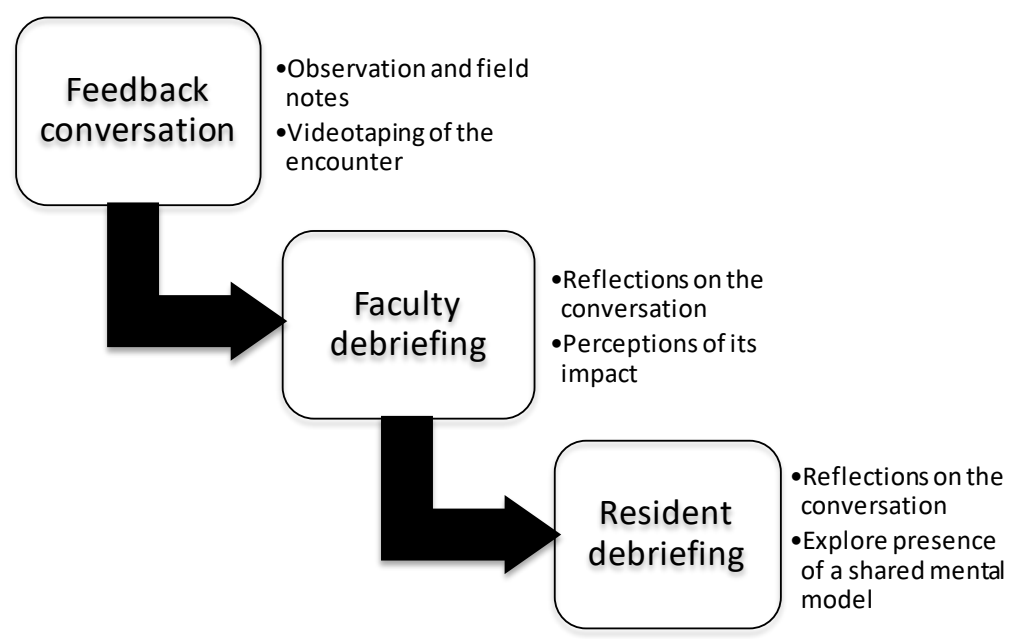

Figure 1: Phases of Data Collection 


\section{Phase 1- Observation and videotaping of formal feedback conversations}

The lead investigator (SR) contacted participants to schedule observation and videotaping of one feedback conversation per resident-faculty pair. SR recorded field notes focussing on verbal and non-verbal behaviours, mood and tone of the interaction. A small tablet computer was used for the videotaping, the observer's intent was to be a 'fly-on-thewall' and minimise the intrusion on the authenticity of the encounter. In total, approximately 150 minutes of video-observational data and 240 minutes of interview transcripts from 12 feedback conversations were collected.

\section{Phase 2: Faculty debriefing}

SR conducted preceptor debriefing after each feedback conversation based on their recollections of the conversation. Sample triggers, listed in Table 1, invited them to reflect on their behaviours that may have positively or negatively impacted the conversation, as well as unexpected moments that arose during the encounter. Reflexive insights were encouraged by asking preceptors to recall behaviours that they might consider changing in future conversations.

\section{Phase 3: Resident Debriefing}

Post-encounter resident debriefing after the conversation focussed on their overall impressions of the conversation, their opinions on the effectiveness of feedback strategies used by faculty, and whether useful action plans had been discussed. The triggers and prompts are listed in Table 1.

Table 1: Sample trigger questions and prompts for each phase of data collection

\begin{tabular}{ll}
\hline Data collection phase & Sample prompts \\
\hline Debriefing with & How do you think that went? - general icebreaker \\
faculty participants & Goals: \\
$\begin{array}{l}\text { after the feedback } \\
\text { conversation }\end{array}$ & Did you have specific goals for the conversation? \\
& Were you able to achieve your goals? \\
& If yes, what strategies did you use that were effective: \\
& If no, what strategies do you think were not effective: \\
& Language: Reflecting on the language you used during the conversation: \\
& Did you consciously select certain words to use? \\
& Why? \\
& What would you continue to do the same? \\
& What might you do differently? \\
& Non-verbal communication \\
& Do you have any reflections regarding your body language and other? non-verbal \\
& behaviour that you may have used? \\
& Feedback receiver \\
& Do you think the resident interpreted what you said accurately? - probe why or why \\
& not??
\end{tabular}




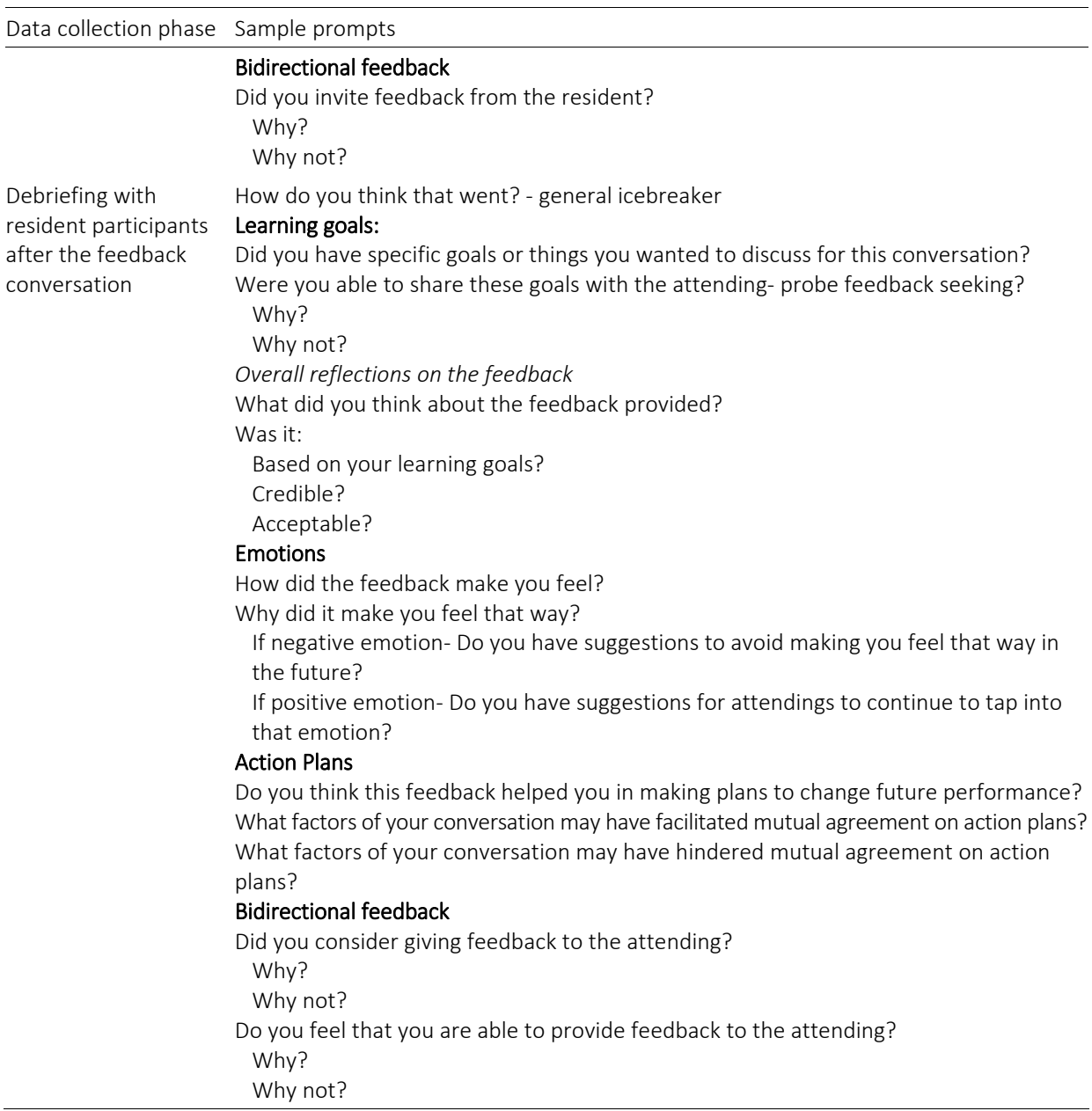

SR performed all data collection including observation and videotaping of the conversations, recording field notes, facilitating and audiotaping the debriefing interviews. SR is an 'insider', who practises and supervises residents at the same practice. She has no role in faculty evaluation, hiring or promotion. Although she is a core educator in the residency program and supervises her own residents (not included in this study), she is not responsible for resident remediation or graduation decisions. Residents were aware that SR was exploring the current state of feedback within the program and leading efforts to improve its quality. Thus, her knowledge of the practice and the educational environment allowed her to explore and question aspects of feedback practices with participants using a shared language. Actions such as easy acceptance of the invitation to participate in the study, sharing of faculty challenges, faculty soliciting feedback from SR, residents proposing suggestions on improving the feedback process, were viewed as a demonstration of trust between her and participants. 


\section{Data analysis}

Using a team-based approach, data collection occurred concurrently with analysis and informed future data collection. All videos and transcripts were reviewed in detail by SR, who identified emerging themes and explored them in subsequent debriefing interviews. Each of the other investigators (SG, KK, CV) reviewed some videotapes and transcripts to get an overall sense of key themes, to ensure that SR assumptions did not drive the analysis, and reach consensus on the coding scheme and themes. We initially reviewed the data looking for teacher and learner behaviours consistent with each step of the R2C2 model. ${ }^{21}$ Since teacher-learner relationships dominated most debriefing conversations, we decided to conduct an in-depth exploration of preceptor and resident behaviours linked to relationship formation, the first step of the R2C2 model. Therefore, we analysed data through the lens of relationship-centred communication, as described in the REDE (Relationship- Establishment, Development, Engagement) model. ${ }^{41}$ However, we remained open to discovery of unexpected and unanticipated themes.

We assigned a code to each segment of data pertaining to a specific aspect of teacherlearner relationship development, related codes were grouped under coding categories. We then mapped the categories onto each phase of the REDE model. Through ongoing discussions, the team reached consensus on the coding scheme which was then applied to the entire dataset. Analysis moved from the categorical to the conceptual level through identification and elaboration of the impact of preceptor- resident relationships on feedback behaviours. The entire research team had several meetings to discuss overarching themes and to ensure that the study questions were addressed adequately. Manual coding was performed initially followed by computer assisted qualitative data analysis using NVivo software to organize codes, themes and quotes and retrieve data for more detailed analysis. Credibility and dependability were ensured through triangulation, summarising data interpretation and member checking after each debriefing interview.

\section{Ethical approval}

The study was granted exempt status by the Partners Institutional Review Board, the review board for Brigham and Women's Hospital (Protocol\#2013P002270/BWH). Verbal consent was obtained from final participants prior to observation and videotaping.

\section{Results}

The central theme that dominated all discussions pertained to the impact of relationships on feedback conversations. Within this central theme, we identified subthemes related to specific behaviours and strategies used by preceptors and residents, categorised under 
the three phases of the REDE relationship-centred communication model. This is depicted in Table 2 and Figure 2.

Table 2: Phases of relationships, themes and behaviours

\begin{tabular}{llll}
\hline Phases of relationship & Theme & Strategies & Behaviours \\
\hline Establishment & Set the stage & Collaborative agenda & Plan and observe \\
& & Convey value and respect & Motivate and validate \\
Development & The Alliance & Elicit resident narrative & Provide a safe space \\
& & Engage in reflective listening & Listen, respond and redirect \\
& The dialogue & Share information & An invitation to self-reflect \\
Engagement & & Collaborative planning & Make it about a skill or action \\
& & & A game plan for growth \\
\hline
\end{tabular}

\section{THE THREE PHASES OF RELATIONSHIPS}

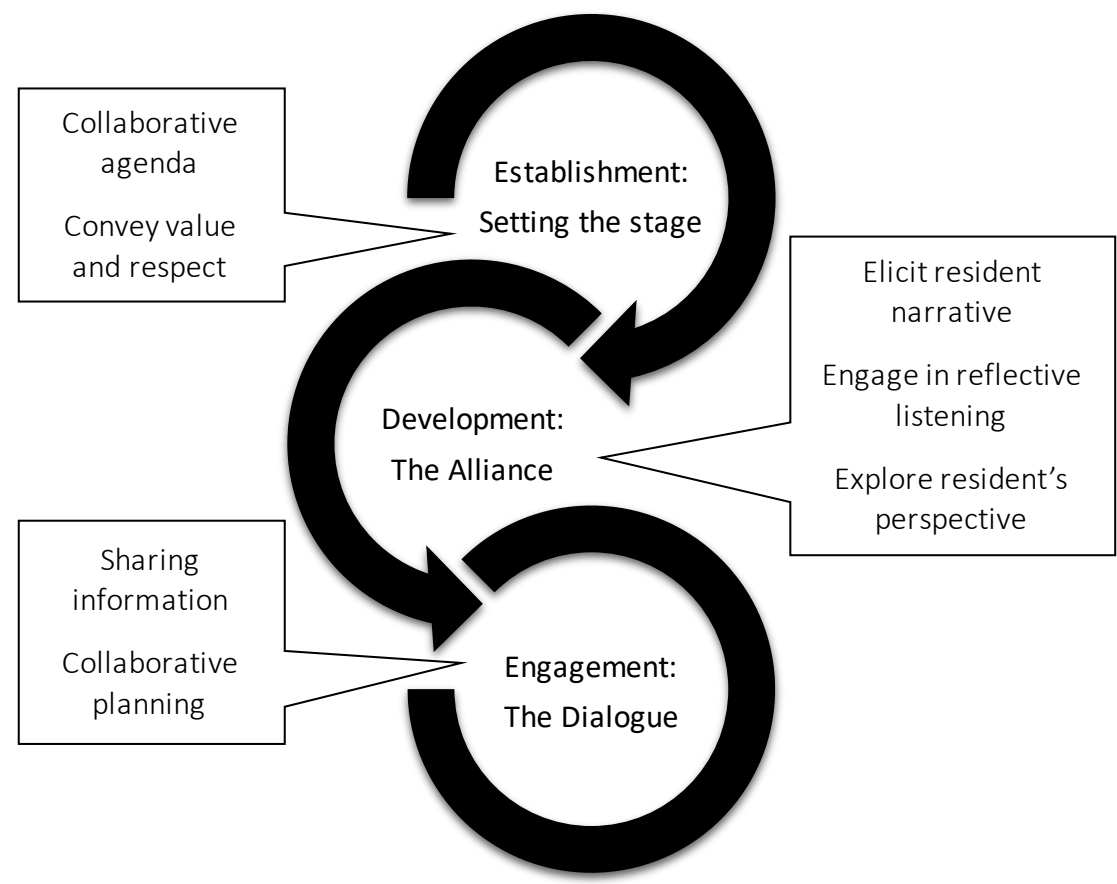

Figure 2: Application of a relationship-centred communication skills framework to feedback conversations: stages and strategies

Description of each theme begins with investigator interpretations of behaviours from observations, field notes and debriefing interviews. These are backed by representative quotes from faculty (abbreviated as F) and residents ( $R$ ). 


\section{It's all about the relationship}

There was evidence of a congenial working relationship during all conversations exemplified by references to what they had been working on previously, prior discussions on learning goals and action plans. This impression was confirmed by emphasis by all preceptors and residents regarding the value of longitudinal relationships which allowed them to get to know each other and establish a comfortable environment in which strengths and deficiencies in performance could be discussed in a non-threatening way.

We've worked together a lot, and that made it very easy for me to ask her to do this observation and, hopefully, made her feel more comfortable in doing it. I hope we will do it more even when you do not encourage it because l enjoyed just seeing her in clinic and unwrapping that mystery. (F4)

One resident, however, wondered whether it would be emotionally difficult to hear something harsh from a faculty she knew well.

She knows me well, so I think the feedback is reliable. I think it might be hard to get something horrible coming from someone who knows you well and who you like. But, in terms of just saying this is what you could do better, and giving really actionable pointers, I think that it's nice coming from someone who's seen you do a lot of stuff and knows how you work very well. (R6)

Within the central theme of relationships, we identified subthemes related to specific behaviours and strategies used by preceptors and residents, categorised under each phase of the REDE relationship-centred communications framework.

\section{Phase 1- Establishment: Set the stage}

The two key strategies under relationship establishment included setting a collaborative agenda, and conveying value and respect. We labelled the themes under these strategies as: plan and observe; and motivate and validate. Observed behaviours included preceptors nodding when residents described their challenges, maintaining eye contact, leaning forward and listening. We interpreted smiles, nods, eye contact with the preceptor and asking the preceptor for suggestions to improve as evidence of ease on the part of residents. We confirmed these impressions during the debriefing interviews.

\section{Collaborative agenda: Plan and observe}

Preceptors usually observe segments of resident-patient interactions, but for this conversation, all of them chose to observe a complete resident-patient encounter using specific examples to frame their feedback. It should be emphasised that SR did not suggest or recommend direct observation of residents during any communication. This process allowed preceptors and residents to formulate a collaborative agenda for the feedback 
conversation. All preceptors stated that the upcoming observation of their feedback conversation prompted deeper reflections about its content and take home messages for residents.

Where it helped me is planning ahead of time, like picking a patient where she had specifically asked me to observe... it was the approach to a challenging patient because she knew going in that it may be a difficult encounter. It allowed me to pick up just those pieces. (F4)

Notifying residents ahead of time about the planned feedback conversation allowed them to formulate specific learning goals and challenges to discuss with their preceptors.

It gave me an opportunity to start to try to critically think about my performance and ways that I can provide better care for patients, things that I am doing well, and areas that, as we all have, areas to improve in. (R1)

\section{Convey value and respect: Motivate and validate}

Motivating residents in their professional growth seemed an important goal for all preceptors and some preceptors raised this specifically during debriefing.

He has a very good skill set, a really good attitude and style. Very promising. I'm thinking of him as someone where I want to encourage him, and I want to motivate him to say, how can he be getting more out of the experience? How can he be broadening what he's doing? (F5)

While preceptors wished to reinforce their residents' strengths and encourage them to continue effective patient care strategies, all of them highlighted areas for improvement. Preceptors stated that even outstanding residents, have areas that need improvement and discussion of these was essential to maximising their potential.

What it forced me to do is to not fall into the trap for the people who look very promising of saying, "You're doing great. Aren't you great?" Pat, pat on the back, and off you go. (F1)

Despite the emphasis on areas for further improvement, all preceptors ended the conversation on a happy note and concluded with recounting resident strengths. They stated that it was important for residents to leave with enhanced self-efficacy.

I think he's doing extremely well, and so I wanted to make sure he knew that overall, he's doing well, which hopefully, I conveyed to him. (F3)

The compulsion to ensure resident self-efficacy sometimes stopped preceptors from giving additional constructive feedback on deficiencies. This was observed as an expression of discomfort on their face, looking down at their notes from their resident observations, 
hesitating a little, folding up the paper and returning to reinforcing feedback. This interpretation was confirmed during the debriefing.

I think she wouldn't have been ready for it. You are so fragile at that stage of training (I was) that I'm not sure I would have said more. Yeah. I think I don't know if I would have wanted to go further or be harsher about some of the gaps I perceived. I think signalling to her that there have been some gaps in her history taking, for example, I think felt like enough. (F3)

Overall, establishing a relationship set the stage for effective feedback dialogue. Preceptors stated that a full observation was helpful in calibrating and discussing residents' performance, and residents found specific examples useful in making action plans. Residents formulated specific learning goals, reflected on their strengths and weaknesses and discussed these with their preceptors, which they stated did not happen often enough. Ensuring resident self-efficacy and ending the conversation on a positive note appeared to be an important goal for preceptors.

\section{Phase 2- Development: The alliance}

An educational alliance between preceptors and residents was observed in all interactions. This was exemplified by verbal and non-verbal behaviours that indicated rapport, such as relaxed appearance despite SR's presence, smiling at each other, nodding, eye contact, open-ended questions from the preceptor, residents' ease in discussing their challenges and deficiencies, preceptors checking for agreement several times during the conversation, and shared decision making about action plans.

The three strategies under this phase include: eliciting resident narrative, engaging in reflective listening and exploring residents' perspective. The themes identified under each strategy were: provide a safe space; listen, respond and redirect; and an invitation to selfreflect.

\section{Elicit resident narrative: Provide a safe space}

Conversations typically started with a question on how residents felt overall about the patient encounter. Residents readily expressed their frustrations if the encounter had been challenging. The questions posed by preceptors appeared to be a genuine invitation to express their reaction, this was confirmed by residents' statements that their preceptors were genuinely supportive and provided a safe environment to discuss their challenges.

Just feel comfortable with her. I find that she's thorough but at the same time she's just easy to feel at ease with. The stuff she doesn't know she says, "I don't know." I feel that when someone is just honest about their limitations it makes you feel more comfortable. (R3) 


\section{Engage in reflective listening: Listen, respond and redirect}

Preceptors asked several open-ended questions, which allowed residents to reflect on their clinical performance overall and greatest challenges. Residents appreciated the listening skills of their preceptors, particularly when the preceptor responded to the points raised and closed the loop.

Reasons why I think it went well, most of it was Dr... listening, so I really got a chance to explore my own performance, and then he took the opportunity to respond to the points that I made. (R1)

Some preceptors, however, found it difficult to redirect the resident and focus on their learning goals.

I think she ended up steering the conversation quite a bit. Which has ups and downs. I think maybe we ended up not being clear enough in terms of what I think the real issue was with her history taking. (F3)

\section{Explore residents' perspective: The diagnostic self-reflection}

Most preceptors initiated conversations by asking residents what they thought they did well and what they found challenging. Residents used this opportunity to critically appraise their performance, reflect on their strengths and areas for improvement. Preceptors used self-reflection to launch constructive feedback discussions. A sense of relief was observed on preceptors' expressions when residents brought up areas for improvement. Self-reflection was also used to assess the resident's level of insight into their performance.

You can learn something about where they think they are. People, especially highly accomplished people, are good at putting up a good front. Letting them talk first, letting them run a little... (F1)

Residents used the invitation to articulate specific goals and contribute meaningfully to the conversation about their performance.

It was nice to start with an invitation for what I thought. I think it also helped prime her (preceptor)too, if I had basically agreed with everything she thought, then, maybe she'll feel more comfortable delivering it. (R2)

In developing the relationship, all preceptors provided a safe space for residents to discuss challenges and deficiencies. They used self-reflection by residents as an opening gambit, which helped them not only to learn about residents' challenges and exchange feedback specific to those challenges, but also to gauge their capacity to accurately selfassess. 


\section{Phase 3-Engagement: The dialogue}

The process of engagement was exemplified by strategies for sharing information, and collaborative planning. Key themes identified under each strategy included: making it about a skill or action; and a game plan for growth.

\section{Share information: Make it about a skill or action}

Most preceptors used concrete examples from the patient encounter as a basis of information exchange, especially in providing constructive feedback. Most checked to see if the residents agreed or disagreed with the information and allowed them to share their perspective on the context of the encounter. A few used vague, "what do you think", rather than specific questions.

You need to find a way to make it about a skill or an action. "Gee, when you said X to the patient, it seemed like they got a little confused." Then again, you add more detail. "It seemed like Miss Smith was confused when you tried to explain how to change her insulin. Are there other ways to...." and trying to draw them out about those deficiencies. (F6)

Residents stated that while positive feedback was nice to hear and validated their strengths, constructive feedback was essential to promote professional growth.

I think one of the things in feedback that is often missing is that-the general feedback that I've had is-one is, "You're doing a great job," which is nice to hear, but I'm a three-month-old intern. I know I have a lot of things I can improve on. (R1)

Hearing constructive feedback almost always produced an emotional reaction that they had done something wrong. This was observed as a change in expression from smiling to serious, widening of eyes, or a look of surprise when it was unexpected. But residents were mostly appreciative of hearing where they could develop further. Supportive faculty, specificity of feedback with examples of their own words and behaviours during patient interactions, and the tone in which it was delivered promoted acceptance.

There's this visceral feeling when you want to do everything right, that all of a sudden you have this area of constructive feedback like, "Oh, I'm doing something wrong," but I think I've come to the realization, it's not a bad thing that I will always have things I need to improve in. (R2)

I also really appreciate how she had constructive, very specific feedback, not just general comments, but exact moments that she captured in time, that supported things I could do better next time. I think it was gently delivered, which is nice. (R5) 


\section{Collaborative planning: A game plan for growth}

All feedback conversations included a 'game plan' for growth, as termed by one resident. Some preceptors were comfortable having residents initiate these plans, while others tended to provide their recommendations first and then checked in with residents. Most preceptors and residents closed the conversation by summarising action plans and discussing next steps.

I felt like that was how the session with her (preceptor), which I think is the most useful, which is a small number of things are talked about, a plan is made on how to change them, and then what we're going to do moving forward with that plan. (R6)

Sometimes the action plans were not clearly outlined beyond a vague mention of an aspect of performance could be improved.

It was discussed but not perhaps very concretely, but I still think that the things she gave me as feedback were very actionable items. I don't know if I reset new goals for next session, though. (R3)

Pertaining to the engagement phase, all preceptors used self-reflection to frame constructive feedback. A few pairs co-constructed future learning opportunities to enact these plans, but not all. Some faculty closed the conversation with a summary of performance areas that could improve and checked for resident agreement, but did not discuss how and when to enact these plans.

\section{Discussion}

In this study, we explored how residents and their continuity clinic preceptors structured and acted during feedback conversations, through the lens of relationship-centred communication. Data from investigator observations as well as faculty and resident debriefing were used to construct meaning. The results of this study advance previous knowledge regarding sociocultural influences on feedback by providing unique insights into the actions and behaviours of participants in a real-life feedback conversation, and examines in greater depth the first R (relationship) of the R2C2 model. ${ }^{21,33}$ Our participants stated that longitudinal relationships allowed faculty and residents to get to know each other, interact in a safe space, freely discuss challenges in performance, and facilitate exchange and acceptance of constructive feedback. Faculty typically observe segments of resident-patient encounters, but for this exercise, they spontaneously chose to perform direct observation of a full resident-patient encounter. They stated that data and examples from a full encounter helped them frame the feedback and exchange more meaningful feedback. Additionally, faculty and residents admitted that while they frequently exchanged brief on-the-fly feedback on specific patient care issues, they rarely sat down for formal 
feedback exchanges. Facilitating resident self-reflection on performance allowed faculty to be aware of residents' challenges and fears, target their performance observation, and gain insights into residents' ability to self-assess. Although all conversations included discussion of action plans for improvement, these plans were not always clear and did not consistently include concrete next steps to try new behaviours. Finally, although preceptors and residents were keen to discuss constructive feedback that facilitated improvement and growth, they were greatly desirous of residents leaving the conversation happy and with enhanced self-efficacy.

With teacher-learner relationships taking centre-stage, we explored perceptions regarding impact of longitudinal teacher-learner relationships on acceptance and incorporation of constructive feedback. Our residents' comfort in discussing challenges and 'deficiencies', seemed to stem from collegial and longitudinal relationships with preceptors, trust in their judgment and conviction about faculty investment in their growth. Continuity clinics could provide a unique setting to foster relationships, allow faculty to watch residents develop over time, and create feedback loops where action plans can be implemented. It has been reported that short rotations with limited faculty-resident interactions lead to infrequent direct observation of performance, ${ }^{42,43}$ and longitudinal teacherlearner relationships enhance perceived credibility of feedback. ${ }^{16,18}$ Since feedback is only truly effective when it leads to recipient behaviour change, ${ }^{3,14}$ it is essential that institutions examine and address factors to enhance the credibility of feedback provided and its acceptance by learners. ${ }^{12,19,29,44}$

Trusting relationships can in turn promote formation of effective educational alliances. Overall, most of our participants seemed to spontaneously adopt strategies emphasised by learner-centred feedback models, such as rapport, a safe learning environment, resident self-reflection, concrete next steps and co-constructing learning opportunities. ${ }^{4,13,15,21,32,33}$ Newer feedback models, such as the R2C2 model by Sargeant and colleagues, ${ }^{21,22,33}$ the educational alliance by Telio et al., modelled on the therapeutic alliance model, ${ }^{4,13}$ and the feedback tango model by Bing-You and colleagues, ${ }^{15}$ place learners at the heart of a feedback conversation, seeking goal-directed feedback and initiating action plans for improvement As observed in our study, congenial feedback conversations can occur when teachers facilitate self-reflection, allow learners to discuss their challenges, acknowledge the challenges of the clinical context and coach their learners targeting behaviour change and performance growth. 4,13,15,21,32

Specific faculty behaviours that appeared to promote acceptance and incorporation of constructive feedback included facilitated self-reflection of performance, use of selfreflection as a launching pad for constructive feedback, use of specific examples from the patient encounter, and collaborative formulation of action plans. These behaviours seemed to be effective in ensuring resident agreement and defusing emotion. Sargeant et al. have performed elegant research into emotional responses that are unleashed during feedback conversations and how they influence feedback acceptance or rejection. ${ }^{29,45}$ While the ECO model (emotions, content, outcomes), ${ }^{29}$ started the discussion on how the 
influence of emotions on the content and outcome of such conversations, the R2C2 model $21,32,33$ has greatly expanded understanding of the impact of relationships, emotion and coaching strategies on feedback acceptance, behaviour change and growth. Though our faculty were unaware of the newer models of feedback, they seemed to gravitate to these behaviours naturally. We postulate that relationship-centred communication styles may be natural to clinicians in primary care settings where therapeutic relationships and communication skills are fundamental.

Though all six of our preceptors used relationship-centred communication skills and created a safe space for residents, not all faculty were equally skilled communicators. ${ }^{46}$ Some were more comfortable with silence and allowed residents to initiate and lead the discussion of goals, challenges and action plans; others did not wait long enough before providing their own impressions and recommendations. As teachers continue to develop professionally and engage in increasingly complex learner interactions, they need to develop holistic and flexible communication styles. ${ }^{46}$ This includes deciding what techniques are appropriate to a given context, learning to adapt their approach for different learners even on the fly, and understanding that skilled communication is inherently a creative phenomenon. ${ }^{46,47}$ Skilled communicators are also more likely to involve advanced learners such as residents in co-constructing the learning environment and learning opportunities. ${ }^{48-50}$

\section{Limitations}

This study has a few limitations that need to be discussed. The inquiry was based at a single residency program, and our interpretations may not be directly transferable to other training programs and/or institutions. Our participants were a small sample of a larger faculty and resident population, and we may not have captured a full range of opinions. Non-participants might have hesitated to participate due to shyness at being videotaped, insecurity about their feedback skills, contrasting viewpoints about teacherlearner relationships, or variable feedback practices. All feedback conversations in this study were preceded by direct observations of full resident-patient encounters, but preceptors typically observe short segments of resident-patient encounters. Thus, there was a change from their usual practice. The presence of a peer observer could have changed the dynamics of the conversation with resulting change in participant behaviours. Moreover, our study was limited to continuity clinic settings, such conversations are bound to have a different scope and different challenges in other clinical settings, and more so in different departments. Finally, we did not study the process of on-the-fly feedback exchanges, which are brief conversations focussing on one or two specific performance domains immediately after completion of a task. Thus, the above themes should be applied to the more informal, brief conversations with caution.

To ensure rigor, our data sources were triangulated, themes were finalised after multiple team discussions to ensure that the discovered themes were not guided by a single 
investigator's assumptions or biases, and data interpretations were verified through member checking. Our context is typical of continuity clinic settings in large medicine residency programs and the findings are potentially transferable to similar postgraduate education settings.

\section{Suggestions for further research}

A reflexive ethnographic approach provided interesting insights into verbal and non-verbal behaviours during feedback conversations and educational alliances between faculty and residents. More research is needed on whether behaviours are consistent across all types of feedback settings- short, on-the-fly feedback or longer, formal feedback, whether observed or unobserved. Similar research inquiries are needed to examine learner-centred feedback practices in a variety of departments at multiple institutions, as the results of this study cannot be directly applied to all medical education settings. Finally, it is essential to study whether feedback initiatives that place focus on teacherlearner relationships lead to behaviour change.

\section{Conclusions}

Extending the insights gained from the R2C2 model, our findings support the premise that relationship-centred communication strategies can stimulate meaningful feedback conversations between clinical supervisors and trainees and enhance its quality and impact. We hypothesise that trusting and supportive teacher-learner relationships should form the foundation on which feedback conversations are based, for feedback to be received, accepted and incorporated and lead to behaviour change. 


\section{REFERENCES}

1. Delva D, Sargeant J, MacLeod T. Feedback: a perennial problem. Med Teach 2011;33:861-2.

2. Cantillon P, Sargeant J. Giving feedback in clinical settings. BMJ 2008;337:a1961.

3. Boud D. Feedback: ensuring that it leads to enhanced learning. Clin Teach 2015;12:3-7.

4. Telio S, Ajjawi R, Regehr G. The "educational alliance" as a framework for reconceptualizing feedback in medical education. Acad Med 2015;90:609-14.

5. Perera J, Lee N, Win K, Wijesuriya L. Formative feedback to students: the mismatch between faculty perceptions and student expectations. Med Teach 2008;30:395-9.

6. Branch WT, Jr., Paranjape A. Feedback and reflection: teaching methods for clinical settings. Acad Med 2002;77:1185-8.

7. Mazor KM, Holtman MC, Shchukin Y, Mee J, Katsufrakis PJ. The relationship between direct observation, knowledge, and feedback: results of a national survey. Acad Med 2011;86:S63-7; quiz S8.

8. Bing-You RG, Paterson J, Levine MA. Feedback falling on deaf ears: residents' receptivity to feedback tempered by sender credibility. Medical Teacher 1997;19:40-4.

9. Finn AN, Paul Schrodt P, Witt PL, Elledge N, Jernberg KA, Larson LM. A meta-analytical review of teacher credibility and its associations with teacher behaviors and student outcomes. Commun Educ 2008;60:75-94.

10. van de Ridder JM, Berk FC, Stokking KM, Ten Cate OT. Feedback providers' credibility impacts students' satisfaction with feedback and delayed performance. Med Teach 2014:1-8.

11. Watling C, Driessen $E$, van der Vleuten CP, Lingard L. Learning from clinical work: the roles of learning cues and credibility judgements. Med Educ 2012;46:192-200.

12. Sargeant J, Mann K, Ferrier S. Exploring family physicians' reactions to multisource feedback: perceptions of credibility and usefulness. Med Educ 2005;39:497-504.

13. Telio S, Regehr G, Ajjawi R. Feedback and the educational alliance: examining credibility judgements and their consequences. Med Educ 2016;50:933-42.

14. Molloy E, Boud D. Seeking a different angle on feedback in clinical education: the learner as seeker, judge and user of performance information. Med Educ 2013;47:227-9.

15. Bing-You R, Varaklis K, Hayes V, Trowbridge R, Kemp H, McKelvy D. The Feedback Tango: An Integrative Review and Analysis of the Content of the Teacher-Learner Feedback Exchange. Acad Med 2017.

16. Watling C. Cognition, culture, and credibility: deconstructing feedback in medical education. Perspect Med Educ 2014;3:124-8.

17. Watling C, Driessen E, van der Vleuten CP, Lingard L. Learning culture and feedback: an international study of medical athletes and musicians. Med Educ 2014;48:713-23.

18. Watling $C$, Driessen $E$, van der Vleuten $C P$, Vanstone $M$, Lingard L. Beyond individualism: professional culture and its influence on feedback. Med Educ 2013;47:585-94.

19. Watling CJ. Unfulfilled promise, untapped potential: feedback at the crossroads. Med Teach 2014;36:692-7.

20. Ramani S, Post SE, Konings K, Mann K, Katz JT, van der Vleuten C. "It's Just Not the Culture": A Qualitative Study Exploring Residents' Perceptions of the Impact of Institutional Culture on Feedback. Teach Learn Med 2016:1-9.

21. Sargeant J, Lockyer J, Mann K, et al. Facilitated Reflective Performance Feedback: Developing an Evidenceand Theory-Based Model That Builds Relationship, Explores Reactions and Content, and Coaches for Performance Change (R2C2). Acad Med 2015;90:1698-706.

22. Bing-You RG, Trowbridge RL. Why medical educators may be failing at feedback. JAMA 2009;302:1330-1.

23. Anderson PA. Giving feedback on clinical skills: are we starving our young? J Grad Med Educ 2012;4:154-8.

24. Ramani S, Post SE, Konings K, Mann K, Katz JT, van der Vleuten C. "It's Just Not the Culture": A Qualitative Study Exploring Residents' Perceptions of the Impact of Institutional Culture on Feedback. Teach Learn Med 2017;29:153-61.

25. Ramani S, Konings KD, Mann KV, Pisarski EE, van der Vleuten CPM. About Politeness, Face, and Feedback: Exploring Resident and Faculty Perceptions of How Institutional Feedback Culture Influences Feedback Practices. Acad Med 2018. 
26. Eva $\mathrm{KW}$, Armson $\mathrm{H}$, Holmboe $\mathrm{E}$, et al. Factors influencing responsiveness to feedback: on the interplay between fear, confidence, and reasoning processes. Adv Health Sci Educ Theory Pract 2012;17:15-26.

27. Mann K, van der Vleuten C, Eva K, et al. Tensions in informed self-assessment: how the desire for feedback and reticence to collect and use it can conflict. Acad Med 2011;86:1120-7.

28. Sargeant J, Armson $H$, Chesluk B, et al. The processes and dimensions of informed self-assessment: a conceptual model. Acad Med 2010;85:1212-20.

29. Sargeant J, McNaughton E, Mercer S, Murphy D, Sullivan P, Bruce DA. Providing feedback: exploring a model (emotion, content, outcomes) for facilitating multisource feedback. Med Teach 2011;33:744-9.

30. Sargeant JM, Mann KV, van der Vleuten CP, Metsemakers JF. Reflection: a link between receiving and using assessment feedback. Adv Health Sci Educ Theory Pract 2009;14:399-410.

31. Dudek NL, Dojeiji S, Day K, Varpio L. Feedback to Supervisors: Is Anonymity Really So Important? Acad Med 2016;91:1305-12.

32. Sargeant J, Mann K, Manos S, et al. R2C2 in Action: Testing an Evidence-Based Model to Facilitate Feedback and Coaching in Residency. J Grad Med Educ 2017;9:165-70.

33. Sargeant J, Lockyer JM, Mann K, et al. The R2C2 Model in Residency Education: How Does It Foster Coaching and Promote Feedback Use? Acad Med 2018.

34. Wolcott HF. Ethnography : a way of seeing. 2nd ed. Lanham, MD: Altamira Press; 2008.

35. Hockings P. Principles of visual anthropology. 2nd ed. Berlin ; New York: Mouton de Gruyter; 1995.

36. Urquhart LM, Ker JS, Rees CE. Exploring the influence of context on feedback at medical school: a videoethnography study. Adv Health Sci Educ Theory Pract 2018;23:159-86.

37. ledema R, Mesman J, Carroll K. Visualising health care practice improvement : innovation from within. London ; New York: Radcliffe Pub.; 2013.

38. Shaw JA. Reflexivity and the "Acting Subject": Conceptualizing the Unit of Analysis in Qualitative Health Research. Qual Health Res 2016.

39. Steen M. Virtues in participatory design: cooperation, curiosity, creativity, empowerment and reflexivity. Sci Eng Ethics 2013;19:945-62.

40. Brockmann M. Problematising short-term participant observation and multi-method ethnographic studies. Ethnography and Education 2011;6:229-43.

41. Windover AK, Boissy A, Rice TW, Gilligan T, Velez VJ, Merlino J. The REDE Model of Healthcare Communication: Optimizing Relationship as a Therapeutic Agent. J Patient Exp 2014;1:8-13.

42. Holmboe E, Ginsburg S, Bernabeo E. The rotational approach to medical education: time to confront our assumptions? Med Educ 2011;45:69-80.

43. Bernabeo EC, Holtman MC, Ginsburg S, Rosenbaum JR, Holmboe ES. Lost in transition: the experience and impact of frequent changes in the inpatient learning environment. Acad Med 2011;86:591-8.

44. Ross S, Dudek N, Halman S, Humphrey-Murto S. Context, time, and building relationships: bringing in situ feedback into the conversation. Med Educ 2016;50:893-5.

45. Sargeant J, Mann K, Sinclair D, Van der Vleuten C, Metsemakers J. Understanding the influence of emotions and reflection upon multi-source feedback acceptance and use. Adv Health Sci Educ Theory Pract 2008;13:275-88.

46. Salmon P, Young B. Creativity in clinical communication: from communication skills to skilled communication. Med Educ 2011;45:217-26.

47. Salmon P, Young B. A new paradigm for clinical communication: critical review of literature in cancer care. Med Educ 2017;51:258-68.

48. Könings KD, Seidel T, van Merriënboer JJG. Participatory design of learning environments: integrating perspectives of students, teachers, and designers. Instr Sci 2014;42:1-9.

49. Könings KD, Brand-Gruwel S, van Merriënboer JJG. Towards more powerful learning environments through combining the perspectives of designers, teachers, and students. Br J Educ Psychol 2005;75:645-60.

50. Rich JV. Proposing a Model of Co-Regulated Learning for Graduate Medical Education. Acad Med 2017;92:1100-4. 


\section{Chapter}

\section{Twelve Tips To Promote A Feedback Culture With A Growth Mind-Set: Swinging the feedback pendulum from recipes to relationships}

Published as: Ramani S, Könings K, Ginsburg, S, van der Vleuten CPM. Twelve tips to promote a feedback culture with a growth mind-set: Swinging the feedback pendulum from recipes to relationships. Med Teach. 2018 Feb 7. [Epub ahead of print] 


\section{Abstract}

Feedback in medical education has traditionally showcased techniques and skills of giving feedback, and models used in staff development have focussed on feedback providers (teachers) not receivers (learners). More recent definitions have questioned this approach, arguing that the impact of feedback lies in learner acceptance and assimilation of feedback with improvement in practice and professional growth. Over the last decade, research findings have emphasised that feedback conversations are complex interpersonal interactions influenced by a multitude of sociocultural factors. However, feedback culture is a concept that is challenging to define, thus strategies to enhance culture are difficult to pin down. In this twelve tips paper, we have attempted to define elements that constitute a feedback culture from four different perspectives and describe distinct strategies that can be used to foster a learning culture with a growth mind-set. 


\section{Introduction}

Newer definitions of effective feedback emphasise learner self-assessment, behaviour change and professional growth. ${ }^{1-5}$ Feedback training initiatives are gradually shifting away from provider technique-focussed approaches to receiver goals and impact-focussed approaches. ${ }^{6-8}$ Yet, teachers and learners may not agree on the adequacy and quality of feedback, with learners frequently reporting vague and non-actionable faculty feedback even when faculty believe they have provided meaningful and specific feedback. ${ }^{2,9-11}$ Faculty also hesitate to provide 'negative' feedback to avoid hurting learners' feelings and self-esteem; this could result in feedback that is not goal-directed or actionable. ${ }^{11-14}$ If the knowledge gained through research studies is not communicated to feedback receivers and providers, this could lead to a mismatch between what is known and what occurs in real-life.

Over the last decade, medical educators have begun to place greater emphasis on the influence of sociocultural factors, such as relationships, perceptions of credibility and institutional learning culture on the content of the conversation and learner receptivity to feedback. ${ }^{13,15,16}$ Telio et al. proposed that effective feedback interactions require an educational alliance between teachers and learners with a strong learner involvement in the process. $^{8,17}$ Sargeant et al. described the R2C2 model (relationship, reaction, content and coaching) emphasising full learner engagement in the feedback conversation. ${ }^{7,18,19}$ Relationships and learner engagement would enhance the credibility of feedback provided. Watling and colleagues reported that the learning culture of medicine is dominated by focus on autonomy and lack of performance observation, in contrast to the culture of music or sports. ${ }^{20-22}$ While an institutional culture of politeness is conducive to learning and collegial work; it could hinder honest narrative comments on evaluations and constructive feedback. ${ }^{10,23,24}$ The learning culture at institutions needs to be understood and addressed before instituting feedback initiatives aimed at bidirectional professional development.

The three levels of organisational culture described by Schein are applicable to the feedback culture in medical education. ${ }^{25}$ The deepest level refers to unwritten values and assumptions of how the organisation is viewed by the outside world (that's the way things are done here). The mid-level refers to written values and expectations such as mission statements and curricular documents. The visible level is characterised by how its members behave day to day to maintain the image presented to the world. These behaviours are influenced by practical realities and needs of daily life, and may even contradict assumptions and values. Each level, as it relates to feedback alliances, would need to be dissected and understood, and facilitators and barriers identified before successful staff development can be designed and implemented.

In this paper, we have reviewed the latest research which redefines feedback as a sociocultural process and generated practical strategies that teachers, learners as well as institutions can adopt to promote feedback aimed at professional development. The fol- 
lowing twelve tips to enhance the feedback culture are informed by our research exploring the impact of institutional culture on feedback in a postgraduate training programme, ${ }^{10,11,26}$ supplemented by a comprehensive review of recent literature, as well as our collective experience in staff development related to feedback training. We classify these tips focusing on the sociocultural aspects of feedback under four key categories related to: Feedback providers, Feedback recipients, Feedback relationships, and Institutional context, these are depicted in Figure 1. Under each category, individual strategies are described in detail with a view to enhancing the culture of feedback and emphasising a growth mind-set among teachers and learners.

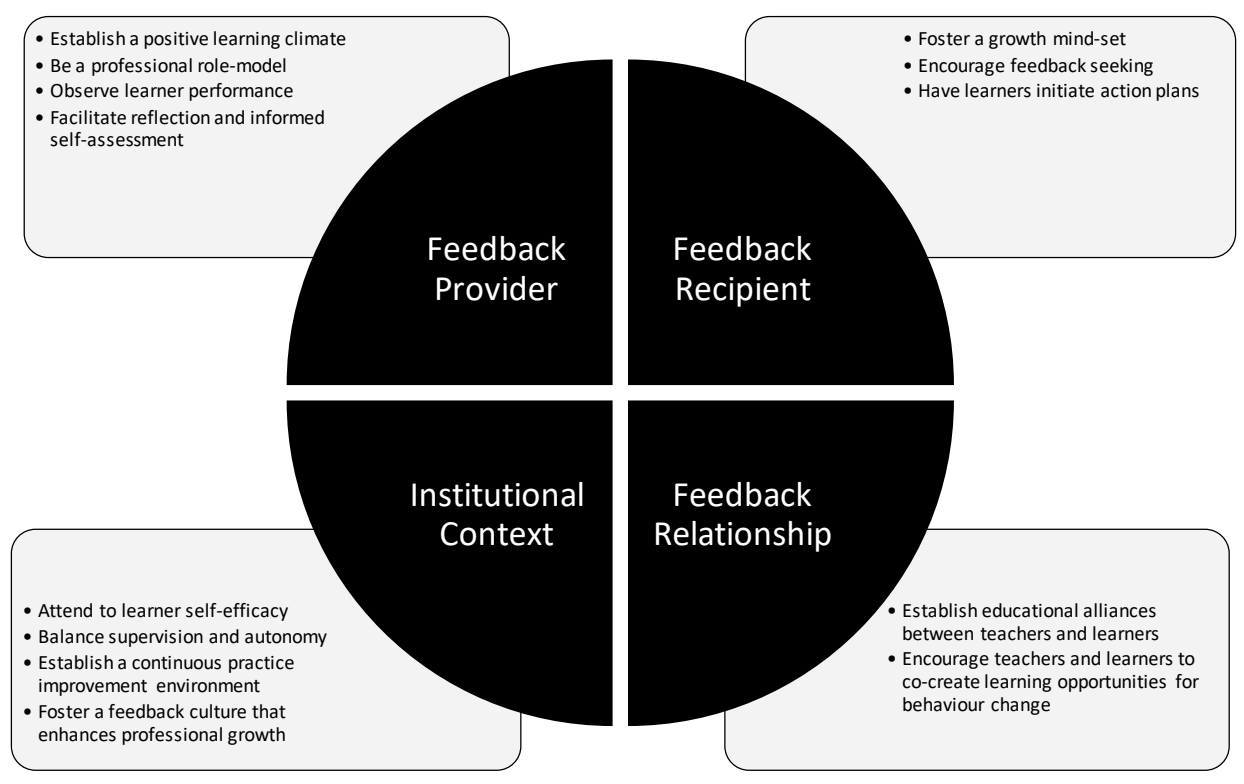

Figure 1: Establishing a feedback culture with a growth mind-set: strategies from multiple perspectives

\section{Feedback Providers}

The following strategies could enhance the credibility and acceptability of feedback data, and potentially lead to behaviour change and performance improvement. Though teacher-initiated, these strategies aim to improve the overall feedback culture rather than specific skills of feedback provision.

\section{Tip 1- Establish a positive learning climate and be a professional role-model}

Many teachers and learners react to upcoming feedback conversations with trepidation. Feedback providers can alleviate some of this negativity by proactively establishing a positive learning climate and setting expectations that they would facilitate frequent, formative feedback conversations that focus on goals and observed performance. Even if the 
duration of the working relationship is short, establishing a congenial learning environment could lead to more productive feedback conversations. When teachers serve as role-models in demonstrating respect for all, willingness to welcome multiple opinions, and readiness to admit own limitations and errors, this would set the stage for growthenhancing feedback and thus more acceptable to learners. ${ }^{27,28}$ The concept of two-way feedback conversations can also be discussed, emphasising teachers' openness to receiving feedback from learners.

\section{Tip 2- Use direct observation of performance to generate feedback data}

Learners' perception of the credibility of feedback can be influenced by several factors including the source of feedback, their relationship with the feedback provider, the manner of its communication, and congruence with their own self-assessment. ${ }^{13,20,29}$ Direct observation of performance appears to be one significant determinant of credibility. Clinical learners are rarely observed by faculty during their interactions with patients or staff. ${ }^{30,31}$ In contrast to the coaching culture in music or sports, clinical teachers often accept the accuracy of learner case presentations without direct observation of data gathering, particularly from more senior learners. ${ }^{21,29,32}$ It is important that clinical teachers observe their learners directly and frequently, and provide specific feedback on performance, thus enhancing learners' perception of its credibility.

\section{Tip 3- Facilitate reflection and informed self-assessment}

Learners tend to reject feedback that conflicts with their self-assessment; however, unguided self-assessment is fraught with inaccuracies in calibration of own performance. ${ }^{16,33}$ Educational experts have argued that external data from multiple sources should be combined with self-reflection for accurate self-appraisal. ${ }^{13,34-36}$ Additionally, initiating conversations with self-assessment can help teachers to diagnose learners' insights (or lack of) into their strengths and weaknesses, and serve as a starting point for reinforcing as well as constructive feedback.

The Johari window, a framework described by psychologists to enhance self-awareness in interpersonal communications, can serve as a robust model for feedback conversations. ${ }^{37}$ The window consists of four quadrants, with varying levels of awareness of behaviours: (1) what is known to self and others (open), (2) unknown to self but known to others (blind), (3) known to self and unknown to others (hidden), and (4) unknown to self and others (unknown). Applying this model to feedback: reinforcing strengths and enhancing self-efficacy can expand the open quadrant; promoting a learning goal-orientation and feedback seeking can address the blind quadrant; building educational alliances and trusting relationships can narrow the hidden quadrant; and stimulating a spirit of self-discovery can shrink the unknown quadrant. ${ }^{26}$ 


\section{Feedback Recipients}

The following three tips would help stimulate a growth mind-set among learners. By encouraging this mind-set and providing training in these learner-initiated strategies. institutions can promote a culture where learners accept and assimilate feedback.

\section{Tip 4- Foster a growth mind-set among learners}

Two types of mind-sets have been described by Dweck, a fixed mind-set and a growth mind-set. ${ }^{38,39}$ Learners with a fixed mind-set believe that success is driven by innate ability, perceive failure as a negative statement of their abilities and tend to reject constructive feedback. Learners with a growth mind-set believe that success results from hard work, learning, training, and ongoing learning, and that learning comes from failure. A growth mind-set would allow learners to engage in feedback seeking, be more receptive to constructive feedback, and incorporate feedback into daily performance. Teachers have an important role to play in stimulating a growth mind-set by using language that focuses on performance (e.g. a teacher might say, "it might be easier to feel hepatomegaly or hear a systolic murmur if you used the following technique") rather than words that simply praise or judge (e.g. "excellent job, poor patient communication"). Institutions should encourage a growth mind-set by normalising constructive feedback, prioritising professional development at all levels, and providing training in receiving and assimilating feedback into performance.

\section{Tip 5- Encourage feedback seeking behaviour}

Learners can gain awareness of their strengths and areas needing improvement through active feedback-seeking which helps in calibrating the gap between their current performance and desired performance. ${ }^{40}$ Feedback-seeking behaviour can be influenced by goal orientation of individuals. ${ }^{41-44}$ Professionals with a performance goal-orientation focus on performance that creates a good impression, and may not welcome feedback that might reveal limitations and threaten their image. This tendency has been referred to as 'playing the game'. ${ }^{45}$ On the other hand, professionals with a learning goal-orientation focus on achieving mastery in their field, and are more likely to seek and accept constructive feedback that helps them grow. Institutions can foster a learning goal-orientation among all levels of learners by setting explicit expectations for continuing learning and improvement, providing training on establishing specific learning goals, and seeking specific goal-directed feedback.

\section{Tip 6-Promote learner initiated action plans for behaviour change}

Medical learners state that feedback from their teachers is often not 'actionable' and a typical feedback conversation does not conclude with a performance improvement plan. ${ }^{2,9-11}$ Even if teachers recommend specific action plans, it cannot be assumed that learners would change their practice. Behaviour change is more likely if adult learners 
formulate their own learning goals, communicate these to their teachers, calibrate where they are in terms of these goals and describe steps to achieve these goals. As adult learners and future reflective practitioners, action plans are best initiated by learners for performance improvement. These strategies described are more consistent with newer conceptualisations of feedback which emphasise impact on learners rather than how it is provided. ${ }^{4}$

\section{The Feedback Relationship}

While numerous factors can impact a teacher-learner relationship, we focus on two key approaches to enhance feedback relationships. Each tip comprises multiple smaller steps that teachers, learners and institutions can employ in building effective relationships between teachers and learners.

\section{Tip 7- Establish an educational alliance}

Feedback conversations are complex interpersonal communications rather than simple one-way exchanges. ${ }^{2,3,14,16,22,46,47}$ Using the therapeutic alliance as a model, Telio et al proposed an "educational alliance" framework to construct feedback conversations. 8,17 Forming an alliance with their learners would allow educators to develop a more meaningful understanding of the context of learner performance and provide specific and useful feedback. Similarly, Sargeant et al described the R2C2 model with the following suggested steps: establish relationships, explore reaction, check understanding of the content and coach for growth. ${ }^{7,18}$ Bing-You et al used the tango dance as a metaphor to move from a static one-sided feedback recipe to a dynamic partnership-based conversation. ${ }^{48}$ Applying these recent frameworks for feedback, institutions should encourage and orient teachers in establishing educational alliances / relationships with their learners, emphasise learner engagement in the conversation, and focus on assimilation of feedback and behaviour change as end points.

\section{Tip 8-Encourage teachers and learners co-create learning opportunities for behaviour change}

Learners must have time to assimilate feedback and opportunities to change practice.

In their research, Könings et al. reported that a participatory design, which combines perspectives from teachers, learners and educational leaders, is a more effective strategy for designing learning environments. ${ }^{49,50}$ We therefore propose a participatory design loop for a feedback conversation comprising: establishment of goals by learners and teachers, direct observation of performance by teachers, feedback conversation that includes facilitated self-reflection, creating learning / work opportunities to incorporate feedback and change behaviour, debriefing of new performance, and re-entering the cycle through discussion of new goals by teachers and learners. This is depicted in figure 2 . 


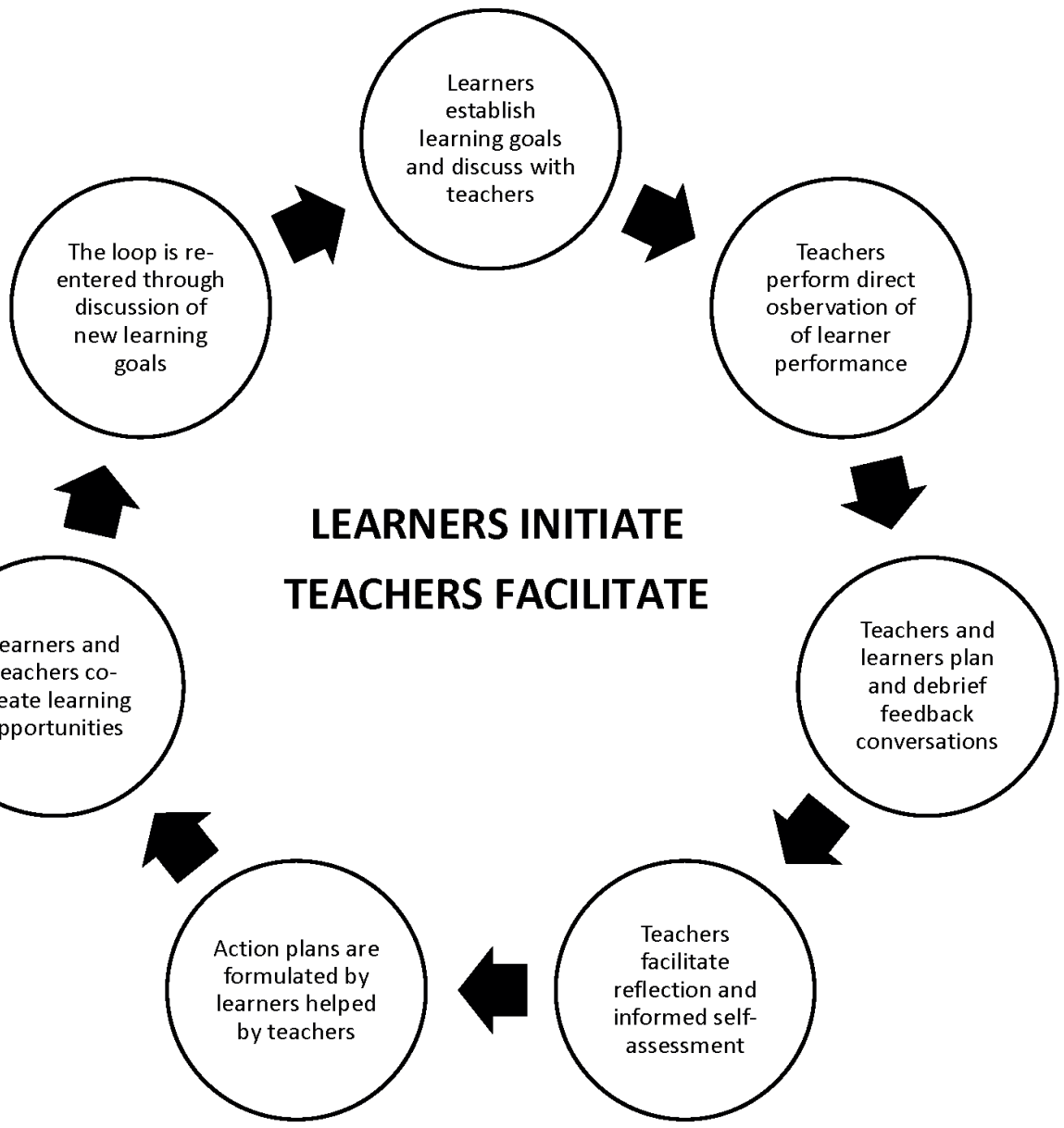

Figure 2: A participatory design feedback loop: Co-creation of learning opportunities by learners and teachers

\section{The Institutional context}

Institutions have a major role to play in setting the stage for feedback that promotes a learning culture that prioritises professional growth. We focus on four key tips in this section, that are complex in themselves and comprise multiple simpler strategies.

\section{Tip 9- Ensure appropriate attention to learner self-efficacy}

'Face' is a term used to describe the image individuals desire to project to the outside world. ${ }^{51}$ Face is further classified as positive and negative (see tip 10), where positive face is an individual's desire for affirmation or self-efficacy. Medical teachers are often reluctant to provide constructive feedback, for fear of hurting learners' feelings or damaging their self-esteem. 6,14,20,46,52 Though learners report that constructive feedback is more in- 
strumental in changing practice, they too tend to seek positive feedback and avoid feedback that could damage their ego or image in summative workplace based assessment settings. ${ }^{45}$ Since confrontation with one's behaviour has been identified as the first step to the change of behaviour, ${ }^{53}$ a formative assessment setting could help learners to better balance ego costs (negative feelings resulting from constructive feedback) and ego benefits (increased self-esteem resulting from reinforcing feedback) leading to increased acceptance of constructive feedback. ${ }^{45}$ Hearing constructive feedback will likely upset learners regardless of how it is phrased, but it is essential for their development and progression to the next level. Institutional expectations for ongoing formative feedback and establishing a climate of assessment for learning would be key in promoting professional growth.

\section{Tip 10- Promote optimal balance of supervision and autonomy}

The term negative face has been defined as 'the want of every competent adult member that his actions be unimpeded by others. ${ }^{51} \mathrm{~A}$ key goal of clinical training is to help learners proceed towards independent practice, yet patient safety and quality concerns necessitate supervision of learners. ${ }^{11,20}$ Thus, it is important for clinical teachers to balance supervision with autonomy. Ten Cate and colleagues described the concept of shared guidance where teachers can move along a spectrum of full external guidance of learners to shared guidance and finally full internal guidance when learners are capable of independent practice. ${ }^{54}$ Since needs and goals of learners are different at different stages of their training, shared guidance requires an ongoing dialogue with learners, monitoring of their progress, and adapting teaching to their learning needs. Moreover, clinical learning occurs during social interactions with a team including teachers, peers, and multidisciplinary professionals, therefore a model of co-regulated learning (rather than self-regulated learning) may better serve postgraduate medical education, especially in the context of entrustment based assessment decisions and help teachers balance supervision with autonomy. ${ }^{55}$

\section{Tip 11- Establish a continuous practice improvement environment}

In medical education, feedback is often referred to as positive or negative and the term remediation is used to describe performance improvement plans. Thus, constructive feedback can have negative connotations for both feedback providers and recipients. Institutions can play an important role in normalising the presence of strengths and weaknesses among professionals at all levels by encouraging the use of non-judgmental frameworks with a continuous improvement approach. The Plus Delta approach is a formative evaluation process described by the Lean Construction Institute (http://leanconstruction.org/media/learning_laboratory/Plus_Delta/Plus-Delta.pdf). This approach is framed in improvement language (what would you change or do differently, how would you improve your practice) rather than positive or negative judgmental language (good, bad, did well, did poorly, satisfactory, unsatisfactory). The plus refers to what went well and delta refers to what could be changed to improve future practice. This framework can be applied to individuals or teams. Training teachers and learners in the use of language framed 
in a continuous practice improvement approach could normalise constructive feedback, thereby encouraging exchange of meaningful constructive feedback which is more acceptable to learners.

\section{Tip 12-Emphasise a feedback culture that enhances professional growth}

It is important for institutions to explicitly establish a learning culture that is conducive to growth enhancing feedback at all levels. Such a culture would emphasise: explicit guidelines for ongoing formative feedback; a learning environment that normalises strengths as well as areas for improvement among learners and teachers; longitudinal and trusting relationships between learners and teachers; direct observation of performance; feedback seeking among teachers and learners; and training in goal-directed and actionable feedback conversations. The Royal College of Physicians and Surgeons of Canada has recommended a coaching mindset among teachers to promote performance improvement among clinical learners, this model would be helpful in faculty development worldwide (http://www.royalcollege.ca/rcsite/cbd/implementation/wbas/coaching-wbas-e).

Finally, individual institutional feedback initiatives need to move away from training that focuses on recipes for 'giving' feedback towards training that emphasises relationships, learning-goal orientation, and a growth mind-set.

\section{Conclusion}

The definition of a feedback culture and what elements contribute to such a culture can vary between institutions and even between departments at a single institution. In this twelve tips paper, key aspects of a feedback culture are described from four different perspectives, as depicted in figure 1, with specific principles and strategies that could be applied at any institution by medical educators worldwide. Application of these tips can facilitate the feedback culture at institutions in the following ways. Feedback providers or teachers can use these strategies to build educational alliances with their learners and provide credible feedback that is more acceptable. Language used during conversations can vary based on the context, the learners, the relationship, level of performance etc., there is no 'one-size-fits-all'. Feedback receivers or learners can use these strategies to develop a growth rather than a fixed mind-set, have a learning goal rather than performance goal-orientation, be proactive in feedback-seeking and assimilation, thereby targeting performance improvement. Institutions can employ these tips to design dynamic feedback training that focuses on relationships, performance observation, normalises constructive feedback and targets behaviour change. Ultimately, we believe that feedback that results in professional growth requires a continuous practice improvement mind-set, attention to teacher-learner relationships and an institutional learning culture that moves away from feedback recipes to improve feedback practice. 


\section{REFERENCES}

1. Boud D. Feedback: ensuring that it leads to enhanced learning. Clin Teach 2015;12:3-7.

2. Bing-You RG, Trowbridge RL. Why medical educators may be failing at feedback. JAMA 2009;302:1330-1.

3. Delva D, Sargeant J, MacLeod T. Feedback: a perennial problem. Med Teach 2011;33:861-2.

4. Molloy E, Boud D. Seeking a different angle on feedback in clinical education: the learner as seeker, judge and user of performance information. Med Educ 2013;47:227-9.

5. van de Ridder JM, Stokking KM, McGaghie WC, ten Cate OT. What is feedback in clinical education? Med Educ 2008;42:189-97.

6. Bing-You R, Hayes V, Varaklis K, Trowbridge R, Kemp H, McKelvy D. Feedback for Learners in Medical Education: What Is Known? A Scoping Review. Acad Med 2017;92:1346-54.

7. Sargeant J, Lockyer J, Mann K, et al. Facilitated Reflective Performance Feedback: Developing an Evidenceand Theory-Based Model That Builds Relationship, Explores Reactions and Content, and Coaches for Performance Change (R2C2). Acad Med 2015;90:1698-706.

8. Telio S, Ajjawi R, Regehr G. The "educational alliance" as a framework for reconceptualizing feedback in medical education. Acad Med 2015;90:609-14.

9. Anderson PA. Giving feedback on clinical skills: are we starving our young? J Grad Med Educ 2012;4:154-8.

10. Ramani S, Post SE, Konings K, Mann K, Katz JT, van der Vleuten C. "It's Just Not the Culture": A Qualitative Study Exploring Residents' Perceptions of the Impact of Institutional Culture on Feedback. Teach Learn Med 2017;29:153-61.

11. Ramani S, Konings KD, Mann KV, Pisarski EE, van der Vleuten CPM. About Politeness, Face, and Feedback: Exploring Resident and Faculty Perceptions of How Institutional Feedback Culture Influences Feedback Practices. Acad Med 2018.

12. Bing-You R, Hayes V, Varaklis K, Trowbridge R, Kemp H, McKelvy D. Feedback for Learners in Medical Education: What Is Known? A Scoping Review. Acad Med 2017.

13. Mann K, van der Vleuten C, Eva K, et al. Tensions in informed self-assessment: how the desire for feedback and reticence to collect and use it can conflict. Acad Med 2011;86:1120-7.

14. Watling CJ. Unfulfilled promise, untapped potential: feedback at the crossroads. Med Teach 2014;36:6927.

15. Eva KW, Armson $\mathrm{H}$, Holmboe $\mathrm{E}$, et al. Factors influencing responsiveness to feedback: on the interplay between fear, confidence, and reasoning processes. Adv Health Sci Educ Theory Pract 2012;17:15-26.

16. Sargeant J, McNaughton E, Mercer S, Murphy D, Sullivan P, Bruce DA. Providing feedback: exploring a model (emotion, content, outcomes) for facilitating multisource feedback. Med Teach 2011;33:744-9.

17. Telio S, Regehr G, Ajjawi R. Feedback and the educational alliance: examining credibility judgements and their consequences. Med Educ 2016;50:933-42.

18. Sargeant J, Lockyer JM, Mann K, et al. The R2C2 Model in Residency Education: How Does It Foster Coaching and Promote Feedback Use? Acad Med 2018.

19. Sargeant J, Mann K, Manos S, et al. R2C2 in Action: Testing an Evidence-Based Model to Facilitate Feedback and Coaching in Residency. J Grad Med Educ 2017;9:165-70.

20. Watling $C$, Driessen $E$, van der Vleuten $C P$, Vanstone $M$, Lingard L. Beyond individualism: professional culture and its influence on feedback. Med Educ 2013;47:585-94.

21. Watling $C$, Driessen E, van der Vleuten CP, Vanstone M, Lingard L. Music lessons: revealing medicine's learning culture through a comparison with that of music. Med Educ 2013;47:842-50.

22. Watling $C$, Driessen $E$, van der Vleuten CP, Lingard L. Learning culture and feedback: an international study of medical athletes and musicians. Med Educ 2014;48:713-23.

23. Ginsburg S, Regehr G, Lingard L, Eva KW. Reading between the lines: faculty interpretations of narrative evaluation comments. Med Educ 2015;49:296-306.

24. Ginsburg S, van der Vleuten C, Eva KW, Lingard L. Hedging to save face: a linguistic analysis of written comments on in-training evaluation reports. Adv Health Sci Educ Theory Pract 2016;21:175-88.

25. Schein EH. Organizational culture and leadership. 4th ed. San Francisco: Jossey-Bass; 2010. 
26. Ramani S, Konings K, Mann KV, van der Vleuten C. Uncovering the unknown: A grounded theory study exploring the impact of self-awareness on the culture of feedback in residency education. Med Teach 2017;39:1065-73.

27. Skeff KM, Mutha S. Role models--guiding the future of medicine. N Engl J Med 1998;339:2015-7.

28. Srinivasan M, Li ST, Meyers FJ, et al. "Teaching as a Competency": competencies for medical educators. Acad Med 2011;86:1211-20.

29. Watling C. Cognition, culture, and credibility: deconstructing feedback in medical education. Perspect Med Educ 2014;3:124-8.

30. Kogan JR, Conforti LN, Bernabeo EC, Durning SJ, Hauer KE, Holmboe ES. Faculty staff perceptions of feedback to residents after direct observation of clinical skills. Med Educ 2012;46:201-15.

31. Kogan JR, Hatala R, Hauer KE, Holmboe E. Guidelines: The do's, don'ts and don't knows of direct observation of clinical skills in medical education. Perspect Med Educ 2017;6:286-305.

32. Watling C. The uneasy alliance of assessment and feedback. Perspect Med Educ 2016;5:262-4.

33. Sargeant J, Mann K, Sinclair D, van der Vleuten C, Metsemakers J. Challenges in multisource feedback: intended and unintended outcomes. Med Educ 2007;41:583-91.

34. Eva KW, Regehr G. "I'll never play professional football" and other fallacies of self-assessment. J Contin Educ Health Prof 2008;28:14-9.

35. Sargeant J, Eva KW, Armson $\mathrm{H}$, et al. Features of assessment learners use to make informed selfassessments of clinical performance. Med Educ 2011;45:636-47.

36. Sargeant J, Armson $H$, Chesluk B, et al. The processes and dimensions of informed self-assessment: a conceptual model. Acad Med 2010;85:1212-20.

37. Luft J. Of human interaction. Palo Alto, Calif.,: National Press Books; 1969.

38. Dweck CS. Self-theories and goals: their role in motivation, personality, and development. Nebr Symp Motiv 1990;38:199-235.

39. Dweck CS. Mindsets and human nature: promoting change in the Middle East, the schoolyard, the racial divide, and willpower. Am Psychol 2012;67:614-22.

40. Crommelinck M, Anseel F. Understanding and encouraging feedback-seeking behaviour: a literature review. Med Educ 2013;47:232-41.

41. Teunissen PW, Bok HG. Believing is seeing: how people's beliefs influence goals, emotions and behaviour. Med Educ 2013;47:1064-72.

42. Teunissen PW, Stapel DA, van der Vleuten C, Scherpbier A, Boor K, Scheele F. Who wants feedback? An investigation of the variables influencing residents' feedback-seeking behavior in relation to night shifts. Acad Med 2009;84:910-7.

43. VandeWalle D, Cron WL, Slocum JW, Jr. The role of goal orientation following performance feedback. J Appl Psychol 2001;86:629-40.

44. VandeWalle D, Cummings LL. A test of the influence of goal orientation on the feedback-seeking process. J Appl Psychol 1997;82:390-400.

45. Gaunt A, Patel A, Rusius V, Royle TJ, Markham DH, Pawlikowska T. 'Playing the game': How do surgical trainees seek feedback using workplace-based assessment? Med Educ 2017;51:953-62.

46. Sargeant J, Mann K, Sinclair D, Van der Vleuten C, Metsemakers J. Understanding the influence of emotions and reflection upon multi-source feedback acceptance and use. Adv Health Sci Educ Theory Pract 2008;13:275-88.

47. Watling CJ, Lingard L. Grounded theory in medical education research: AMEE Guide No. 70. Med Teach 2012;34:850-61.

48. Bing-You R, Varaklis K, Hayes V, Trowbridge R, Kemp H, McKelvy D. The Feedback Tango: An Integrative Review and Analysis of the Content of the Teacher-Learner Feedback Exchange. Acad Med 2017.

49. Könings KD, Brand-Gruwel S, van Merriënboer JJG. Towards more powerful learning environments through combining the perspectives of designers, teachers, and students. Br J Educ Psychol 2005;75:645-60.

50. Könings KD, Seidel T, van Merriënboer JJG. Participatory design of learning environments: integrating perspectives of students, teachers, and designers. Instr Sci 2014;42:1-9. 
51. Brown P, Levinson SC. Politeness : some universals in language usage. Cambridge Cambridgeshire ; New York: Cambridge University Press; 1987.

52. Lefroy J, Watling C, Teunissen PW, Brand P. Guidelines: the do's, don'ts and don't knows of feedback for clinical education. Perspect Med Educ 2015;4:284-99.

53. van den Eertwegh V, van der Vleuten C, Stalmeijer R, van Dalen J, Scherpbier A, van Dulmen S. Exploring residents' communication learning process in the workplace: a five-phase model. PLoS One 2015;10:e0125958.

54. ten Cate O, Snell L, Mann K, Vermunt J. Orienting teaching toward the learning process. Acad Med 2004;79:219-28.

55. Rich JV. Proposing a Model of Co-Regulated Learning for Graduate Medical Education. Acad Med 2017;92:1100-4. 

Chapter

\section{Discussion and Conclusions}





\section{Discussion: Where is the feedback pendulum?}

The overall goal of this research was to shift the feedback conversation from a static teacher to learner monologue towards a dynamic learner-initiated and directed co-constructed dialogue. This series of research studies aimed to examine what institutional factors are perceived by residents and faculty to be key components of a feedback culture, and how these factors influence the quality and impact of feedback conversations in postgraduate medical education settings. To achieve this overall research aim, we posed two broad research aims and four specific research questions. The two broad aims were to: (1) explore resident and faculty perceptions regarding the institutional feedback culture and how this culture can be enhanced to optimise professional growth, and (2) explore whether their opinions about feedback in general and feedback culture in particular, translated into action during real-life feedback conversations.

In this section, the studies presented in this thesis will be briefly summarised by study question followed by an overall synthesis of findings. Chapters 3-6 describe each of the research studies conducted. Study questions 1 and 2 address the first broad aim, and questions 3 and 4 address the second broad aim, Specific research questions were:

1. What are the perceptions of residents and faculty regarding a definition of feedback culture and what elements constitute this culture?

2. How do residents and faculty view the current department culture and its influence on the quality of feedback conversations between residents and faculty?

The second broad aim related to feedback practices during real-life conversations. Specific research questions were:

3. What language and behaviours are used by teachers and learners during formal feedback conversations between faculty and residents who have a longitudinal relationship in continuity clinics?

4. Can video-facilitated reflection and reflexivity enhance faculty awareness of effective and ineffective behaviours and promote future behaviour change?

In this chapter we summarise the overall findings by research question, demonstrate how our findings came full circle as well as yielded surprising insights, ${ }^{1}$ and discuss key findings in light of recent literature. We then return to the three theories discussed in the Introduction and review how specific tenets of each of these theories relate to our findings, and what implications they have for feedback conversations in medical education. To link findings across the individual studies and discover common themes, we propose a new model for educators and institutions to enhance feedback conversations and promote a growth-oriented feedback culture. We then discuss limitations of the research, identify key conclusions, and conclude with what implications our research has for medical educators and suggestions for further research in this area. 


\section{Research questions:}

Question 1: What are the perceptions of residents and faculty regarding a definition of feedback culture and what elements constitute this culture?

This question was addressed in Chapters 3 through 5. In Chapter 3, we describe a study where we conducted an open-ended exploration of resident perspectives on the current state of feedback and their insights into what factors facilitated or impeded feedback. Similar to findings reported by other investigators, we found that residents expressed dissatisfaction with the quality of feedback provided by faculty overall. ${ }^{2-5}$ Several recent studies have emphasised the impact of sociocultural factors such as the learning culture, teacher characteristics, teacher-learner relationships, observation of performance, perceived credibility of feedback data etc., on feedback conversations. ${ }^{6-9}$ While we were hoping to discover whether our participants perceived similar sociocultural factors to be major facilitators or barriers to meaningful feedback, we were surprised to discover that all generated themes prominently featured culture in some form. However, it was still not clear how residents defined a feedback culture and what factors influenced this culture. Moreover, these were the opinions of residents only and it was important to obtain perspectives from the other side of the conversation, namely faculty.

In our next study, described in Chapter 4, we included residents and faculty as participants for an in-depth exploration of their definition of feedback culture, what factors constituted the culture, and how this culture can be harnessed to maximise professional growth. Key factors that were believed to contribute to a feedback culture were establishment of longitudinal relationships, attention to self-efficacy and autonomy, normalising of constructive feedback, expectations for feedback seeking by residents and faculty, and direct observation of performance.

As self-assessment and reflection were considered central to feedback seeking and acceptance, in the study described in Chapter 5, resident and faculty discussions were analysed through the framework of the Johari window, a psychological framework that views interpersonal interactions through the degree of awareness of behaviours or performance. Each quadrant in this model depicts a different level of knowledge of behaviours by self and others. We found that this framework is very applicable to enhancing feedback and were able to generate individual and institutional strategies under each quadrant to encourage self-awareness, feedback seeking, receptivity to feedback, and assimilation of feedback leading to behaviour change. No prescriptions on strategies are provided, but essential principles that could be adopted by teachers, learners and the institution are described with the goal of ultimately expanding the 'open' quadrant and shrinking the 'unknown' quadrant. 
Question 2: How do residents and faculty view the current departmental / institutional culture and its influence on the quality of feedback conversations between residents and faculty

Our first study, discussed in Chapter 3, explored resident opinions regarding the departmental culture. Their narratives were dominated by beliefs that the institutional culture was not conducive to honest feedback conversations. Specifically, they described a culture of politeness at the institution which they applauded for many reasons and found nurturing. However, they believed that this very culture was a deterrent to honest constructive comments during feedback conversations. Additionally, they stated that the cultural norms did not promote bidirectional feedback from residents to faculty, as well as junior to senior residents. Residents felt that it was an obligation on the part of the institution to promote a culture of growth, facilitate opportunities to establish longitudinal mentoring relationships with faculty and provide faculty development. Other investigators have reported that avoidance of constructive feedback was a trait commonly seen in medical education, as faculty did not want to be seen as mean, damage working relationships or learners' self-esteem. ${ }^{6-10}$ Politeness concepts have also been raised as one potential reason for non-specific comments by faculty on formal evaluations. ${ }^{11,12}$

In the study described in Chapter 4, we explored resident as well as faculty opinions on the institutional feedback culture, in particular, regarding the culture of politeness. When asked to describe the institutional culture, both groups indicated that this could be summarised in two terms: a culture of excellence and a culture of politeness. The culture of excellence refers to the outstanding academic reputation of the institution and pedigree of its trainees, which led to assumptions of excellence in all domains and rendered constructive feedback as an unnecessary topic. Culture of politeness was defined by participants as the collegial and supportive work environment that provided a family like work atmosphere for residents. This culture caused avoidance of language with any potential of adversely affecting resident self-esteem. Despite the agreement that there was an overarching culture of politeness, this still did not seem to flatten out the hierarchical culture that impedes bidirectional feedback (feedback from lower to upper levels).

Despite many recent research papers emphasising the impact of sociocultural factors on the credibility and acceptability of feedback to learners, $2,9,10$ it was exciting to discover insights from faculty and residents themselves about what factors mattered most to them as facilitators or barriers to feedback. The majority of their narratives discussed cultural barriers and they freely expressed that the institution needs to establish a culture of growth. Participants believed that a feedback culture should normalise the fact that professionals at all levels will have areas for improvement, provide a safe space to admit limitations, promote teacher-learner longitudinal relationships, encourage proactive feedback seeking on both sides, increase opportunities for performance observation and provide training in feedback seeking and acceptance. Politeness concepts seemed to be 
prominent in all discussions. Because the culture of politeness was nurturing and facilitated a positive learning and work environment, and collegial relationships among residents and between residents and faculty, participants hesitated to diminish this culture. However, politeness was seen as a definite barrier to honest constructive conversations and this could potentially be overcome by emphasising that kindness and politeness had an obligation to promoting mutual growth.

Thus far, we had abundant data regarding resident and faculty opinions and perceptions of the institutional culture, but they were still stated opinions. How opinions may translate into action became the subject of the next two research questions. In the study described in Chapter 6, we tackled research questions 3 and 4 through observations of feedback conversations between continuity clinic faculty and residents with whom they have a longitudinal relationship.

\section{Question 3: What language and behaviours are used by teachers and learners during formal feedback sessions between faculty and residents who have a longitudinal relationship in continuity clinics?}

To answer study questions 3 and 4, we conducted the ethnographic study described in Chapter 6. Study question 3 was based on investigator field observations and faculty and resident reflections on the encounter during separate debriefing sessions. Study question 4 aimed to explore the impact of video review of behaviours on faculty self-awareness of feedback behaviours, and summarised under the next study question.

Six faculty were observed during their scheduled feedback conversations with two of their residents whom they precepted in continuity clinics. We observed their non-verbal behaviours for signs of rapport or educational alliance, ${ }^{13,14}$ communication skills (opening the conversation, gathering data, establishing plans and closing the conversation), ${ }^{15,16}$ and strategies that would indicate skilled communication beyond basic communication skills. ${ }^{17}$ We observed clear evidence of rapport between all faculty and residents. All conversations were preceded by direct observation of resident-patient encounter. Residents were allowed to share their overall insights of the encounter, express their challenges, prompted to self-assess and reflect on their strengths and deficiencies. Faculty presented specific examples from patient encounters, used resident self-reflections as the basis of constructive feedback, practised shared decision making and formulation of goal-directed action plans. Moving beyond communication skills, the most skilled communicators were more comfortable in drawing challenges and uncertainties from residents, with periods of silence, and facilitating specific action plans but allowing residents to lead this planning.

Faculty acknowledged that they did not have feedback conversations often enough, and also volunteered that they would feel more challenged when having such conversations with struggling learners. We attributed the overall comfort and quality of these conversations to the fact that they had longitudinal relationships in continuity clinics and felt invested in the growth of their residents. In addition, we postulated that their high-quality 
communication skills could emanate from their primary care physician roles. Since feedback conversations are complex social interactions, just applying a communication framework may not be sufficient. Previous work on communication has emphasised that discrete communication skills alone cannot explain the concept of a skilled communication experience which is inherently creative, sincere, authentic, consists of subjective elements which cannot be fully explained, fraught with some uncertainty, and should be viewed holistically and not superficially. ${ }^{17}$ We believe that these principles are very applicable to teacher-learner feedback conversations as much as physician-patient interactions. Sargeant et al proposed a model for feedback conversations titled R2C2 (relationships, reaction, content and coaching), which emphasises a learner-centred approach and use of coaching strategies rather than a unidirectional provision of feedback by teachers. ${ }^{18-20}$ Our observations suggested that faculty instinctively and unconsciously followed the structure of physician-patient communication, and used several coaching techniques such as listening, questioning, keeping the focus on the learner, encouraging and supporting, gently challenging, and seeing different perspectives. Their strategies were also consistent with the educational alliance framework that has been proposed by Telio et al. ${ }^{13,14}$ Coaching is a technique used commonly in other professions such as music, sports and management, and medical educators are increasingly encouraging clinical teachers to develop coaching skills especially as principal goals of advanced learners are independent practice and professional growth. ${ }^{21-24}$

\section{Question 4: Can video-facilitated reflection and reflexivity enhance faculty} awareness of effective and ineffective behaviours and promote future behaviour change?

Using a video-reflexive ethnographic approach, we were able to address this study question in the same study described under question 3.25-27 Only one of the faculty had ever been videotaped during her teaching sessions in the past. Despite their initial discomfort, all participating faculty agreed to be videotaped because they were curious to view their feedback strategies and reflect on the effectiveness of their behaviours. This methodology was used to promote reflexivity among participating faculty, namely to view their own behaviours, assess the fit between their intentions and perceptions, judge what behaviours were effective and what might need to change in future conversations. Some faculty were uncertain whether they had successfully achieved their goals for the conversation, but they felt reassured that they had accomplished what they considered to be the most important goals- establishing rapport, allowing resident narrative, expression of resident challenges and formulating a few action plans. All but one felt that they had gained insights into some behaviours that might not have been effective and these insights would be helpful in planning future feedback conversations. All of them expressed that the effectiveness of many of their feedback practices were reinforced during the video-facilitated debriefing. Finally, they believed that they should have more of these 
conversations with their residents, and despite the awkwardness of the observation and videotaping, this exercise forced them to reflect on goals for their feedback conversations and observe resident-patient encounters prior to these conversations. Overall, faculty found the video-facilitated debriefing very helpful in calibrating their own behaviours and develop strategies for future conversations.

\section{Synthesis of research to date}

Synthesising the findings from all the research studies to date, our findings have 2 key elements consistent with Lingard's suggested formats ${ }^{1}$ : (1) coming full circle (answering research questions and achieving study objectives formulated at the start, thereby closing the loop), and (2) some surprising insights (surprising and unintended discoveries that emerge from the research).

Coming full circle: Our participants confirmed that sociocultural factors, such as relationships, tone and perceived intent, institutional culture, feedback seeking etc., play a central role in the quality of feedback exchanges, as reported by previous investigators. ${ }^{2,6,8-10,28,29}$ Further, we were able to apply Schein's three levels of organisational culture to feedback culture consisting of assumptions, written expectations and resulting behaviour, where we propose that assumptions (culture of excellence), espoused values (Feedback Fridays), and expressed behaviours (avoidance of honest constructive feedback and bidirectional feedback) may contradict each other. ${ }^{30}$

Surprising insights: Cultural concepts not previously described but raised by our participants and resonating with most of the groups, were the institutional 'culture of politeness' and 'culture of excellence'. We also suggest that the Johari window framework of interpersonal communications would be useful to teachers, learners and institutions in structuring feedback conversations to promote self-assessment, self-reflection, self-disclosure, feedback seeking and receptivity and readiness to self-discovery regarding own performance. $^{31}$

In the next section, we reflect on what these findings mean, what psychosocial theories are relevant to these findings and what the implications are for teachers, learners and educational institutions to raise the bar for meaningful feedback conversations that result in professional growth. Reviewing themes from all the studies, we saw one common thread: the balancing act between learner factors, and teacher or institutional factors. We termed this the 'self' and 'other' respectively and argue that without an optimal balance between the two sides, feedback conversations will not result in acceptance by learners or contribute to changes in their practice. 


\section{Balancing the Self and the Other: A new construct to promote growth-enhancing feedback}

Based on our research findings, we hypothesise that the impact of feedback conversations lies in the balance between the 'self' and the 'other'. 'Self' is defined from the perspective of the learner as a holistic term that stimulates learners to calibrate, seek knowledge about their performance, incorporate data from multiple sources and change practice. The 'other' perspective consists of teacher and institutional factors and how they can facilitate or impede learner self-characteristics. The self and other co-exist in an institutional context which features both an organisational culture as well as a learning culture. Below, we discuss the various factors related to self and other which would significantly influence the impact of feedback conversations, informed by our participant narratives and actions. Figure 1 aims to map out what self-characteristics and resulting behaviours can facilitate and what self-characteristics and resulting behaviours can inhibit the impact of feedback.

\section{Self-characteristics and feedback (Learner)}

We propose that the self, in feedback conversations, can be viewed through the lens of self-concepts or traits in oneself which could result in certain behaviours and practices. For the purposes of feedback and what self-factors could influence its impact, the following characteristics are included as they emerged from our research findings: mind-set, goal-orientation, self-awareness, self-efficacy, and desire for autonomy. We will discuss each one of these characteristics and how they could influence feedback related behaviours.

\section{Mind-set}

It would be appropriate to start with a discussion of mind-set as this influences all other self-traits discussed below. Mind-set is a concept developed by the psychologist Carol Dweck, one of the leading researchers in the field of motivation, personality and development. Based on her extensive research on professional achievement and success, she described two core mind-sets: a fixed mind-set and a growth mind-set. ${ }^{32,33}$ People with a fixed mind-set believe that their success is a result of fixed traits such as innate intelligence, talent and ability. They tend to spend more time showcasing their skills and perceive failure as a negative statement of their abilities. Those with a growth mind-set believe that innate abilities can be developed through hard work, training, and ongoing learning, and view failure as an essential stop along the journey to further learning. This perspective could lead to a passion for learning and mastery and acceptance of limitations. In terms of feedback, a growth mind-set would allow learners to engage in feedback seeking to learn about areas for improvement; disclose limitations as they would view these as opportunities to expand knowledge and skills; be more receptive to constructive 
feedback as they see failure as an opportunity rather than an insult to their abilities; and likely engage in co-creating opportunities for growth and success.

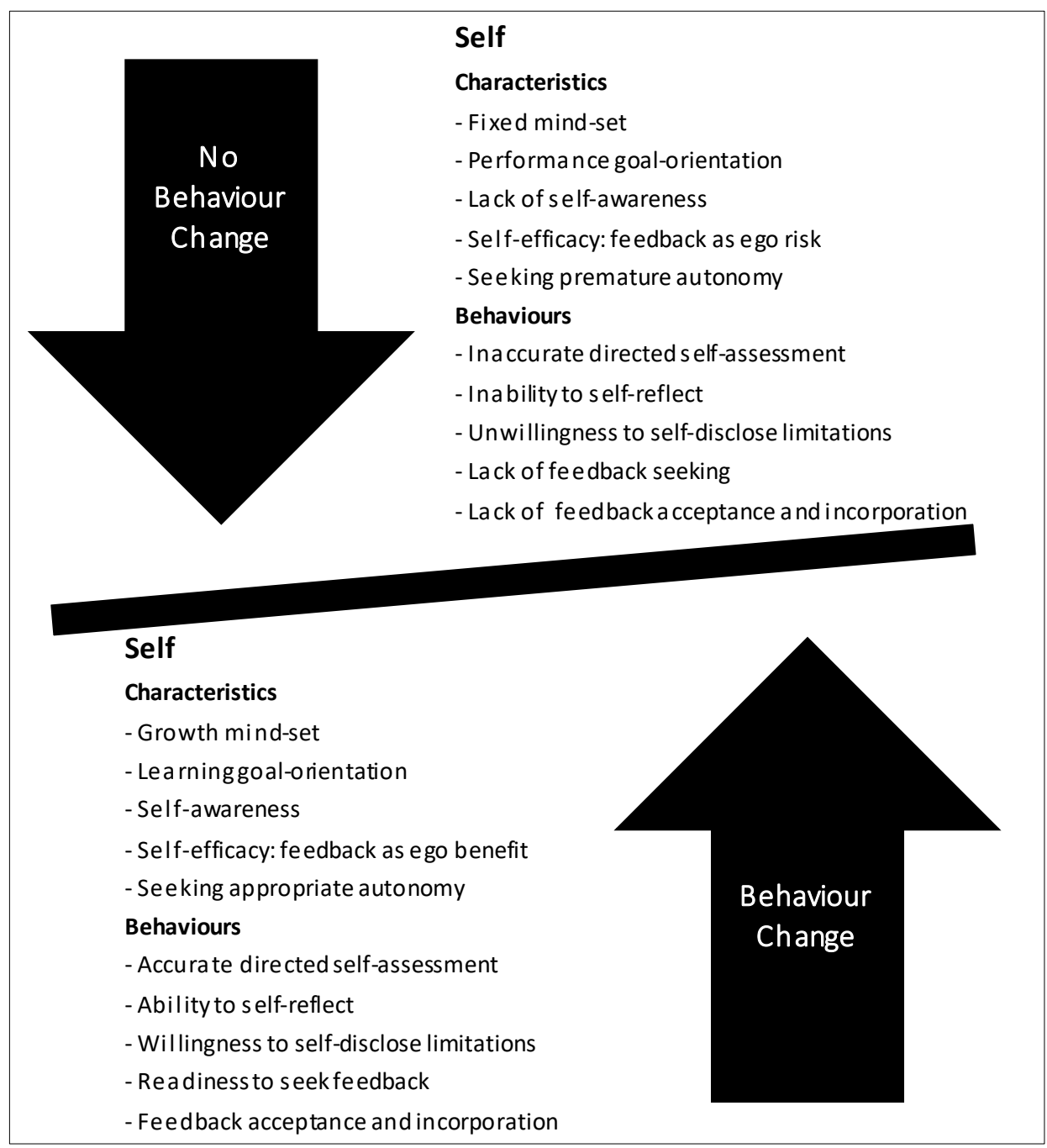

Figure 1

Figure legend: This figure depicts self-characteristics and self-behaviours that can impede (down arrow and downward trajectory of the see-saw), and those that can facilitate (up arrow and upward trajectory of the seesaw) learner assimilation of feedback and willingness to change practice.

\section{Goal-orientation}

Goal-orientation has been defined as 'an individual disposition towards developing or validating one's ability in achievement settings'. ${ }^{34-36}$ The concept of goal-orientation was first proposed in the 1970s, but later expanded upon by Dweck and others. ${ }^{28,37}$ Research 
has shown that some children with high abilities used maladaptive strategies when confronted with difficult tasks leading to feeling of helplessness, while others used more coping strategies. ${ }^{37}$ These differences were attributed to two types of achievement goals: (1) task involvement, where individuals sought to develop competence relative to their abilities, and (2) ego involvement, where individuals sought to develop competence relative to others. As a result, two types of goal orientation were proposed: performance goalorientation and learning goal-orientation. It was postulated that those with performance goals approached tasks to gain approval from others, whereas those with learning goals approach tasks to acquire new skills. ${ }^{38}$ Applying goal-orientation to feedback, professionals with a performance goal-orientation may focus on creating a good impression and not welcome feedback that could reveal limitations and threaten their image. On the other hand, professionals with a learning goal-orientation tend to focus on achieving mastery in their field and are more likely to seek and accept constructive feedback that helps them grow.

\section{Self-awareness}

Self-awareness refers to one's capacity for introspection and accurate appraisal of one's own behaviour. Increased self-awareness could encourage individuals to align their behaviour with expected standards and develops gradually through analysis of behaviours in different situations. Multiple levels of self-awareness have been described from confusion (complete unawareness of self) to meta self-awareness (the ability to be aware of how one is seen through others' eyes). ${ }^{39}$ This trait can influence the accuracy of self-assessment, feedback seeking and acceptance, and motivation to change behaviours. We have previously described the Johari window in Chapter 5, a two-by-two model with four quadrants signifying different levels of self-awareness. ${ }^{31}$ To maximise performance, the open quadrant should be enlarged whereas the blind, hidden and unknown quadrants should be shrunk. Learners should engage in feedback seeking to learn about aspects of their performance that they are unaware of, disclose their limitations so that teachers can provide accurate feedback based on the context of the performance and engage in self-discovery through gathering of performance data from multiple sources to bring unknown areas to light. When the unknown quadrant shrinks, individuals may have arrived at meta-awareness.

\section{Self-efficacy}

Belief in one's ability to succeed, which includes self-esteem as well as self-efficacy influences how individuals think, behave and feel. Self-esteem refers to a person's sense of self-worth in a global sense, whereas self-efficacy refers to a person's confidence in their ability to perform certain actions and achieve specific outcomes. ${ }^{40,41}$ For the purposes of feedback, we believe it is more important to discuss self-efficacy as it relates to motivation and professional development. A professional's assessment of self-efficacy influences his / her behaviours, and the efforts to overcome barriers in achieving their goals. ${ }^{42}$ 
In academic settings, research suggests that previous performance accomplishments are the most powerful source of self-efficacy. ${ }^{40,42}$ Strong self-efficacy motivates professionals to overcome challenges and these individuals are not easily discouraged by such obstacles. Such individuals also tend to be more self-aware of strengths, weaknesses and ability to succeed in a certain task. ${ }^{28,40}$ Applying these principles to feedback, learners with increased self-efficacy are likely also to be more self-aware, as well as internally motivated to face challenges, overcome obstacles and succeed in their practice. They will likely engage more in conversations involving directed self-assessment, seek and accept feedback, reflect on their performance and commit to behaviour change. How the 'other' (teachers and institutions) can enhance self-efficacy will be discussed in a later section.

\section{Seeking autonomy}

Many human behaviours are executed with intent to yield specific outcomes. Some behaviours are initiated and regulated through choice, characterised as autonomous, and others are driven by external factors, referred to as controlled. ${ }^{43,44}$ Autonomy refers to the desire to act independently and to be self-directed. It has a major impact on internal motivation, creative thinking and action. It has been said that to be fully motivated, individuals must be able to control what they do, when they do it and who they do it with. ${ }^{43-}$

45 Professionals might look at their work context as either supportive of their autonomy or controlling, and this perception could affect their attitudes and behaviours. It has been hypothesised that autonomy-supportive contexts would enhance intrinsic motivation and controlling contexts would undermine motivation. It has also been shown that sometimes rewards may be considered as controlling and therefore undermine intrinsic motivation. Relating autonomy concepts to our feedback research findings, providing positive feedback alone can affirm learners' sense of competence, but can also undermine intrinsic motivation if learners perceive positive feedback as a form of interpersonal control rather than autonomy-supportive.

\section{The Other- The Teacher and the Institution}

We define the 'other' as teacher and institution-related factors that could significantly impact the learner-related factors discussed above and propose strategies to appropriately enhance the self-traits to maximise professional growth. Figure 2 is a proposed model of how a balance of self-factors and other-factors can promote behaviour change among learners. We also show self and other factors as co-existing with an institutional context composed of both an organisational culture as well as a learning culture. 


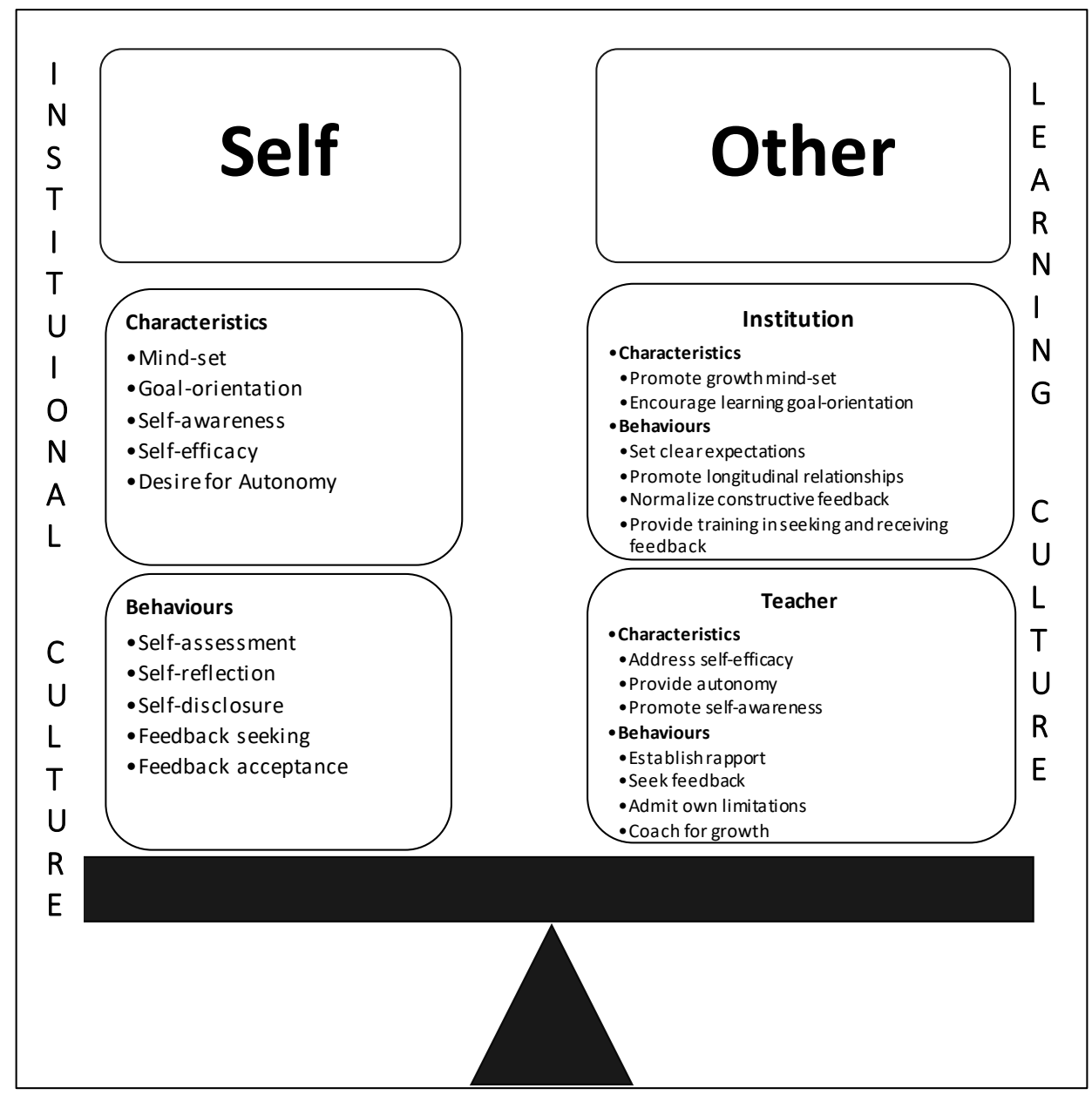

Figure 2

Figure legend: This is a proposed model of how a balance of self-factors and other-factors can promote behaviour change among learners. We also show self and other factors as co-existing with an institutional context composed of both an organisational culture as well as a learning culture.

Below, we describe teacher-related and institution-related characteristics that would be important in influencing self- characteristics that could enhance intrinsic motivation and potentially a commitment to change. Discrete behaviours related to these characteristics are also listed. We propose that teachers focus on addressing self-efficacy, self-awareness and autonomy, whereas institutions focus on optimising mind-set and goal-orientation to act synergistically and promote learners' professional development. 


\section{Teacher-related factors}

\section{Influencing self-efficacy}

As previously discussed, learners with higher self-efficacy are likely to have increased internal motivation and willingness to face challenges. ${ }^{40,41}$ Since self-efficacy arises from previous performance accomplishments, teachers can play a major role in helping learners recall previous professional successes and help learners navigate obstacles when faced with new tasks. However, it is not sufficient for teachers to just be supportive, they need to challenge learners to help them develop and move to the next level. ${ }^{46}$ Self-efficacy will not be enhanced by positive reinforcement alone, it is necessary for learners to self-assess and reflect on their performance and ability to accomplish tasks. To promote accurate calibration of performance and enhance learner acceptance of feedback, teachers should have conversations that include informed self-assessment. ${ }^{47,48}$ As discussed in Chapter 5, professionals' ability to accurately self-assess when unguided is suboptimal, ${ }^{49,50}$ and learners reject feedback that conflicts with their self-assessment, be it accurate or flawed. Therefore, teachers should promote informed self-assessment where data from multiple sources are incorporated into and guide calibration of one's performance. ${ }^{47}$ In summary, teachers can enhance learners' self-efficacy by facilitating recall of previous successes in task performance, reinforcing behaviours that contributed to success (support), encouraging them to tackle new and complex tasks (challenge), providing constructive feedback to assist them in succeeding at new tasks, thereby increasing intrinsic motivation which will help them grow.

\section{Providing autonomy}

Autonomy, the desire to act independently and to be self-directed, is critical in enhancing internal motivation. ${ }^{43}$ However, learning is developmental and appropriate levels of autonomy should be provided gradually as learners' knowledge and skills increase over time. Ten Cate et al propose a model for teaching which can help teachers understand learners' internal motivators and orient teaching to learning processes. ${ }^{51}$ This model proposes that teachers should balance supervision and autonomy based on learner level and ability and gradually move along the spectrum from full external regulation to full selfregulation of learning. We recommend that individual teachers rather than institutions should attend to the affective component of the learning process, which includes motivation, self-efficacy (discussed above) and coping with challenges as learners try to gain competence in new and increasingly complex tasks. Once cognitive, metacognitive and affective components of the learning process are addressed, teachers should focus on helping the learner develop into an independent practitioner and this is done as a gradual shift from full external guidance to shared guidance to full internal guidance over the course of training. All levels of guidance require that teachers encourage learners to take ownership of their learning by asking them to formulate learning goals, discussing their 
goals, facilitating reflection and self-assessment, providing feedback and having them initiate action plans for progression to the next level. The speed and progress along this continuum will vary across learners based on their capability to successfully to perform different clinical tasks. ${ }^{51}$ Balancing supervision and autonomy is one of the most challenging tasks required of clinical teachers, especially in postgraduate medical training, but safe patient care mandates this balance. The balance between guidance to self-regulation has been termed 'constructive friction' between teaching and learning. ${ }^{52}$ One other implication of autonomous learning enhancing intrinsic motivation would be for teachers to engage in participatory design of learning environments and opportunities with learners, which has been shown to have positive effects on attitudes, commitment and productivity in educational as well as business settings. ${ }^{53-55}$ It is imperative that institutions establish clear expectations for regulation of learning and provide faculty development in providing autonomy that is appropriate to the level and skill of individual learners.

\section{Enhancing self-awareness}

Self-awareness can be defined as an individual's tendency to focus on own emotions, attitudes and behaviour in response to specific situations, as well as the extent to which self-perceptions are congruent with others' perceptions. ${ }^{56}$ Thus, it can be seen as a measure of the person's ability to observe components of the self accurately and objectively. It is a key personal capability that helps individuals learn new skills and gain new competencies and is a dynamic rather than a static process. Self-awareness has also been described as the first component of emotional intelligence and has two facets: internal (recognising own inner state), and external (recognising impact on others). ${ }^{57,58}$ Kegan has described a model of identity development which involves an individual's ability to see the self with objectivity, and observe the self as if from a distance. ${ }^{59}$ In a social environment such as the clinical education settings, self-awareness likely develops with others rather than independent of others. ${ }^{60}$ Several medical educational experts have argued that expertise in the art of medicine, involving patient communication, rapport, shared decisions making etc., requires personal awareness on the part of physicians. ${ }^{61,62}$ Personal awareness is said to help them 'calibrate' their instruments and use them more effectively in complex patient interactions, understand patient behaviours and become humanistic physician-healers. Awareness of one's clinical abilities, assumptions and reactions to clinical situations can help learners better understand how their actions are perceived by patients and may help them handle challenging clinical situations better. Clinical teachers can be most helpful by imparting insights into learners' emotional responses to specific clinical situations rather than attempt to change their intrinsic self-traits. ${ }^{56}$ Taking into account the importance of developing self-awareness among clinical learners and the fact that this trait is ideally co-constructed with others, we believe the Johari window is an excellent model to apply to feedback conversations, as described in Chapter 5. ${ }^{31,56}$ Effective strategies that teachers can apply to enhance self-awareness of learners include: de- 
veloping an educational alliance, facilitating reflection of performance, debriefing challenging clinical situations, sharing own professional challenges and limitations, and encouraging informed self-assessment. These strategies could help expand the 'known' quadrant while shrinking the 'blind' and 'hidden' quadrants. Ongoing conversations can shrink the unknown quadrant by stimulating self-discovery.

\section{Institution-related factors}

\section{Stimulating a growth mind-set}

Mind-set refers to a set of assumptions held by individuals which directs their choices and behaviours. The two mind-sets described by Carol Dweck, the fixed and growth mind-set, have been discussed previously. ${ }^{33}$ The two mind-sets can be distinguished specifically by individuals' response to failure. As defined by Dweck, 'In a fixed mind-set student believe their basic abilities, their intelligence, their talents, are just fixed traits. They have a certain amount and that's that, and then their goal becomes to look smart all the time and never look dumb. In a growth mind-set student understand that their talents and abilities can be developed through effort, good teaching and persistence. They don't necessarily think everyone's the same or anyone can be Einstein, but they believe everyone can get smarter if they work at it' "(an interview with Carol Dweck: https://onedublin.org/2012/06/19/stanford-universitys-carol-dweck-on-the-growth-mindset-and-education/, accessed 2018-03-09). In medical education, a growth mind-set is more desirable as clinical learners will always continue to gain new knowledge, learn new skills and perform new tasks. Therefore, they need to be prepared for unsuccessful task completion and 'failure', however academically brilliant they may be. A growth mind-set will allow learners to continue to work hard, cope with challenges and setbacks and treat failure as a learning opportunity. Feedback on performance is critical to development of mind-sets. If institutions, implicitly or explicitly, appear to promote positive feedback, this will result in avoidance of constructive feedback by teachers and rejection of constructive feedback by learners. In our research findings described in Chapter 4, our participants raised the 'culture of excellence' as a major barrier to honest feedback, where the 'pedigree' of the learners and institution prevented teachers from using any language that might be threatening to learners' self-esteem. Furthermore, our teachers worried about being taken to task by the educational leadership for giving anything other than positive feedback to the residents. Short duration of working relationships adds to the discomfort of honest feedback exchanges. Other researchers have also stated that clinical teachers hesitate to offer any comments that might upset hurting learners or damage working relationships, and commented on the lack of longitudinal relationships which makes it harder to build an educational alliance. , $9,10,63$ In summary, institutions should create opportunities for longitudinal teacher-learner relationships, communicate that professionals at all 
levels are expected to have strengths as well as areas for improvement, normalise exchange of constructive feedback, prioritise performance improvement through a growth mind-set (Chapters 3-5).

\section{Encouraging learning goal-orientation}

Goal orientation is a disposition towards validation of one's ability, and significantly influences intrinsic motivation among individuals. Earlier descriptions of this concept included two types of achievement goals: task involvement, where individuals define their competence against their own abilities, and ego involvement, where individuals define their competence relative to others. ${ }^{37}$ Later work by Dweck described two types of goal orientation, performance and goal orientation. ${ }^{33}$ Learners with a learning goal orientation are focussed on acquiring new skills and gaining competence, thus they are more likely to seek feedback and accept constructive feedback as a means of correcting deficiencies and improving future performance. ${ }^{29-31}$ Performance goal orientation leads learners to focus on gaining approval from others. This orientation was further categorised as avoidant and prove performance goal orientation. ${ }^{36}$ The former focuses on avoidance of failure and the latter on showcasing performance to prove competence The traditional learning environment in medical education is one that promotes summative assessments and assessment 'of' rather than 'for' learning, which in turn promote a performance-goal orientation among learners. Institutions have a major role to play in moving towards formative assessments and assessment for learning. This can be done through establishing a learner-centred learning culture, focussing on competence and mastery of tasks rather than self-image, encouraging ongoing feedback seeking, and fostering educational alliances between learners and teachers with regular performance-based feedback targeting learner growth. Additionally, institutions should engage in participatory design with learning environments co-constructed by teachers, learners and institutional leaders. ${ }^{54,55}$ This approach will likely promote a learning culture which promotes proactive feedback seeking, normalises constructive feedback on performance, discussion of action plans for improvement and bidirectional feedback.

In summary, we describe five key learner self-attributes which we believe are essential to foster internal motivation, engagement in feedback seeking, acceptance of constructive feedback, and willingness to change practice with an eye on the prize, namely professional growth. On the other side of the balance, we see important teacher and institutional attributes and resulting strategies that can guide learner self-characteristics in an optimal direction to seek, receive feedback, reflect on performance, formulate performance improvement goals, continue to improve performance and successfully accomplish increasingly complex clinical tasks thereby proceeding towards independent practice. Teachers can promote self-awareness, attend to self-efficacy (even if constructive feedback is being given, previous successes can be discussed and reinforced) and balance external guidance and internal guidance (autonomy) based on the level and capabilities 
of learners. The role of institutions should be to promote a growth mind-set and a learning goal orientation among learners, promote a developmental learning climate, focus on assessment for learning, provide opportunities for longitudinal teacher-learner relationships, and establish a culture of growth. These key traits will now be brought together under three key theories which were discussed in the introduction, but now applied to our research findings.

\section{Linking key theoretical principles to our research findings}

Three key psychosocial theories were discussed in the Introduction section as applicable to our research into the sociocultural aspects of the feedback exchange; the giving, receiving, acceptance and incorporation into performance: Sociocultural theory, Politeness theory and Self-determination theory. In this section, we will discuss how each of these theories relate to our research findings and what principles from these theories would be most useful in establishing a feedback culture of professional growth.

\section{A. Sociocultural theory and feedback}

Informed by a sociocultural perspective, learning is thought to occur through interaction, negotiation, and collaboration, thus institutions and teachers should support learners to engage increasingly in professional activities of the community. ${ }^{64,65}$ In medical education, learning occurs developmentally as learners go through basic to advanced levels of training, and continues after formal training is completed. This training is intended to develop professionals who will provide high quality patient care. Today, in clinical settings, the emphasis is on team-based patient care where physician trainees interact with peers, teachers, as well as multi-professional staff. Thus, beyond medical school learning occurs in a community of practice, where team members learn from and develop with others. Applying these concepts to feedback and our own research, institutions need to attend to the broader social system in which learning is occurring and how development of individual learners occurs as they participate in activities as a team or community. When this theory is applied to educational assessment and feedback, as studied in our own research, institutions should establish explicit expectations for teachers and learners to coconstruct a learning environment where they: (a) practice facilitated reflection on strengths and areas that need improvement, (b) formulate and discuss discrete learning goals depending on the clinical task at hand, (c) attempt to predict the gap between current performance and expected performance, and (d) exchange meaningful formative feedback on performance focussing on growth, and (e) develop action plans to narrow the gap between observed and expected performance. It must be emphasised that learners, especially in postgraduate settings, should take the lead on each of these steps and teachers and institutions should engage in participatory design of learning environments. ${ }^{54,55}$ This will help learners to become valuable members in their community of practice. ${ }^{64}$ 


\section{B. Politeness theory and feedback}

Politeness theory assumes that most conversations are potential face-threatening acts either to the hearer or speaker. ${ }^{66,67}$ Face has been categorised as positive face (the need to project a positive image to others) and negative face (freedom to act without imposition). In clinical training, positive face can be viewed as the self-efficacy of learners and negative face as learner autonomy. Self-efficacy and autonomy play an even more dominant role when the learners are residents or junior doctors, who are not only trainees but also professionals directly responsible for patient care. In this context, exchanges viewed as "negative", such as constructive feedback, may be perceived as a breach of the norms of expected politeness. Honest constructive feedback is essential for longitudinal growth professional improvement, even if advanced learners' sense of self-efficacy could be adversely affected. Just as Ginsburg and colleagues reported that faculty comments on learner evaluations exhibited non-specific language, and related this tendency to politeness concepts; our participants also stated that most feedback comments from faculty were vague, not linked to goals and unhelpful in developing improvement plans. ${ }^{11,12}$ Without prompting, our teachers and learners used the term, 'culture of niceness' and the 'culture of excellence', a culture which impedes honest constructive feedback conversations. In exploring the intersection of politeness and learning culture and their effects on feedback conversations we believe our research has advanced the understanding of how feedback could impact positive face (self-efficacy) and negative face (autonomy). We also developed a model from the narratives of participants demonstrating how institutional feedback culture, including politeness concepts, could potentially influence feedback seeking, acceptance of constructive feedback, and bidirectional feedback (see Chapter 4).

\section{Self-determination theory and feedback}

The final theory applicable to our research findings is the self-determination theory. ${ }^{68,69}$ This theory proposes that professionals have three key needs: competence, relatedness and autonomy. These needs enhance intrinsic motivation, which is further amplified by factors such as challenge, curiosity, control or autonomy, cooperation and completion, and recognition. In applying motivation to performance-based feedback, we argue that learners driven by intrinsic motivation are more likely to engage in feedback seeking behaviours, accept and assimilate feedback, and therefore work on performance improvement. Since the goal in medical education is to provide increasing autonomy to learners during training, thereby preparing them for independent practice, the learning culture should emphasise intrinsic motivation rather extrinsic motivation. ${ }^{70}$ Ten Cate et al suggest that three approaches can boost motivation during feedback conversations: shifting the focus from the individual to the context; shifting from instructional messages to selfregulation; and shifting the focus from the perspective of feedback provider to recipient.

${ }^{71}$ Our participants raised comparable strategies to enhance the impact of feedback: focus on observed behaviours in the workplace, centre feedback conversations around learning 
goals, provide learning opportunities to incorporate feedback and improve performance. These learner-centred and behaviour focussed feedback should occur in a context where longitudinal relationships between teachers and learners are promoted, learners are provided increasing autonomy based on ability and task complexity, and are internally motivated to work on continuing improvement.

\section{Limitations and strengths}

While our research has provided new insights into the sociocultural landscape of feedback, thereby advancing the field, there are several limitations that need to be discussed. First, the research was conducted at a single institution. Since institutional culture and learning culture are central to our studies, our descriptions of culture at our institution cannot be generalised to other institutions without further study. Academic institutions differ in location, size, affiliation with universities, setting etc. with varying priorities and missions. These attributes drive the three levels of culture: assumptions, written values and behaviours. ${ }^{28}$ As discussed in Chapter 2, the three levels do not often function in concert with each other, further contributing to the variations in institutional culture and behaviour.

Second, the entire research was carried out in a single clinical department, the department of medicine. Institutional feedback culture is likely to be different in different departments, thus these results may not be applicable without further explorations of the specific cultural context. The culture in departments focussed on procedural skills will be markedly different from non-procedure-based departments. For example, in surgery and anaesthesia, a key learning setting is the operating room where the culture is more hierarchical, contact between supervisors and trainees may be limited to the duration of the procedure, and the focus is likely to be on constructive skills-based feedback. Though surgical trainees may engage in feedback seeking as much as non-surgical trainees and are likely to be receptive to feedback from supportive supervisors, relationship building in these settings would be different and the politeness concepts discussed previously may not be fully applicable. While specific departmental sociocultural facilitators and barriers that impact feedback in a given setting should be explored, the overarching principles of our findings that sociocultural factors play a dominant role in the quality and impact of feedback, and the levels of organisational culture will still apply.

Although a large quantity of data was available, our participants were a sample of a large resident and faculty populations, and we may not have captured a full range of opinions from non-participants. Non-participants may have strong and contradictory feelings about feedback and the institutional feedback culture which we could have missed. Moreover, the more junior residents may not have shared their opinions openly in a mixed focus group where their senior residents were also present. When using focus group discussions for data collection, we cannot always be sure that all participants had sufficient time to express opinions in detail. ${ }^{72}$ Focus groups aim to discover participants' 
opinions on a given subject, but such perceptions may differ from actual actions. However, if focus groups are facilitated skilfully, in-depth open-ended explorations of participant opinions, challenges, perceptions can be effectively accomplished and with the right participant group, theories and models can be developed.

A potential critique could be that this series of studies used the approaches of ethnography and grounded theory to answer the research questions. We would respond that these approaches helped each study to provide a scaffolding upon which the next study was based. For example, we started the journey with the goal of exploring sociocultural influences of feedback, but from the point of view of learners and teachers and not from the perspective of educational experts. The concept of institutional culture emerged from resident opinions, and participants were also quick to point out the paradox of a hierarchical culture coexisting with a culture of politeness (Chapter 3 ). This combination of strange bedfellows ended up being perceived as a major barrier to honest and meaningful feedback conversations, therefore with little impact on behaviour and growth. This allowed us to continue further in-depth explorations on the feedback culture with the addition of faculty participants to examine the view from both sides (Chapter 4). Since the goal of grounded theory studies are to gain new understanding of otherwise poorly understood social phenomena, this methodology was appropriate to answer research questions 1 and 2. We continued exploration of this phenomenon through the framework of the Johari window as self-awareness appeared to significantly influence feedback seeking and receptivity to feedback, without which there would be no impact on the learner (Chapter 5). Therefore, we believe that the Johari window could be quite useful in directing initiatives to enhance feedback quality and its effects on behaviour change. It must be emphasised that the constructivist approach embraces co-construction of themes and theory between researcher and participants grounded in participant narratives. Armed with these findings, we proceeded with an ethnographic study to examine practices during feedback conversations (Chapter 6) as well as to compare the congruence and incongruence between expressed opinions and real-life action.

The ethnographic study, described in Chapter 6, was conducted entirely in continuity clinics, the only setting where residents and faculty have longitudinal relationships. ${ }^{25,27}$ The educational alliance that we observed between teachers and learners is likely born out of this relationship where they have gotten comfortable with each other over time. Moreover, we hypothesise that the teachers, who are primary care physicians, naturally adopt an open-ended stance which is typical of physician-patient communications in this setting. The implications of these observations may not directly translate even to inpatient settings in the same department, let alone other departments. In inpatient settings, duration of working relationships is typically two weeks and there are days off within that period. How can we take our conclusions from continuity clinics and impose it on other settings and other departments? Regardless, we conclude that there is a case for institutions and departments to foster longitudinal relationships between teachers and learners, perhaps even outside of an assessment setting, where each is invested in the growth 
and development of the other. As one of our cardiologists said, 'How can I feel any ownership for this resident if we work together for a week?' (Chapter 4). Thus, we argue that the concepts proposed by other researchers such as the educational alliance and the R2C2 models would apply at any institution and any department, albeit requiring attention to the work setting and specific institutional and learning cultures ${ }^{13,14,18-20}$

Finally, we do believe that the recommendations that we propose to enhance a feedback culture are in line with the findings of our research studies, relevant psychosocial theories and build on previous research findings on the sociocultural influences of feedback, self-assessment and reflection and how they impact feedback seeking and receptivity, and a coaching mind-set for clinical teachers. $6,7,9,10,13,20$

\section{Implications for practice and further research: Swimming in a sea of paradoxes and reaching the shore}

The four research studies and one synthesis paper presented in this thesis indicate that it is time to stop focussing on teacher feedback providing techniques in feedback initiatives once and for all. The feedback conversation should be turned on its head and viewed from the learner perspective, ${ }^{73}$ with a discussion of teacher and institutional factors as facilitators and barriers to learner feedback seeking, acceptance, incorporation and behaviour change. Below is a discussion of key themes that seem to arise from all the studies. The themes are not isolated, in fact they are interwoven and concepts from each might rear their head in others.

\section{A. Culture is the axis around which feedback revolves: The culture paradox}

In all our studies our participants, teachers and residents, raised institutional culture as a major factor that influences the exchange of feedback. Both sets of participants saw the departmental culture as very nurturing and supportive of residents which helped residents gain knowledge and skills and move on to fellowship training programs at top institutions. However, the same supportive culture was not conducive to exchanging honest, meaningful feedback. This is the cultural paradox that we heard over and over in most of our discussions. There seemed to be two aspects of the culture that served as barriers to growth-enhancing feedback: (1) a culture of politeness, which caused faculty and residents to avoid any language that could hurt others or damage relationships, and (2) a culture of excellence, the assumption that outstanding residents matched into the institution and they were academically brilliant in all domains and do not need any 'negative' feedback. It has been stated that excess of support without adequate challenge does not promote growth and in fact produces stasis. ${ }^{74}$ Our message to medical educators and institutions are that they should be cognisant that all adult learners, even the most gifted and brilliant individuals, have areas that need improvement. The cultures of politeness and excellence need not be eliminated, rather they should be cultivated, harnessed and redirected to target improvement and growth as their essential obligation. 


\section{B. Politeness theory concepts are critical in addressing facilitators and barriers to feedback: The face paradox}

The perspective of Politeness theory, ${ }^{60}$ which views all interpersonal interactions as a potential threat to the 'face' of the speaker or the recipient, appears to be very applicable to our research findings. From the mouths of speakers and recipients, we found that they hesitated to provide or receive constructive feedback respectively. Teachers and the more senior residents mostly avoided saying anything that could potentially hurt the selfesteem of their learners or damage working relationships. Some residents also acknowledged unwillingness to receive constructive feedback as they were doing their best, often overwhelmed by work obligations, and did not have the mental or emotional space to hear criticism. We observed the following paradoxes in our research: teachers (faculty and senior residents) stated having their learners' best interests at heart, yet avoided any language that could damage their self-esteem until the most egregious errors were noted (positive face); some residents stated that feedback would be more credible if teachers observed them directly, yet others stated that this would be an infringement on their autonomy (negative face); faculty themselves rarely observed residents, assuming that their excellent residents could successfully carry out all clinical care tasks without direct observation (culture of excellence and negative face). We propose that both positive face (self-efficacy) and negative face (autonomy) can be optimally enhanced using the following strategies: emphasise to teachers and learners that constructive feedback is essential to focus on continuing performance improvement and professional growth, thus normalising its exchange; preserve self-efficacy while providing constructive feedback through reinforcement of previous successes and using these to scaffold new areas for improvement; enhance self-efficacy by exchanging feedback targeted towards learner goals; encourage learner self-reflection; and co-construction of new learning opportunities by teachers and learners. Autonomy should be defined as a developmental phenomenon, i.e. all residents would go through the stages of full external, guided and full internal regulation; ${ }^{51}$ and all teachers should be trained in this approach. Regardless of the stage of development, direct observation should be a requirement so that all resident competencies are observed at various times during their training.

\section{Self-awareness is integral to feedback seeking and acceptance: The paradox of the known and unknown}

Our participants' opinions indicated that they considered themselves to be accurate at self-assessment and their own harshest critics. Yet, the literature is awash with findings that professionals at all levels are not necessarily accurate at self-calibration of performance. ${ }^{48-50,75,76}$ In fact, recollection of suboptimal performance is more flawed than skilled performance. Furthermore, the mind-set of individuals seems to influence the accuracy of their self-assessment. ${ }^{33}$ We further discuss the implications of mind-set below, but here we propose strategies to enhance self-awareness. The Johari window can be a robust framework to enhance self-awareness among clinical learners. ${ }^{31}$ If the goal is to 
maximise the 'open' quadrant (awareness of behaviours by self and others), the following strategies may be effective: facilitating self-reflection by learners to diagnose the level of their self-awareness; discussion of behaviours that are known to self and others to reinforce the strengths and validate their calibration of areas that need improvement; promoting a spirit of self-discovery so that they continue to seek to discover new areas of excellence as well as new areas for improvement. Self-discovery will allow learners to seek feedback regularly, seek it from multiple sources and continue to formulate new goals once previous goals have been achieved. These strategies simultaneously can enhance self-esteem.

\section{It's not how the feedback is given but it is all about the alliance: The recipe and relationship paradox}

Decades of feedback faculty development have focussed on arming teachers with the skills and techniques (recipes) for providing effective feedback. Research during this time has also shown that learners perceive that feedback is not provided frequently, the feedback they receive is not helpful, or there is a mismatch of perceptions between teachers and learners on the adequacy and quality of feedback. Turning the field of feedback on its head, recent work emphasises that the learner is central to the exchange of feedback and for them to develop as professionals, a congenial educational alliance is needed between teachers and learners. Tenets from communication theory are very applicable to a learner-centred, alliance-focussed approach to feedback. Learners must occupy centre stage in feedback conversations. As in physician-patient communications, a feedback conversation should be planned ahead, and the stage set by establishing rapport and formulation of goals. Learners should be encouraged to initiate conversations, discuss goals, self-assess on strengths and challenges, formulate action plans for improvement. Teachers should guide these narratives, probe as needed, provide additional data, facilitate self-reflection by learners, assess emotional reaction, and ensure understanding. Together, they should reach a shared understanding of the learners' performance level, engage in shared decision making and forward planning. Returning to the Johari window, the 'blind' areas (known to others but not to self) can be tackled by establishing a strong educational alliance, demonstration of beneficence, use of non-judgemental tone and language, and reaching a shared agreement. An educational alliance might be the single most important strategy to uncover the hidden quadrant by encouraging self-disclosure by learners of their challenges, limitations and fears. As other researchers have stated, a feedback conversation is a complex social encounter and rules and recipes might not have the impact that a trusting working relationship can.

\section{Institutions have an obligation to encourage a growth mind-set: The performance and growth paradox}

Our research into sociocultural influences of feedback emphasises the importance of feedback seeking, its acceptance, and assimilation if the end goal is behaviour change. 
The two core types of mind-sets that impact individuals' intrinsic motivation to change and ongoing learning are a fixed and a growth mind-set. ${ }^{33}$ In the past, the learning environment in medical education with its focus on summative assessment has encouraged a fixed mind-set among learners, which makes individuals believe that success is a result of innate intelligence, talents and abilities. Those with a growth mind-set, on the other hand, believe that success can occur through hard work, learning is ongoing and skills can be developed. In addition to mind-set, another individual disposition to consider among learners is their goal-orientation, which has a strong influence on intrinsic motivation and coping strategies when they face challenging situations. ${ }^{32}$ Though individuals may shift between goal orientations for different tasks, most tend to have a dominant orientation. Learners with a performance goal orientation focus on how they perform on exams or other forms of assessment, and whether they project a positive image to others, thus they do not engage in feedback seeking or only seek feedback that would enhance their self-image or is congruent with their self-assessment. ${ }^{34,35,77,78}$ Those with a learning goal orientation seek to acquire new skills and master new tasks, they seek feedback, are receptive to constructive feedback, and motivated to incorporate feedback into performance. From our study results, we discovered that residents were interested in ongoing improvement, professed willingness to accept constructive feedback. Yet, they rarely communicated clear mastery goals to their teachers, sought feedback or initiated clear plans to move to the next level. As medical education embraces assessment for learning, and programmatic assessment, it is vital that institutions promote a growth mind-set among teachers and learners. In designing curricula and assessment methods, institutions need to promote ongoing learning, understanding rather than knowledge, intrinsic motivation, feedback seeking and acceptance, and create opportunities that would showcase learning goals rather than performance goals.

\section{E Co-regulation of learning may maximise the impact of feedback: The regulation paradox}

Resident physicians engage in training while simultaneously serving at the front line of patient care. From our findings, we conclude that they value their relationship as the primary physician with patients, and their autonomy, while they continue their training and develop the competencies needed for independent practice. During their training, they need to move along a spectrum of full external guidance to full internal guidance as they learn new concepts. As they develop their knowledge of clinical medicine and gain patient care and other technical skills, they are also expected to learn the art of self-regulation of their practice through feedback seeking, incorporation of feedback from multiple sources into their practice, and reflection. This occurs in a social context, namely within a community of practice. Additionally, they should engage in discussion of learning goals, direct observation of their performance, self-assessment and formulation of action plans. While our residents appeared to agree with these strategies in principle, there were statements that also indicated that they did not discuss specific learning goals with their teachers, seek feedback on goals regularly, desired autonomy rather prematurely and 
hesitated to lose face in front of the patients that they cared for. Yet, in the interest of safe patient care, self-regulated learning during early levels of clinical training would be inappropriate. Teachers also hesitated to observe their residents and avoided any action that could threaten their autonomy. It was evident that teachers were operating under the assumption that residents had acquired enough patient care skills that they could be mostly unsupervised, and excellence in one domain meant excellence in all. We endorse the model of co-regulated learning described by Rich, ${ }^{79}$ which can be described as a process of interdependency between residents and their supervising faculty as they share common patient care goals. This model of co-regulation of learning has also been described as participatory design of learning environments which has been found to result in improved learner outcomes. ${ }^{54,55}$ Specific strategies would be for teachers and learners to form an educational partnership, discuss learning goals at each stage of training based on mastery of competence, have a two-way exchange during feedback conversations, engage in shared decision making regarding future plans. In Chapter 6 , we propose a participatory design feedback loop for co-creation of learning opportunities by learners and teachers, consisting of discussion of goals, direct observation, debriefing, informed selfassessment and facilitated reflection and development of action plans.

\section{Implications for faculty development}

Rather than the design of new feedback initiatives that recommend more techniques for faculty to 'give' feedback to learners, newer feedback initiatives should target the factors that facilitate the quality and impact of this powerful social interaction. Faculty should be trained in establishing a congenial learning climate, forging educational alliances with their learners, and forming trusting relationships where their beneficence would not be in doubt. They should be encouraged to engage in informed self-assessment and facilitated reflection with learners. Faculty, in turn, should stimulate feedback-seeking behaviours among learners and foster a growth mind-set and learning goal orientation. They should receive training in direct observation skills and accurate calibration of learner performance upon which to base their feedback data. Learner self-efficacy should be attended to, and autonomy should be provided to learners appropriate to their level and ability. In the interest of performance improvement and professional growth, constructive feedback should be exchanged which can be done without damaging self-efficacy. They need to be trained in coaching strategies which specifically target growth of learners. Finally, faculty need training in seeking and receiving feedback themselves as rolemodels to their learners.

\section{What is the role of residents in optimizing feedback culture? It takes two to tango}

If co-creation of educational environments and learning opportunities is to be achieved, residents themselves have a responsibility in the feedback loop. First, residents should be 
encouraged to develop a growth mind-set with a conviction that ongoing hard work and learning will raise them from good to great. Next, a learning goal-orientation should be fostered especially at advanced levels of professional training. This would manifest as goal-setting, feedback seeking, receptivity to feedback, willingness to engage in informed self-assessment and reflection on their performance, develop performance improvement plans, change in behaviour / practice and creating learning opportunities with their teachers. Finally, they need to be able to disclose their challenges and fears during the discussion of learning goals and be open to self-discovery of hidden areas of strengths and deficiencies.

\section{Conclusions}

In this thesis, we have uncovered further sociocultural factors that significantly influence feedback conversations and impact learner growth, and linked these to the three levels of organisational culture. Additionally, we have demonstrated that three fundamental psychological theories have major applications as we move feedback in medical education forward. Medical education, regardless of context, appears to have a cultural paradox. On the one hand, we are moving to a polite culture that facilitates a congenial learning and working climate, and on the other hand, learners continue to perceive a hierarchical culture which prevents bidirectional feedback. On the one hand, we focus on learner self-efficacy to reinforce good practice, and on the other hand, we fear that any constructive feedback will threaten self-efficacy. We have constructed a see-saw with learner (self) traits on one end and teacher and institutional traits (other) on the opposite end. We propose that these be optimally balanced to promote behaviours that will promote change and growth on both sides. This means that teachers and learners should develop a learning goal-orientation, actively seek feedback, accept and incorporate reinforcing as well as constructive feedback, acknowledge that everyone has limitations and develop a growth mind-set. The pendulum seems to have swung from a harsh learning climate that did not promote growth, but has it swung too far? It is time to bring it back to middle ground and we believe co-creation of the learning environment is the right direction to achieve this. 


\section{REFERENCES}

1. Lingard L. Does your discussion realize its potential? Perspect Med Educ 2017;6:344-6.

2. Watling CJ. Unfulfilled promise, untapped potential: feedback at the crossroads. Med Teach 2014;36:692-7.

3. Bing-You RG, Trowbridge RL. Why medical educators may be failing at feedback. JAMA 2009;302:1330-1.

4. Anderson PA. Giving feedback on clinical skills: are we starving our young? J Grad Med Educ 2012;4:154-8.

5. Sender Liberman A, Liberman M, Steinert Y, McLeod P, Meterissian S. Surgery residents and attending surgeons have different perceptions of feedback. Med Teach 2005;27:470-2.

6. Sargeant J, Mann K, Sinclair D, Van der Vleuten C, Metsemakers J. Understanding the influence of emotions and reflection upon multi-source feedback acceptance and use. Adv Health Sci Educ Theory Pract 2008; 13:275-88.

7. van de Ridder JM, McGaghie WC, Stokking KM, ten Cate OT. Variables that affect the process and outcome of feedback, relevant for medical training: a meta-review. Med Educ 2015;49:658-73.

8. Sargeant J, Mann K, Sinclair D, van der Vleuten C, Metsemakers J. Challenges in multisource feedback: intended and unintended outcomes. Med Educ 2007;41:583-91.

9. Watling $C$, Driessen $E$, van der Vleuten $C P$, Vanstone $M$, Lingard L. Beyond individualism: professional culture and its influence on feedback. Med Educ 2013;47:585-94.

10. Watling C. Cognition, culture, and credibility: deconstructing feedback in medical education. Perspect Med Educ 2014;3:124-8.

11. Ginsburg S, Regehr G, Lingard L, Eva KW. Reading between the lines: faculty interpretations of narrative evaluation comments. Med Educ 2015;49:296-306.

12. Ginsburg S, van der Vleuten C, Eva KW, Lingard L. Hedging to save face: a linguistic analysis of written comments on in-training evaluation reports. Adv Health Sci Educ Theory Pract 2016;21:175-88.

13. Telio S, Regehr G, Ajjawi R. Feedback and the educational alliance: examining credibility judgements and their consequences. Med Educ 2016;50:933-42.

14. Telio S, Ajjawi R, Regehr G. The "educational alliance" as a framework for reconceptualizing feedback in medical education. Acad Med 2015;90:609-14.

15. Kurtz S, Silverman J, Benson J, Draper J. Marrying content and process in clinical method teaching: enhancing the Calgary-Cambridge guides. Acad Med 2003;78:802-9.

16. Kurtz SM, Silverman JD. The Calgary-Cambridge Referenced Observation Guides: an aid to defining the curriculum and organizing the teaching in communication training programmes. Med Educ 1996;30:83-9.

17. Salmon P, Young B. Creativity in clinical communication: from communication skills to skilled communication. Med Educ 2011;45:217-26.

18. Sargeant J, Lockyer J, Mann K, et al. The R2C2 model in residency education: How does it improve feedback use? . Acad Med 2017; In press.

19. Sargeant J, Mann K, Manos S, et al. R2C2 in Action: Testing an Evidence-Based Model to Facilitate Feedback and Coaching in Residency. J Grad Med Educ 2017;9:165-70.

20. Sargeant J, Lockyer J, Mann K, et al. Facilitated Reflective Performance Feedback: Developing an Evidenceand Theory-Based Model That Builds Relationship, Explores Reactions and Content, and Coaches for Performance Change (R2C2). Acad Med 2015;90:1698-706.

21. Gavriel J. Cognitive Behavioural Coaching principles and basic tools to support trainees. Educ Prim Care 2016;27:326-9.

22. Rangachari D, Brown LE, Kern DE, Melia MT. Clinical coaching: Evolving the apprenticeship model for modern housestaff. Med Teach 2017;39:780-2.

23. Lovell B. What do we know about coaching in medical education? A literature review. Med Educ 2017.

24. Kopechek J, Bardales C, Lash AT, Walker C, Jr., Pfeil S, Ledford CH. Coaching the Coach: A Program for Development of Faculty Portfolio Coaches. Teach Learn Med 2017;29:326-36.

25. Carroll K, ledema R, Kerridge R. Reshaping ICU ward round practices using video-reflexive ethnography. Qual Health Res 2008;18:380-90. 
26. Gordon L, Rees C, Ker J, Cleland J. Using video-reflexive ethnography to capture the complexity of leadership enactment in the healthcare workplace. Adv Health Sci Educ Theory Pract 2017;22:1101-21.

27. ledema R. Creating safety by strengthening clinicians' capacity for reflexivity. BMJ Qual Saf 2011;20 Suppl 1:i83-6.

28. Schein EH. Organizational culture and leadership. 4th ed. San Francisco: Jossey-Bass; 2010.

29. van de Ridder JM, Berk FC, Stokking KM, Ten Cate OT. Feedback providers' credibility impacts students' satisfaction with feedback and delayed performance. Med Teach 2014:1-8.

30. Sargeant J, McNaughton E, Mercer S, Murphy D, Sullivan P, Bruce DA. Providing feedback: exploring a model (emotion, content, outcomes) for facilitating multisource feedback. Med Teach 2011;33:744-9.

31. Luft J. Of human interaction. Palo Alto, Calif., : National Press Books; 1969.

32. Dweck CS. Self-theories and goals: their role in motivation, personality, and development. Nebr Symp Motiv 1990;38:199-235.

33. Dweck CS. Mindset: The New Psychology of Success. New York: Randpm House; 2006.

34. VandeWalle D, Cron WL, Slocum JW, Jr. The role of goal orientation following performance feedback. J Appl Psychol 2001;86:629-40.

35. VandeWalle D, Ganesan S, Challagalla GN, Brown SP. An integrated model of feedback-seeking behavior: disposition, context, and cognition. J Appl Psychol 2000;85:996-1003.

36. VandeWalle D, Cummings LL. A test of the influence of goal orientation on the feedback-seeking process. J Appl Psychol 1997;82:390-400.

37. Nicholls JG. Development of perception of own attainment and causal attributions for success and failure in reading. J Educ Psychol 1979;71:94-9.

38. Dweck CS. From needs to goals and representations: Foundations for a unified theory of motivation, personality, and development. Psychol Rev 2017;124:689-719.

39. Rochat P. Five levels of self-awareness as they unfold early in life. Conscious Cogn 2003;12:717-31.

40. Bandura A. Self-efficacy: toward a unifying theory of behavioral change. Psychol Rev 1977;84:191-215.

41. Lane J, Lane AM, Kyprianou A. Self-efficacy, Self-esteen and their impact on academic performance Social Behavior and Personality 2004;32:247-56.

42. Bandura A. Self-efficacy: The exercise of control. New York: W.H. Freeman; 1997.

43. Deci EL, Ryan RM. The support of autonomy and the control of behavior. J Pers Soc Psychol 1987;53:1024-37.

44. Ryan RM, Kuhl J, Deci EL. Nature and autonomy: an organizational view of social and neurobiological aspects of self-regulation in behavior and development. Dev Psychopathol 1997;9:701-28.

45. Pink DH. Drive : the surprising truth about what motivates us. New York, NY: Riverhead Books; 2009.

46. Daloz LA. Effective teaching and mentoring. 1st ed. San Francisco, Calif.: Jossey-Bass; 1986.

47. Mann K, van der Vleuten C, Eva K, et al. Tensions in informed self-assessment: how the desire for feedback and reticence to collect and use it can conflict. Acad Med 2011;86:1120-7.

48. Boud D. Enhancing learning through self assessment. London; Philadelphia: Kogan Page; 1995.

49. Dunning D, Heath C, Suls JM. Flawed Self-Assessment: Implications for Health, Education, and the Workplace. Psychol Sci Public Interest 2004;5:69-106.

50. Eva KW, Regehr G. Self-assessment in the health professions: a reformulation and research agenda. Acad Med 2005;80:S46-54.

51. ten Cate O, Snell L, Mann K, Vermunt J. Orienting teaching toward the learning process. Acad Med 2004;79:219-28.

52. Vermunt JD, Verloop N. Congruence and friction between learning and teaching. Learning and Instruction 1999;9:257-80.

53. Spector PE. Perceived control by employees: A meta-analysis of studies concerning autonomy and participation at work. Human Relations 1986;39:1005-16.

54. Könings KD, Brand-Gruwel S, van Merriënboer JJG. Towards more powerful learning environments through combining the perspectives of designers, teachers, and students. Br J Educ Psychol 2005;75:645-60.

55. Könings KD, Seidel T, van Merriënboer JJG. Participatory design of learning environments: integrating perspectives of students, teachers, and designers. Instr Sci 2014;42:1-9. 
56. Benbassat J, Baumal R. Enhancing self-awareness in medical students: an overview of teaching approaches. Acad Med 2005;80:156-61.

57. Goleman D. What makes a leader? Harv Bus Rev 1998;76:93-102.

58. Goleman D. The emotionally competent leader. Healthc Forum J 1998;41:36, 8, 76.

59. Kegan R. The evolving self : problem and process in human development. Cambridge, Mass.: Harvard University Press; 1982.

60. Rochat P, Broesch T, Jayne K. Social awareness and early self-recognition. Conscious Cogn 2012;21:1491-7.

61. Novack DH, Epstein RM, Paulsen RH. Toward creating physician-healers: fostering medical students' selfawareness, personal growth, and well-being. Acad Med 1999;74:516-20.

62. Novack DH, Suchman AL, Clark W, Epstein RM, Najberg E, Kaplan C. Calibrating the physician. Personal awareness and effective patient care. Working Group on Promoting Physician Personal Awareness, American Academy on Physician and Patient. JAMA 1997;278:502-9.

63. van de Ridder JM, Berk FC, Stokking KM, Ten Cate OT. Feedback providers' credibility impacts students' satisfaction with feedback and delayed performance. Med Teach 2014:1-8.

64. Lave J, Wenger E. Situated learning : legitimate peripheral participation. Cambridge England; New York: Cambridge University Press; 1991.

65. Wertsch JV. Voices of the mind : a sociocultural approach to mediated action. Cambridge, Mass.: Harvard University Press; 1991.

66. Brown P, Levinson SC. Politeness : some universals in language usage. Cambridge Cambridgeshire ; New York: Cambridge University Press; 1987.

67. Brown P, Levinson S. Universals in language usage: Politeness phenomena. Cambridge: Cambridge University Press; 1978.

68. Ryan RM, Deci EL. Self-determination theory and the facilitation of intrinsic motivation, social development, and well-being. Am Psychol 2000;55:68-78.

69. Ryan R. Thoughts on the genesis of self-determination theory. American journal of health promotion : AJHP 2013;27:TAHP8.

70. Mann KV. Thinking about learning: implications for principle-based professional education. The Journal of continuing education in the health professions 2002;22:69-76.

71. Ten Cate TJ, Kusurkar RA, Williams GC. How self-determination theory can assist our understanding of the teaching and learning processes in medical education. AMEE guide No. 59. Med Teach 2011;33:961-73.

72. Stalmeijer RE, McNaughton N, Van Mook WN. Using focus groups in medical education research: AMEE Guide No. 91. Med Teach 2014;36:923-39.

73. Boud D. Feedback: ensuring that it leads to enhanced learning. Clin Teach 2015;12:3-7.

74. Daloz LA. Mentor : guiding the journey of adult learners. Second edition with new foreword, preface, and afterword. ed. San Francisco, CA: Jossey-Bass, a Wiley imprint; 2012.

75. Eva KW, Cunnington JP, Reiter HI, Keane DR, Norman GR. How can I know what I don't know? Poor self assessment in a well-defined domain. Adv Health Sci Educ Theory Pract 2004;9:211-24.

76. Eva KW, Regehr G. "I'll never play professional football" and other fallacies of self-assessment. J Contin Educ Health Prof 2008;28:14-9.

77. Gaunt A, Patel A, Fallis S, et al. Surgical Trainee Feedback-Seeking Behavior in the Context of WorkplaceBased Assessment in Clinical Settings. Acad Med 2017;92:827-34.

78. Gaunt A, Patel A, Rusius V, Royle TJ, Markham DH, Pawlikowska T. 'Playing the game': How do surgical trainees seek feedback using workplace-based assessment? Med Educ 2017;51:953-62.

79. Rich JV. Proposing a Model of Co-Regulated Learning for Graduate Medical Education. Acad Med 2017;92:1100-4. 
Summary 

It is imperative that all medical professionals, from trainees at all levels to practising clinicians, seek and receive feedback from multiple sources to calibrate their performance and engage in continuous self-improvement. With the move towards competency-based medical education, meaningful feedback on clinical performance and targeted towards learning goals is essential for trainees to progress towards independent and reflective practice of patient care. However, feedback conversations have traditionally been dominated by a unidirectional teacher to learner monologue. Though expert medical educators have described models and strategies for 'giving' feedback that included learner engagement, several research reports continue to report learner dissatisfaction with frequency and quality of feedback from their faculty. Additionally, such feedback seems to have little impact on behaviour change and improvement in practice. Clearly, a teachercentred feedback model is less than successful in influencing learner performance. It is also likely that the learning environment in medical education promotes a performance goal-orientation (one where learners are focussed on how they perform on assessments and how they are viewed by others) rather than a learning goal- orientation (one where ongoing learning is the goal and mistakes are considered an essential motivator of learning). The former goal orientation encourages learners to value image and ego over acknowledgement of limitations, therefore they are less likely to seek feedback, accept constructive feedback or incorporate feedback into practice. Over the last decade, the conversation on feedback has emphatically shifted to a learner-centred and indeed learner-initiated focus. Several investigators and educational experts have redefined feedback as a complex social exchange with the goal of recipient acceptance, assimilation and growth. These newer definitions remove the spotlight from the provider and place it on the recipient. If we accept a definition that targets recipient practice improvement and professional growth, we also need to view the feedback conversation through the lens of the recipient - what makes feedback credible and acceptable; what will encourage feedback seeking; and what will promote a growth mind-set?

Research in this area has started shifting the feedback conversation from a static teacher focussed monologue, which may be partially or even completely rejected by learners, towards a dynamic learner-initiated and teacher-facilitated bidirectional exchange. In our research, we aimed to extend the illuminating insights that have arisen from recent feedback research as a sociocultural phenomenon that necessitates active learner engagement and a coaching mind-set for teachers. To achieve this goal, we posed two broad research aims: (1) explore residents' and faculty perceptions regarding the institutional feedback culture and how this culture can be enhanced to optimise professional growth, and (2) explore whether their expressed opinions on feedback culture and best practices translated into action during real-life feedback conversations. This thesis focussed on residents and faculty in the Department of Medicine at the Brigham and Women's Hospital, where several resident surveys distributed by the graduate medical education office reported inadequate frequency of feedback exchanges and poor quality 
of faculty feedback. Informal faculty surveys indicated their struggles with providing impactful feedback, particularly constructive feedback. Feedback training workshops are available to faculty on the medical campus, but not mandated.

Specific research questions were:

1. What are the perceptions of residents and faculty regarding a definition of feedback culture and what elements constitute this culture?

2. How do residents and faculty view the current departmental culture and its influence on the quality of feedback conversations between residents and faculty

3. What language and behaviours are used by teachers and learners during formal feedback conversations between faculty and residents who have a longitudinal relationship in continuity clinics?

4. Can video-facilitated reflection and reflexivity enhance faculty awareness of effective and ineffective behaviours and promote future behaviour change?

The introduction in Chapter 1 traces the evolution of feedback, its adoption beyond the engineering world, traditions of feedback in medical education, from the older teachercentred to the newer learner-centred definitions and strategies and models that correspond to these definitions. We emphasise feedback as central to learner growth in the era of competency based medical education and describe why teachers and learners find these conversations challenging. Feedback is redefined as a sociocultural phenomenon which should focus on learner feedback seeking, acceptance, openness to receiving constructive data, and a growth mind-set. If the above factors are to be achieved, what makes feedback credible and acceptable needed explanation. For if learners reject feedback provided by teachers, it is as if the conversations never happened. A model is proposed that places learner performance improvement at the heart of a feedback conversation with teacher, learner and culture factors that could influence this. The feedback conversation, its challenges and its impact are viewed from multiple perspectives (teacher, learner and culture), with a postulation that these viewpoints may conflict with each other. We identified three psychosocial theories that have direct bearing on the effectiveness and impact of feedback exchanges: sociocultural theory, politeness theory and self-determination theory. How each of these theories intersect and influence feedback behaviours: feedback seeking, acceptance and behaviour change etc. is described in detail. We further described the two broad and four specific research questions intended to push the envelope of feedback research into deeper sociocultural realms and advance the field further. The chapter concludes with an overview of each chapter aimed at preparing readers for the storyline that emerged.

We take a slight detour in Chapter 2, but for an important reason. Since the approach to the entire research was through the use of rigorous qualitative methodology, specifically 
grounded theory and ethnographic approaches, we describe strategies to enhance reflexivity in qualitative research. Rigour mandates reflexivity on the part of qualitative researchers and the research team believed that it was essential to familiarise ourselves with our own beliefs and assumptions, as well as our relationship with the participants and the research topic that may influence data collection, analysis and interpretation. We embarked on an in-depth study of the concept of reflexivity aiming to equip ourselves with the knowledge and skills to conduct high-quality credible qualitative research. This effort culminated in a graphic depiction of the various steps of qualitative research and strategies to promote reflexivity in each step. Reflexivity was viewed from a personal (investigator) and epistemological perspective.

In the study described in Chapter 3, we report our first research study which was an openended exploration of the opinions of residents on how institutional factors influence the quality and impact of feedback, and their receptivity to feedback. Though we wanted to discover institutional and other sociocultural factors that impacted feedback, we used open-ended questions that did not mention culture. Surprisingly, resident participants repeatedly brought up the institutional culture as a challenge to meaningful feedback conversations. All themes emphasised the institutional culture in one form or another. The most surprising insight was the emergence of a culture of politeness at the institution as perceived by most of the participants. They emphasised that such a culture was nurturing and provided a family like work environment. However, this same culture was a deterrent to honest conversations that could include constructive feedback. Residents concluded that the culture needed to be changed to allow for meaningful feedback that could contribute to their growth, without damaging the friendly learning environment. Although residents highlighted culture-related themes, it was not entirely clear what elements drove this culture. Additionally, it was important to obtain perspectives from faculty on what challenges they face in having feedback conversations with residents and how they viewed the institutional culture- as a facilitator or barrier. Additionally, they stated that the cultural norms did not promote bidirectional feedback, from residents to faculty, as well as from junior to senior residents.

In Chapter 4, we present our next study where we conducted an in-depth exploration of residents' and faculty definition of a feedback culture, what elements constituted this culture, their views on the existence of a culture of politeness and whether such a culture helped or hindered feedback targeting professional growth. Two terms were used by both groups to define the institutional culture: culture of politeness and culture of excellence. The outstanding academic reputation of the institution and pedigree of its trainees constitutes the culture of excellence, one that can inhibit constructive feedback. The department valued a collegial and supportive work environment for residents, thus a culture of politeness. However, such a culture resulted in avoidance of any language that could be viewed as a threat to resident self-esteem. Most residents and faculty stated that longitudinal relationships, exchange of constructive feedback while addressing self-efficacy 
and autonomy were key factors in stimulating a feedback culture that could influence behaviour change. Interestingly, despite the consensus regarding the importance of bidirectional feedback, participants did not believe that the existing culture of politeness flattened out the hierarchical culture enough to promote feedback from junior to senior levels. Suggested strategies included normalising of constructive feedback, feedback seeking by residents and faculty and frequent direct observation of performance.

Frequent referrals to feedback seeking, receptivity and bidirectional feedback led to further inquiry on the impact of self-awareness on the quality and impact of feedback. In Chapter 5, resident and faculty discussions were analysed through the framework of the Johari window, a psychological framework that views interpersonal interactions through self-awareness of behaviours or performance and level of congruence with others' impressions of an individual's performance. The four quadrants described in this model are: open (the individual as well as others are aware of specific behaviours), blind (others are aware but the individual is unaware of these behaviours), hidden (the individual is aware of own behaviours but others are unaware of the context), and unknown (undiscovered behaviours by individuals and others). Since informed self-assessment and facilitated reflection are essential to accurate calibration of performance and resulting behaviour change, we propose that this framework would be useful in framing feedback conversations. We were able to generate individual and institutional strategies under each quadrant to encourage self-awareness, feedback seeking, receptivity to feedback, assimilation of feedback leading to behaviour change.

In the study described in Chapter 6, we observed and videotaped formal feedback conversations between residents and their continuity clinic preceptors to explore what verbal and non-verbal behaviours are adopted by teachers and learners. Using an ethnographic approach, six faculty were observed twice during their scheduled feedback conversations with residents whom they precepted in continuity clinics, making a total of 12 observations. There was clear evidence of rapport between faculty and residents, in the form of open body language, appearance of comfort during the conversation, nodding and smiling. Faculty typically employed self-reflection as an opening gambit and used specific examples from observed resident-patient encounter observations as a foundation for providing feedback and facilitation of action plans. The most skilled communicators were able to encourage residents to discuss their challenges and limitations, reach a shared agreement and allow residents to initiate action plans. We postulate that longitudinal relationships in continuity clinic settings promoted the easy rapport between faculty and residents and overall comfort in having feedback conversations. In addition, we raise the question whether primary care physicians naturally and unconsciously use physicianpatient communication skills in their feedback conversations.

A second part of this study examined the effect of video-facilitated debriefing on faculty self-awareness of feedback behaviours. This methodology, described as video-reflex- 
ive ethnography, allowed faculty to view their own behaviours, judge which of their behaviours were effective and what behaviours they might consider changing in future conversations. Watching the videos appeared to have reinforced many of their feedback practices, and also provided them with insights into strategies that were ineffective. Finally, they acknowledged that such conversations needed to occur more frequently, and despite the awkwardness of the observation and videotaping, the exercise forced them to formulate goals for feedback conversations and prompted them to observe residentpatient encounters.

On review and analysis of research findings from all our studies, we discovered some unique concepts that could enhance feedback cultures at academic medical institutions. In Chapter 7, we take a different look at feedback in describing strategies to promote a growth enhancing feedback culture. This culture is viewed from four different perspectives: the teacher, the learner, the relationship and the institutional context. Moving drastically away from techniques to provide and receive feedback, we propose strategies for teachers, learners and institutions to promote a feedback culture focussed on behaviour change and professional growth. Strategies proposed for teachers target building educational alliances with their learners; learner strategies focus on development of a growth mind-set and encourage a learning goal goal-orientation, and feedback-seeking; and institutional recommendations emphasise feedback initiatives that encourage longitudinal relationships and performance observation. Overall, we propose that medical education needs to move away from recipes for giving feedback towards relationships that foster a growth mind-set.

\section{Conclusions}

Several recent research reports have appropriately and emphatically described the impact of sociocultural factors on the perceived credibility and acceptability of feedback to learners. We believe that our research has further advanced these insights through exploration of faculty and residents perspectives on cultural factors that are viewed as key facilitators and barriers to feedback. Our participants confirmed that sociocultural factors, such as relationships, tone and perceived intent, institutional culture, feedback seeking etc., play a central role in the quality of feedback exchanges and their impact on behaviour. Though residents and faculty thought that the existing culture of politeness facilitated a positive learning and work environment, it was seen as a significant barrier to honest constructive feedback conversations. The culture of excellence which presumes excellence of learners based on academic pedigree has no role in facilitating growth of clinical learners. We also suggest that the Johari window framework of interpersonal communications would be valuable to teachers, learners and institutions in 
structuring feedback conversations targeting self-assessment, self-reflection, self-disclosure, feedback seeking and engagement in self-discovery. Most participants stated that an optimal feedback culture should normalise deficiencies among professionals at all levels, provide a safe space to admit limitations, promote teacher-learner longitudinal relationships, encourage feedback seeking and performance observation, and set the stage for a growth mind-set and a learning goal orientation. 
Samenvatting 

Het is noodzakelijk dat alle medische professionals, van aiossen op alle niveaus tot praktiserende clinici, diverse bronnen om feedback vragen en deze daarvan ontvangen om hun functioneren te kunnen beoordelen en zich voortdurend te kunnen verbeteren. De omschakeling naar competentiegericht medisch onderwijs maakt het van essentieel belang dat aiossen, om ervoor te zorgen dat zij in staat zijn op onafhankelijke en reflectieve wijze de patiëntenzorg op zich te nemen, zinvolle, op leerdoelen gerichte feedback ontvangen op hun klinisch functioneren. Feedbackgesprekken worden echter van oudsher gedomineerd door een eenrichtingsmonoloog van docent naar student. Hoewel medische onderwijsdeskundigen modellen en strategieën hebben beschreven voor het "geven" van feedback waarvan studentbetrokkenheid een onderdeel vormt, bleven verscheidene onderzoeken vermelden dat studenten ontevreden zijn over de frequentie en kwaliteit van feedback van hun staf. Daarbij leek dergelijke feedback weinig effect te sorteren t.a.v. gedragsverandering en verbetering in de praktijk. Het docentgerichte feedbackmodel slaagde er duidelijk niet in studentprestaties te beïnvloeden. Ook is het waarschijnlijk dat de leeromgeving in het medisch onderwijs een prestatiegerichte attitude (waarbij studenten gefocust zijn op hoe zij hun toetsen maken en hoe zij door anderen worden gezien) stimuleert in plaats van een leerdoelgerichte attitude (waarbij voortdurend leren het doel is en fouten worden gezien als een belangrijke drijfveer om te leren). Bij de eerste attitude zijn studenten geneigd meer waarde te hechten aan hun imago en eigenwaarde dan aan het toegeven van beperkingen, waardoor ze minder snel om feedback zullen vragen, opbouwende feedback zullen accepteren of er in de praktijk iets mee zullen doen. De laatste 10 jaar heeft er in de discussie rondom feedback een duidelijke verschuiving plaatsgevonden naar een focus op de student, waarbij het initiatief daadwerkelijk bij de student ligt. Verschillende onderzoekers en onderwijsdeskundigen hebben feedback opnieuw gedefinieerd als een complexe sociale uitwisseling die de acceptatie, verwerking en groei door de ontvanger als doel heeft. Deze nieuwere definities halen de feedbackgever uit de schijnwerpers om ze vervolgens op de ontvanger te richten. Als we een definitie omarmen die zich richt op praktijkverbetering en professionele groei door de ontvanger, dan moeten we de feedbackdiscussie ook door de bril van de ontvanger gaan bekijken en ons afvragen: Wat maakt feedback geloofwaardig en aanvaardbaar? Wat stimuleert het vragen naar feedback? Hoe kunnen we een groeimindset cultiveren?

Onderzoek op dit gebied is begonnen de feedbackdiscussie te verschuiven van een statische docentgerichte monoloog, die misschien gedeeltelijk of zelfs helemaal door de student wordt verworpen, naar een dynamische, door de docent aangestuurde tweerichtingsdialoog waarbij het initiatief bij de student ligt. In ons onderzoek trachtten we de verlichtende inzichten uit recent onderzoek, waarin feedback wordt beschouwd als een sociaal-cultureel verschijnsel dat actieve studentbetrokkenheid vereist evenals een coaching mindset voor docenten, verder uit te bouwen. Om dit doel te bereiken stelden we ons twee algemene onderzoeksdoeleinden: (1) de percepties van aiossen en staf ten aanzien van de feedbackcultuur binnen de instelling in kaart brengen, alsmede hoe deze cultuur kan worden verbeterd ten bate van professionele groei; en (2) onderzoeken of hun 
geuite meningen over de feedbackcultuur en best practices ook in daden werden omgezet tijdens feedbackgesprekken in de echte praktijk. Dit proefschrift richtte zich op aiossen en staf van de afdeling Geneeskunde aan het "Brigham and Women's"-ziekenhuis, waar diverse door het bureau onderwijs van de masteropleiding Geneeskunde onder aiossen afgenomen enquêtes uitwezen dat de frequentie van feedbackuitwisselingen en de kwaliteit van de door staf gegeven feedback te wensen overlieten. Informele onderzoeken onder stafleden lieten zien dat zij moeite hadden met het geven van doeltreffende feedback, in het bijzonder opbouwende feedback. De stafleden hebben de mogelijkheid deel te nemen aan feedbacktrainingworkshops aan de medische universiteit, maar deze worden niet vaak gegeven, noch worden zij verplicht gesteld.

Concrete onderzoeksvragen waren:

1. Wat zijn de percepties van aiossen en stafleden ten aanzien van een definitie van feedbackcultuur en uit welke elementen bestaat deze cultuur?

2. Hoe zien aiossen en stafleden de huidige afdelingscultuur en de invloed daarvan op de kwaliteit van feedbackgesprekken tussen aiossen en stafleden?

3. Welke taal en gedragingen gebruiken docenten en studenten tijdens formele feedbackgesprekken tussen stafleden en aiossen die een langdurige relatie hebben in zogenaamde continuïteitsklinieken?

4. Kunnen reflectie en reflexiviteit met behulp van video's meer bewustzijn onder stafleden creëren van wat effectieve en ineffectieve gedragingen zijn en kunnen deze toekomstige gedragsverandering bevorderen?

De introductie in Hoofdstuk 1 beschrijft de evolutie van feedback, het gebruik ervan buiten de wereld van de techniek, feedbacktradities in het medisch onderwijs, van de oudere, docentgerichte tot de nieuwere, studentgerichte definities, en de bij deze definities behorende benaderingen en modellen. We benadrukken dat in deze tijd van competentiegericht medisch onderwijs feedback van groot belang is voor groei door de student en beschrijven waarom docenten en studenten deze gesprekken lastig vinden. Feedback wordt opnieuw gedefinieerd als een sociaal-cultureel verschijnsel dat gericht zou moeten zijn op de student die om feedback vraagt, deze aanvaardt, ervoor open staat om opbouwende informatie te ontvangen en die begiftigd is met een groeimindset. Willen we dat aan deze aspecten voldaan wordt, dan moeten we eerst weten wat feedback geloofwaardig en aanvaardbaar maakt. Want als studenten de feedback die zij van docenten ontvangen verwerpen, dan is het net alsof de gesprekken nooit hebben plaatsgevonden. $\mathrm{Er}$ wordt een model voorgesteld dat prestatieverbetering door de student als centraal doel stelt van het feedbackgesprek met docent, student en culturele factoren die daarop van invloed kunnen zijn. Het feedbackgesprek, de uitdagingen en invloed ervan worden vanuit verschillende perspectieven (docent, student en cultuur) bekeken, terwijl ervan wordt uitgegaan dat deze zienswijzen mogelijk met elkaar in strijd zijn. We onderscheidden drie psychosociale theorieën die direct verband houden met de effectiviteit en invloed van 
feedbackuitwisselingen, te weten: sociaal-culturele theorie, beleefdheidstheorie en zelfdeterminatietheorie. Hoe elk van deze theorieën elkaar kruisen en hoe zij van invloed zijn op feedbackgedragingen, zoals het vragen om en aanvaarden van feedback, en gedragsverandering enz. wordt in detail beschreven. Voorts beschreven we de twee algemene en vier concrete onderzoeksvragen die bedoeld waren om het feedbackonderzoek dieper het sociaal-culturele veld in te trekken en het gebied verder te ontwikkelen. Het hoofdstuk sluit af met een samenvatting van elk hoofdstuk met het doel om de lezers voor te bereiden op de verhaallijn die inmiddels gestalte had gekregen.

In Hoofdstuk 2 nemen we een kleine omweg, maar om een belangrijke reden. Aangezien ons hele onderzoek doordrongen was van een aanpak waarbij gebruik gemaakt werd van gedegen kwalitatieve methodologie, namelijk gefundeerde theorie en etnografische benaderingen, beschrijven we strategieën voor het vergroten van reflexiviteit in kwalitatief onderzoek. Om gedegen onderzoek te kunnen verrichten is het noodzakelijk dat kwalitatieve onderzoekers aandacht besteden aan reflexiviteit. Daarom achtte het onderzoeksteam het van essentieel belang dat wij ons verdiepten in onze eigen overtuigingen en aannames, alsook onze relatie met de deelnemers en het onderzoeksonderwerp die van invloed zouden kunnen zijn op de verzameling, analyse en interpretatie van de data. We startten een grondige studie van het begrip "reflexiviteit" omdat we ons wilden voorzien van de kennis en vaardigheden die nodig zijn voor het verrichten van geloofwaardig kwalitatief onderzoek van hoogwaardige kwaliteit. Deze aanpak resulteerde in een grafische afbeelding van de verschillende stappen van kwalitatief onderzoek en de strategieën die bij elke stap werden gebruikt om reflexiviteit te vergroten. Reflexiviteit werd bekeken vanuit een persoonlijk (onderzoeker) en een epistemologisch perspectief.

In de in Hoofdstuk 3 beschreven studie presenteren we ons eerste onderzoek dat een open peiling betrof van de meningen van aiossen met betrekking tot de vraag hoe instellingsfactoren de kwaliteit en invloed van feedback, alsook hun ontvankelijkheid voor feedback, beïnvloeden. Hoewel we op zoek waren naar instellings- en andere sociaal-culturele factoren die van invloed zijn op feedback, gebruikten we open vragen waarin niet over cultuur werd gesproken. Opmerkelijk genoeg brachten de aios-deelnemers de instellingscultuur herhaaldelijk naar voren als iets dat zinvolle feedbackgesprekken in de weg stond. Alle thema's benadrukten op de een of andere manier de instellingscultuur. Het meest verrassende inzicht was het naar boven komen van een beleefdheidscultuur binnen de instelling, zoals de meeste deelnemers dat ervoeren. Ze gaven aan dat een dergelijke cultuur bevorderlijk was en zorgde voor een familie-achtige werkomgeving. Tegelijkertijd vormde deze zelfde cultuur echter een belemmering voor het plaatsvinden van eerlijke gesprekken die opbouwende kritiek zouden kunnen bevatten. De aiossen concludeerden dat de cultuur diende te worden veranderd om ervoor te zorgen dat zinvolle feedback gegeven kon worden die hun groei bevorderde, zonder daarbij de vriendelijke leeromgeving te schaden. Hoewel aiossen cultuurgerelateerde thema's aandroegen, was het niet helemaal duidelijk welke elementen aan deze cultuur ten grondslag lagen. Daarnaast was het belangrijk om 
de standpunten van stafleden te verkrijgen ten aanzien van de moeilijkheden die zij ondervonden tijdens feedbackgesprekken met aiossen en hoe zij de instellingscultuur beschouwden: als bevorderlijk of belemmerend. Ook gaven zij aan dat de culturele normen feedback van twee kanten, d.w.z. van aiossen naar stafleden en van eerdere- naar ouderejaarsaiossen, ontmoedigden.

In Hoofdstuk 4 presenteren we onze volgende studie in het kader waarvan we een diepgaand onderzoek instelden naar de vraag welke definitie aiossen en stafleden toekenden aan een feedbackcultuur, uit welke elementen deze cultuur bestond, wat hun standpunten waren betreft het bestaan van een beleefdheidscultuur en of zij vonden dat een dergelijke cultuur bevorderend of belemmerend werkte voor het geven van feedback die op professionele groei gericht is. Voor het definiëren van de instellingscultuur gebruikten beide groepen twee termen: beleefdheidscultuur en excellentiecultuur. De uitstekende academische reputatie van de instelling en de afkomst van haar aiossen vormen samen de excellentiecultuur die opbouwende feedback in de weg kan staan. De afdeling hechtte waarde aan een collegiale en aanmoedigende werkomgeving voor aiossen; er heerste dus een beleefdheidscultuur. Een dergelijke cultuur zorgde er echter voor dat elke taal die het zelfvertrouwen van aiossen zou kunnen aantasten werd vermeden. De meeste aiossen en stafleden gaven aan dat langdurige relaties, het geven van opbouwende feedback aan elkaar, maar ook ruimte laten voor zelfeffectiviteit en zelfstandig werken belangrijke factoren waren die de totstandkoming van een feedbackcultuur die gedragsverandering kon beïnvloeden bevorderden. Opvallend was dat, hoewel iedereen het belang van feedback van twee kanten onderstreepte, de deelnemers niet vonden dat de bestaande beleefdheidscultuur de hiërarchische cultuur zodanig deed afvlakken dat het geven van feedback van eerdere- naar laterejaarsstudenten bevorderd werd. Onder andere de volgende strategieën werden geopperd: het normaliseren van opbouwende feedback, het vragen om feedback door aiossen en stafleden en regelmatige, directe praktijkobservaties.

De regelmatige verwijzingen naar het vragen om feedback, de ontvankelijkheid voor feedback en feedback van twee kanten leidden ons ertoe een nader onderzoek in te stellen naar de invloed van zelfbewustzijn op de kwaliteit en invloed van feedback. In Hoofdstuk 5 werden gesprekken met aiossen en stafleden geanalyseerd vanuit het kader van het Johari-venster, een psychologisch model dat interacties tussen mensen beschouwt vanuit het bewustzijn van eigen gedragingen en functioneren en de mate waarin dit overeenkomt met het beeld dat anderen hebben van iemands functioneren. De vier kwadranten die in dit model beschreven worden zijn: open ruimte (zowel de persoon in kwestie als anderen zijn zich bewust van bepaalde gedragingen), blinde vlek (anderen zijn zich bewust, maar de persoon in kwestie is zich niet bewust van deze gedragingen), verborgen gebied (de persoon in kwestie is zich bewust van de eigen gedragingen, maar anderen zijn zich niet bewust van de context) en onbekend gebied (gedragingen zijn ontdekt noch door de personen in kwestie, noch door anderen). Omdat voor het juist beoordelen van het eigen functioneren en de daaruit vloeiende gedragsverandering een weloverwogen 
zelfbeoordeling en begeleide reflectie van essentieel belang zijn, stellen we voor dat dit model als leidraad kan dienen bij het voeren van feedbackgesprekken. Het lukte ons om voor elk kwadrant persoonlijke en instellingsstrategieën te bedenken die het vragen om feedback, de ontvankelijkheid voor feedback en de verwerking van feedback met gedragsverandering als gevolg helpen te stimuleren.

In de in Hoofdstuk 6 beschreven studie hebben we formele feedbackgesprekken tussen aiossen en hun opleiders in de zogenaamde continuïteitskliniek geobserveerd en op video opgenomen met als doel te onderzoeken welke verbale en non-verbale gedragingen docenten en studenten aannemen. Middels een etnografische benadering werden zes stafleden tweemaal geobserveerd gedurende hun geplande feedbackgesprekken met aiossen die zij in hun continuïteitsklinieken hadden opgeleid, waarmee het totale aantal observaties uitkwam op 12. Er was duidelijk bewijs dat er contact was tussen stafleden en aiossen dat zich uitte in de vorm van open lichaamstaal, blijk van gemak tijdens het gesprek, knikken en glimlachen. Stafleden maakten doorgaans gebruik van zelfreflectie als ingang voor het gesprek en gebruikten specifieke voorbeelden uit hun observaties van aios-patiëntcontacten als basis voor het geven van feedback en begeleiden van actieplannen. De meest communicatief vaardigen onder hen waren in staat aiossen aan te moedigen hun uitdagingen en beperkingen te bespreken, tot een gezamenlijk akkoord te komen en aiossen aan te zetten om zelf een voorzet voor een actieplan te maken. We veronderstellen dat de langdurigheid van de relaties in de zogenaamde continuïteitsklinieken bevorderlijk was voor het vlotte contact tussen stafleden en aiossen en voor het algehele gemak waarmee de feedbackgesprekken werden gevoerd. Daarbij stellen wij ons de vraag of eerstelijnsartsen gevoelsmatig en onbewust arts-patiëntcommunicatievaardigheden toepassen tijdens hun feedbackgesprekken.

Een tweede deel van deze studie onderzocht het effect van nabesprekingen met behulp van video's op de mate waarin stafleden zich bewust waren van eigen feedbackgedragingen. Met deze methodiek, ook wel beschreven als "etnografie met gebruik van videoreflexiviteit", konden stafleden hun eigen gedragingen zien, beoordelen welk(e) van deze gedragingen effectief waren en welke gedragingen ze in toekomstige gesprekken misschien bij nader inzien zouden veranderen. Het bekijken van de video's leek hun manier van feedback geven kracht te hebben bijgezet en hun ook inzicht te hebben verschaft in de strategieën die niet effectief waren. Ten slotte gaven ze toe dat dergelijke gesprekken vaker zouden moeten plaatsvinden, en ondanks het feit dat zij zich ongemakkelijk voelden door de observaties en video-opnames, dwong de oefening hen ertoe om doelen op te stellen voor feedbackgesprekken en zette deze hen aan tot het observeren van aiospatiëntcontacten.

Bij het nalopen en analyseren van de onderzoeksresultaten uit al onze studies ontdekten we enkele unieke begrippen die aan de in academische medische instellingen heersende feedbackcultuur ten goede zouden kunnen komen. In Hoofdstuk 7 kijken we anders naar 
feedback bij het beschrijven van strategieën die een groeibevorderende feedbackcultuur stimuleren. Deze cultuur wordt vanuit vier verschillende perspectieven bekeken: de docent, de student, de relatie en de instellingscontext. Daarbij nemen we een drastische afwending van technieken voor het geven en ontvangen van feedback, en dragen we strategieën voor docenten, studenten en instellingen aan die een op gedragsverandering en professionele groei gerichte feedbackcultuur bevorderen. De voor docenten voorgestelde strategieën richten zich op het scheppen van een onderwijsband met hun studenten; de strategieën voor studenten richten zich op het ontwikkelen van een groeimindset, het bevorderen van een leerdoelgerichte attitude en het vragen om feedback; en de aanbevelingen voor instellingen benadrukken feedbackinitiatieven die langdurige relaties alsook observatie van functioneren aanmoedigen. Al met al stellen we voor dat het medisch onderwijs moet stoppen met voor te schrijven hoe feedback gegeven moet worden en in plaats daarvan energie moet steken in het stimuleren van relaties die een groeimindset bevorderen.

\section{Conclusie}

Diverse recente onderzoeken hebben terecht en nadrukkelijk de invloed van sociaal-culturele factoren op de mate warin studenten feedback als geloofwaardig beschouwen en er ontvankelijkheid voor zijn beschreven. Wij zijn van mening dat ons onderzoek deze inzichten heeft verbreed door te onderzoeken welke culturele factoren volgens stafleden en aiossen feedback belemmeren of bevorderen. Onze deelnemers bevestigden dat sociaal-culturele factoren, zoals relaties, intonatie en vermeende opzet, instellingscultuur, vragen om feedback enz., zeer bepalend zijn voor de kwaliteit van feedbackdialogen en de invloed daarvan op het gedrag. Hoewel aiossen en stafleden vonden dat de bestaande beleefdheidscultuur voor een positieve leer- en werkomgeving zorgde, vormde deze cultuur in hun ogen ook een aanzienlijke belemmering voor het plaatsvinden van eerlijke, opbouwende feedbackgesprekken. De excellentiecultuur die ervan uitgaat dat studenten gezien hun academische afkomst overal in uitblinken draagt op generlei wijze bij aan de groei van klinische studenten. We denken ook dat het Johari-venstermodel voor communicatie tussen mensen nuttig kan zijn voor docenten, studenten en instellingen bij het vormgeven van feedbackgesprekken gericht op zelfbeoordeling, zelfreflectie, zelfonthulling, het vragen om feedback en het op zelfontdekkingstocht gaan. De meeste deelnemers gaven aan dat een optimale feedbackcultuur ervan uit moet gaan dat er zich onder professionals op alle niveaus imperfecties kunnen voordoen, een veilige ruimte moet bieden waarin men zich vrij voelt om beperkingen toe te geven, langdurige docent-studentrelaties moet bevorderen, het vragen om feedback en observatie van functioneren moet stimuleren en de juiste omstandigheden moet creëren voor het cultiveren van een groeimindset en een leerdoelgerichte attitude. 


\section{Valorisation}





\section{Social Relevance:}

The results from this research could have significant implications for the social and cultural climate of medical schools and postgraduate training programs. We have extended the findings of other educators who began the conversation that feedback exchanges are complex social interactions, greatly influenced by the learning culture at institutions. Our findings move the field further away from a focus on 'providing' feedback and place culture and relationships at the heart of such conversations. As described in Chapter 3, residents spontaneously raised the institutional culture as a major influence on the quality of feedback provided to them by clinical supervisors. Though politeness concepts have been discussed with respect to faculty narratives on evaluation, the link to feedback conversations is new. Our participants' opinions, regarding 'niceness or politeness' being a barrier rather than a facilitator to meaningful feedback, was not an isolated or insignificant perception.

In Chapter 4, further exploration of the institutional feedback culture showed that both faculty and residents agreed that the existing culture of politeness provided a 'warm and fuzzy cocoon' for residents. However, they indicated that this same culture prevented honest constructive conversations between faculty and residents; and emphasised that vague and nice language will not promote professional growth. While time and space constraints and lack of skills or training in providing feedback were also described as challenges, the concept of 'culture' overshadowed all other factors that influence the impact of feedback conversations. Further dissection of the elements of culture, in Chapter 4, showed that faculty and residents defined it as how institutions establish expectations for feedback, provide training in giving and accepting feedback, normalise constructive feedback, encourage bidirectional feedback and emphasise a growth-oriented mindset. Besides the culture of politeness, a culture of assumed excellence was perceived to be a deterrent to constructive feedback conversations. The implications of such a culture is that learners' performance is not observed, their competence and/or excellence is assumed, their deficiencies are not detected and specific growth-enhancing constructive feedback is not given. This may be a bigger problem at prestigious institutions where incoming learners have a 'pedigree' of excellence.

Besides institutional culture, the teacher-learner relationship was another factor considered to significantly influence feedback culture, as noted in Chapter 6. Faculty felt that a congenial longitudinal relationship made it easier to observe, provide constructive feedback and help residents make action plans for improvement. Similarly, residents stated that they perceived an attitude of beneficence from those faculty with whom they had longitudinal relationships; this made it easier to seek feedback, accept and incorporate the feedback into performance. Thus, despite an overall perception that meaningful constructive feedback was exchanged infrequently, faculty-resident pairs in continuity clinics seemed to be more comfortable doing so. For accurate performance calibration, feedback acceptance and assimilation, we believe that self-awareness is essential. In Chapter 
5, we discuss the importance of self-awareness in feedback seeking, acceptance, disclosure of limitations and discovery of performance strengths and deficiencies and once again reiterate how relationships can foster this sense of curiosity and discovery.

To summarise the social relevance of our research, institutions have an essential obligation to train medical students and residents to be reflective practitioners with a responsibility to the society they serve. In order to fulfil that important societal obligation, learners need to reach or excel in many competency domains, but more importantly they need to be aware of their strengths and weaknesses, be willing to recognise and acknowledge own limitations, and seek and accept help from others in providing outstanding healthcare. The concept of positive and negative face, which can be correlated with self-esteem and autonomy respectively, are very relevant to competency-based assessment and feedback in medical education. Overemphasis on learners' self-esteem can result in inaccurate calibration of competence and premature autonomy can have adverse impact on patient care. Balancing support and challenge, with supervision and autonomy would be critical in educating clinical professionals. Institutions should focus on these important goals, establish a climate where their teachers and learners learn to be self-aware, have a growth mind-set and focus on the end goal: uncompromising patient care. The economic relevance is then readily evident: competent and socially responsible future doctors who seek to constantly grow and improve.

\section{Target groups who will benefit from the research}

An important target group that would benefit from this research would be members of the society whose healthcare needs are attended to by motivated and reflective teachers and learners. Patient care can only be enhanced by training physicians to be self-aware, self-reflective, open to seeking help when needed, who possess a growth mindset which would allow them to be lifelong learners. This can be reinforced by clinical teachers and learners working collaboratively in a conducive work and learning environment, where direct observation and targeted feedback occurs consistently.

Beyond the context of medical education, these results would be applicable to all educational settings. Feedback is an integral aspect of development of learners at any levelschool, college and professional training. Ultimately, all those in training have competencies that they need to achieve and/or master, and formative feedback is essential to help in this growth trajectory. Feedback is also not exclusive to educational settings, our findings are fully applicable to performance appraisal and professional development of staff in any workplace.

Another important target group to benefit from this research would be resident trainees. Exploring their perspectives on feedback, we concluded that the learning culture at institutions is an important factor in driving learning and professional growth. 'Culture' is a term often bandied about, but our residents were able to convey their definition of a 
learning culture especially as it relates to feedback in Chapter 4. Although experts have defined this term in the past, residents' perspectives are crucial for institutions to set expectations and actively engage residents in designing conducive learning environments. The more residents are engaged, the more likely they are to reflect, seek and accept feedback, incorporate it into their performance and have a growth mindset.

Yet another group who will benefit are clinical supervisors responsible for supervision, teaching and assessment of residents. Faculty development programs have traditionally provided training in a static unidirectional approach with the teacher as the 'giver' and the learner as the 'recipient'. With findings from recent research, including our own, the landscape of feedback has been redefined. Consequently, future faculty development initiatives should showcase feedback as a dynamic, bidirectional process. Our research has implications beyond the scope of feedback conversations. It has messages for teachers to focus on establishing a positive learning environment, engage in relationship-centred communication with their learners, address learner self-esteem while providing constructive feedback, provide autonomy appropriate to learner level and ability rather than at the end of a defined training period, role-model admission of own limitations, and always encourage a growth mindset. These strategies are described in detail in Chapters 6 and 7 .

Our research findings will be very useful to teaching institutions which train medical students, residents and fellows. In Chapter 3, we describe our resident perceptions that institutional culture plays a major role in the quality and impact of feedback. In Chapter 4, we further explore what faculty and residents believe are essential elements of this culture. Both groups stated that institutional culture can be defined by explicit and implicit expectations for ongoing feedback conversations, normalising strengths and weaknesses among all professionals thereby setting the stage for meaningful constructive feedback, facilitating longitudinal relationships between teachers and learners, provide training to teachers and learners in seeking and accepting feedback, and encouraging growth mindset by showcasing ongoing learning rather than performance and appearance. These recommendations are described in Chapters 6 and 7. Institutions also need to address the three levels of culture and ensure that all levels (assumptions, espoused values and behaviours) are consistent. Finally, institutions should allow for participatory design of learning environments where leaders, teachers and learners are all engaged in establishing expectations for mindset, performance, learning and feedback; designing learning opportunities that foster self-awareness, reflection, ongoing performance improvement and behaviour change; thus setting the stage for bidirectional feedback.

\section{Translation of result into activities/products:}

Local impact: Our findings, along with recommendations from Chapter 7 and the discussion section, can immediately be translated into feedback initiatives at our residency program, as a demonstration of local impact. Although there are sporadic workshops on 
feedback offered at the institution and medical school, there is no requirement that faculty who attend on inpatient services or precept residents in clinics participate in faculty development. There is a "resident as teacher" initiative, but this consists of a one-time workshop on teaching and feedback. Thus, residents who supervise and teach medical students and faculty who supervise and teach residents and students are given little guidance in fulfilling these obligations effectively. By their own admission, in Chapters 3 and 4 , residents and faculty desire such training and some raised the point that training was needed in seeking and receiving feedback also. Almost all workshops offered are limited to traditional feedback models (the sandwich or other similar models) which focus solely on the skills for providing feedback. Given our results, I would like to design initiatives that increase direct observation of residents and provide training in feedback seeking, receiving and promote behaviour change. If such initiatives are impactful, other training programs can adopt and adapt them to their own context. Many of the principles reported in our research are applicable to other training programs, be it undergraduate or postgraduate.

In my role as the Director of Evaluation for my internal medicine residency program, I was charged with redesigning the evaluation system for the program. Through this research work, I have concluded that even the best evaluation tools, whether milestones or EPA-based, will not lead to behaviour change. Ongoing and meaningful feedback is the key to professional development at any level. It is this area that I wish to focus on in my future initiatives, particularly in addressing the feedback culture, promoting feedback seeking, relationships, direct observation, feedback acceptance, ensuring that there are opportunities for implementation of action plans and inculcating a growth mindset.

National and international impact: The Harvard Macy Institute, where I serve as a core faculty, organises annual programs for educators and leaders in health professions education. The aim of these programs is to transform the mindset and develop innovators of education. For the last five years, I have been presenting a large group session on feedback, since feedback is a popular topic among educators most of whom find it challenging in real practice. In the tradition of best evidence medical education, my presentations over the last two years have no similarity to those before. They now lean heavily towards 'culture' and its influence on feedback (Chapter 3), the importance of positive and negative face (Chapters 3 and 4), and include an exercise on self-awareness using the Johari window (Chapter 5). Based on recommendations from Chapter 7 and the discussion, next year I plan to introduce mindsets into the presentation as I believe a growth mindset is essential to inculcate among trainees and even more important for teachers to model. This program is attended by about 100 North American and international educators, who would take these concepts to their own institutions and potentially disseminate key principles from their discoveries. In addition, this topic has also been presented as an AMEE webinar in 2017.

Dissemination of research: A demonstration of how these findings have been translated into faculty development presentations lies in the drastic transformation of my own 
presentations on feedback to other educators. The results of this research have caused a paradigm shift in my thinking about this topic. These presentations now incorporate the work on learning culture into these workshops and emphasise that feedback is a two-way interaction. They have moved away from skills of giving feedback to establishing relationships (chapter 6 ), encouraging self-awareness (chapter 5 ) and promoting a feedback culture with a growth mind-set (chapter 7). We hope that awareness of our research findings and their implications will lead to similar changes in other practices.

New research collaborations: My research supervisors have mentored and collaborated with other educators and educational researchers with expertise in the area of feedback. With their guidance, I have started communicating with the group that designed the R2C2 model. The hope is that these conversations gather momentum and lead to a fruitful collaboration and further discoveries which can be shared with the world of health professions educators. I have gained significant knowledge and skills in qualitative methodology and convinced that it is an important approach to further research to advance the field.

\section{Innovation:}

There has been a remarkable explosion in feedback research over the last decade. From newer definitions that place the learners front and centre, to work on learning cultures, relationships between teachers and learners shaping feedback conversations, and a coaching approach to these conversations, the landscape of feedback has been transformed. Our research findings are innovative and have added significant new information to this growing field.

First, politeness concepts with the focus on positive and negative face are critical to address to enhance the credibility of feedback. Second, we were able to apply Schein's levels of organisational culture to the feedback culture and argue that the three levels (values, assumptions and behaviours) need to convey consistent messages. Our research, described in Chapters 3, 4 and 5, shows that there are often mixed messages which lead to ineffective conversations, rejection of feedback and lack of impact on professional development. In Chapter 4 we also raise a new challenge to the impact of feedback, a culture of assumed excellence where the 'pedigree' of the institution and its trainees leads to assumptions of universal excellence and avoidance of constructive feedback. Third, in Chapter 5 the findings demonstrated the importance of inculcating self-awareness among professionals and how the Johari window can be applied to framing feedback conversations. Fourth, we extended previous research recommendations on the importance of relationships in shaping feedback exchanges, through first-hand observations of feedback conversations between clinical supervisors and residents in continuity clinic (Chapter 6). Relationships appeared to be at the heart of these conversations and we discovered that constructive feedback was readily accepted by residents after observation of 
their patient encounters and from preceptors with whom they had a longitudinal relationship. This has been emphasised by many investigators, but may be the first time such conversations were directly observed.

Finally, in Chapter 7 and the discussion section, we highlight the impact of mindset in feedback seeking, acceptance of constructive feedback, incorporation of feedback into performance and behaviour change. The balance of 'self' and 'other' factors in driving behaviour change is a unique concept that our research adds to the field. Change needs to begin from within, how teachers and institutions can help cultivate practices that can stimulate change and growth through facilitation of self-characteristics has been described in detail in the discussion section.

All our findings will have broad implications for any training program engaged in workplace assessment and feedback. The findings are applicable beyond the field of medical education to all health professions education, all educational settings and in any workplace where performance calibration and feedback are routinely done.

\section{Schedule \& Implementation:}

Novel findings from the research performed as part of this thesis have begun to garner attention. Four chapters as well as the chapter on reflexivity have been published. The thesis book will be published and publicly available by the end of 2018. I have done oral presentations on this research at AMEE meetings and presented plenary sessions and workshops on this topic which incorporate the latest work on feedback. Other educators have communicated with me on the following areas: discussion of their own research; invitation to collaborate on presentations; invitation to collaborate on further research in this area; and invitation to serve as a co-author in publications. The finer details of our research protocol, beyond what is described in the publications, will be made available to any educator interested in the topic for them to replicate studies in their own context. In time, we hope that such studies will be carried out in other disciplines to open the door for further sociocultural discoveries. One investigator is already carrying out ethnographic studies at her institution in the Department of Paediatrics and we have exchanged ideas on the most effective research design.

Market opportunities and financial value are hard to anticipate at this stage. However, we see opportunities to redefine the area of performance appraisal where ongoing feedback is critical. Our recommendations prioritise the application of politeness, sociocultural and self-determination theories in feedback initiatives. Combining our recommendations with those from other researchers could result in new, innovative and personalised feedback training for clinical supervisors as well as clinical trainees. Throughout the thesis, especially in Chapter 7 and the discussion section, we have emphasised the importance of institutions focussing on mindset and goal orientation rather than appear- 
ance of competence and excellence, and teacher-learner relationships rather than recipes for teaching, assessment and feedback. Furthermore, we have showcased the value of qualitative methodology in new discoveries and developing theoretic concepts even in topics that have been studied using quantitative approaches in the past. Open-mindedness and willingness to challenge existing assumptions are critical to new explorations. Ultimately, shifting the landscape of feedback towards relationships between providers and recipients, recipient behaviour change and growth and bidirectional exchanges can nurture reflective healthcare professionals with a growth mindset. Such changes can only benefit patients and society in the end. 

Acknowledgements 

When I began my voyage as an educator in 2001, I did not imagine that it would culminate in a PhD. I kept going from one course to the next, a Masters in Medical Education along the way, and knew it was only a matter of time before my unquenchable thirst drove me towards a doctorate. But, the challenges of a physician-teacher life caused me to place this aspiration on the backburner for years. In 2015, life intruded giving me months of limited mobility and suddenly the luxury of time for reflection and study. There was no looking back. Yes, I have been asked many times why I wanted to do a PhD at this stage of my career, accompanied by odd looks. Has it been worth it? Absolutely!

Where do I begin to pay tribute to those who inspired and mentored me? I should start with my parents (Mr. S. Venkataramani and Mrs. Dr. Sarada Ramani), who made many sacrifices to prioritise my education and academic excellence. My mother, a teacher, had a burning passion for learning which I seemed to have absorbed through osmosis. She completed two PhDs, the last one when she was over 70 years old. How could I not compete with that? My husband, Dr. Robert Thomas, encouraged me all the way, for him hard work has no ceiling and he kept persuading me to push the envelope further and further. He is a sleep disorders specialist, his only medical advice to me was that my insomnia is a blessing for scholarly output.

I owe an enormous debt of gratitude to Karen Mann, my mentor, my inspiration, my beacon and my guide. She gave her time and advice generously and helped me research PhD programmes which would be a good fit for my interests and aspirations. Karen was with me every step of the way when I wrote the thesis proposal and applied to Maastricht University. Her guidance was responsible for acceptance to the programme. She made me read more, dissected all my mistakes (there were many) with vigour. And back to the drawing board I would go. There was a big lump in my throat the day I realised that she could no longer be listed as a co-author in my writing. She will be missed always! I hope to show the same generosity of spirit, which she had in abundance, to others.

The stars were aligned when Karen M led me to Cees van der Vleuten, the superman who advises at the speed of light. At last, I found someone on my speed wavelength. He is the only person who does not complain about my speediness. Cees never minces his words when a product is subpar and challenged me often to write scientifically and yet tell a compelling story. I am convinced that he does not sleep either. It has been a privilege to see how his mind works and a pleasure to learn so much from him. I also discovered that we are fellow foodies and have shared recipes and favourite chef stories. Food for the body, mind and soul.

Karen Könings, the Karen $\mathrm{K}$ of the awesome Karen duo! She is more deliberate in her responses, but no less nit-picky than Karen $\mathrm{M}$. Karen $\mathrm{K}$ led me into new territory, away from medical education into psychological theories applicable to health professions education and concepts from higher education. I could email her and ask her any silly question and she would patiently reply and lead me in the right direction. Thanks to her, my 
kindle is full of the most peculiar book titles. I look forward to switching roles from being a mentee / advisee to being her future collaborator and continuing to advance the field.

I am very grateful to Shiphra Ginsburg for joining the team after our team had suffered a tragic loss. She brings a different dimension to the table on research methodology as well as writing. I have become a much better narrator of scientific stories, she forces me to think deeply about language- its clarity, grammar and art. Despite a heavy clinical load and several leadership roles at her own institution, her generosity in giving me her time and advice is most admirable. I look forward to our continued collaborations.

There are two important mentors without whom I would not have started this journey. Dr. Joseph Loscalzo, the Chair of the Department of Medicine at Brigham and Women's Hospital and Professor of Medicine at Harvard Medical School, is the first. He has been a wonderful mentor to me for well over a decade and pushes me to reach for the stars in my chosen field of educational scholarship and leadership. He did not blink when I informed him of my decision to pursue a doctorate. On the contrary, he challenged me to write down the reasons for my decision and how it would benefit my career as well as the institution I serve. The other is Dr. Elizabeth Armstrong, the Director of the Harvard Macy Institute, who has been my mentor for 13 years now. She has been a strong champion and advocate and continues to challenge me to reach further. I have been fortunate to have Drs. Lozcalzo and Armstrong in my life, they have shaped my professional development greatly.

Lastly, I would like to express my appreciation to the Department of Medicine at Brigham and Women's Hospital for awarding me a generous 2-year CERS (Clinical Education Research Scholars) grant in 2015, the same time that I was accepted to the PhD programme. Talk about the stars being aligned. The grant gave me precious time to dive into my research feet first and complete a series of research projects, leading to many successful publications.

The entire experience has been incredible and humbling. My professional growth during this time has laid a strong foundation for future scholarship and I cannot imagine going back. I can confidently inform Cees that I can tell a great scientific story through my writing. As Karen M often liked to say, 'I am afraid you have had a paradigm shift'.

Thank you Karen M, Cees and Karen K for lighting my way. I will be forever grateful. 
